\title{
Foaming in Hanford River Protection Project Waste Treatment Plant LAW Evaporation Processes - FY01 Summary Report
}

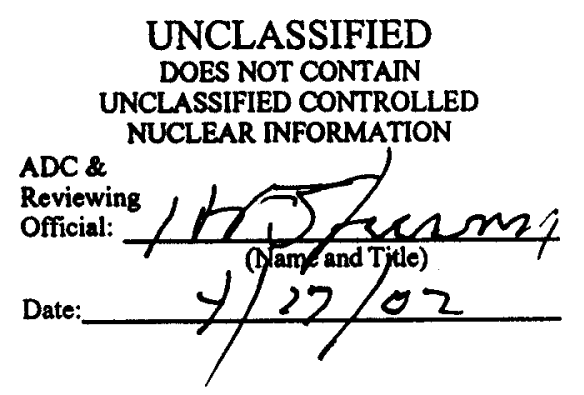

Westinghouse Savannah River Company Savannah River Site Aiken, SC 29808

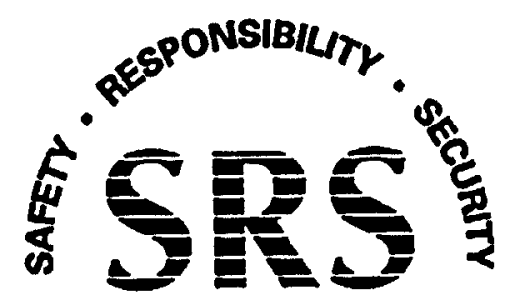


This document was prepared in conjunction with work accomplished under Contract No. DE-AC09-96SR18500 with the U. S. Department of Energy.

\section{DISCLAIMER}

This report was prepared as an account of work sponsored by an agency of the United States Government. Neither the United States Government nor any agency thereof, nor any of their employees, makes any warranty, express or implied, or assumes any legal liability or responsibility for the accuracy, completeness, or usefulness of any information, apparatus, product or process disclosed, or represents that its use would not infringe privately owned rights. Reference herein to any specific commercial product, process or service by trade name, trademark, manufacturer, or otherwise does not necessarily constitute or imply its endorsement, recommendation, or favoring by the United States Government or any agency thereof. The views and opinions of authors expressed herein do not necessarily state or reflect those of the United States Government or any agency thereof.

This report has been reproduced directly from the best available copy.

Available for sale to the public, in paper, from: U.S. Department of Commerce, National Technical Information Service, 5285 Port Royal Road, Springfield, VA 22161, phone: (800) 553-6847, fax: (703) 605-6900

email: orders@ntis.fedworld.gov

online ordering: http://www.ntis.gov/help/index.asp

Available electronically at http://www.osti.gov/bridge

Available for a processing fee to U.S. Department of Energy and its contractors, in paper, from: U.S. Department of Energy, Office of Scientific and Technical Information, P.O. Box 62, Oak Ridge, TN 37831-0062,

phone: (865)576-8401,

fax: (865)576-5728

email: $\underline{\text { reports@ adonis.osti.gov }}$ 
WSRC-TR-2001-00561 Rev. 0

SRT-RPP-2001- 00211

KEYWORDS:

Hanford River Protection Project

Evaporation

Foaming

\section{Foaming in Hanford River Protection Project Waste Treatment Plant LAW Evaporation Processes - FY01 Summary Report}

SAVANNAH RIVER TECHNOLOGY CENTER

J. Josephs

T. Bond Calloway, Jr.

Publication Date: December 2001

Westinghouse Savannah River Company

Savannah River Site

Aiken, SC 29808

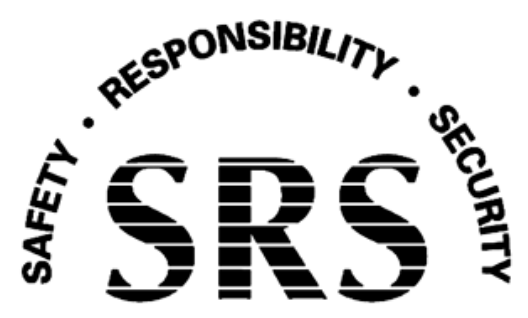

SAVANNAH RIVER SITE

Prepared for the U.S. Department of Energy under Contract No. DE-AC09-96SR18500 
WSRC-TR-2001-00561 Rev. 0

SRT-RPP-2001- 00211

Approvals

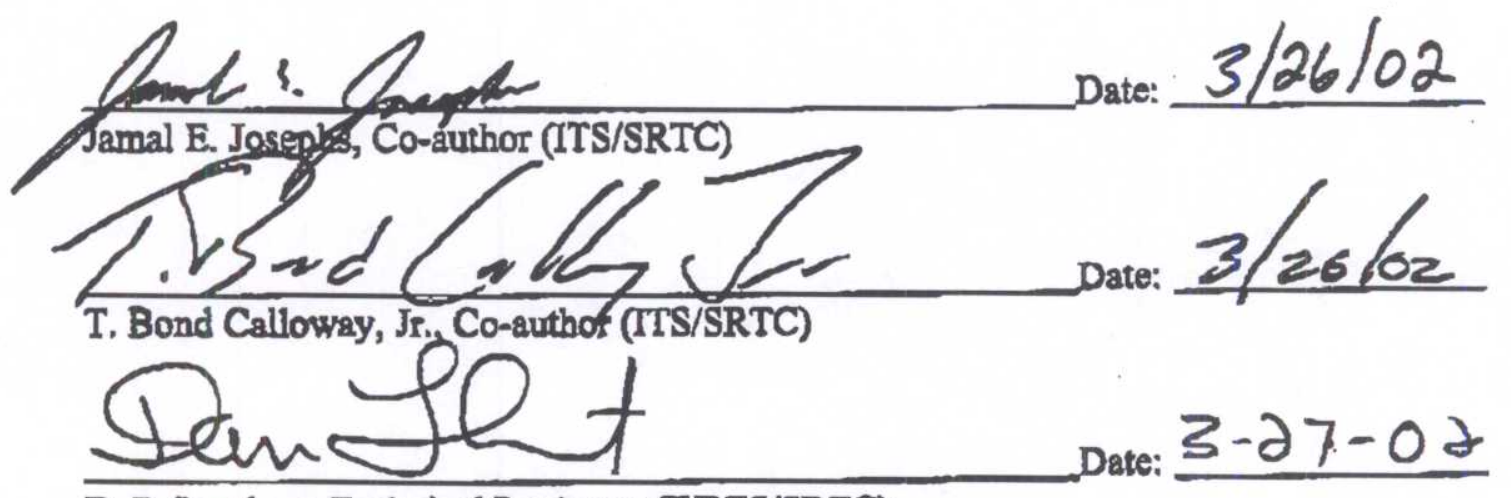

D. P. Lambert, Technical Reviewer (WPTS/SRTC)

David Crowley, SRTC RP P Vitrification Manger er Date: $3 / 22 / 02$

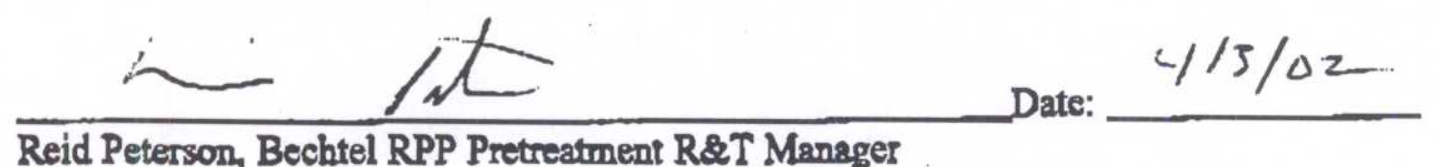

Reid Peterson, Bechtel RPP Pretreatment R\&T Manager

iv 


\section{Table of Contents}

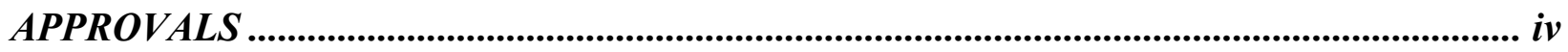

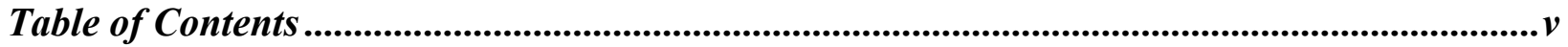

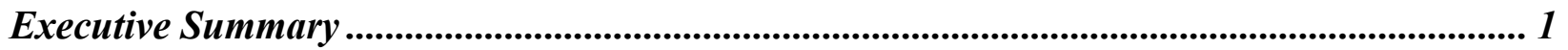

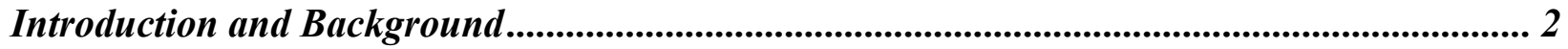

Experimental ..................................................................................................................................... 4

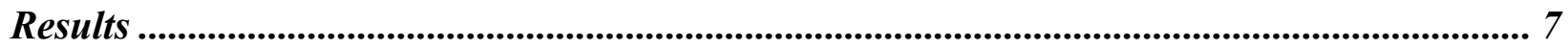

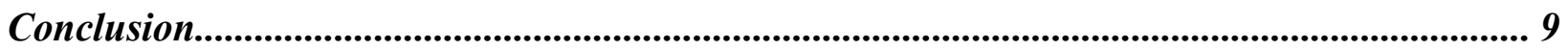

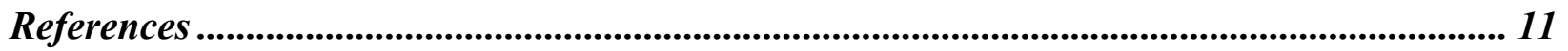

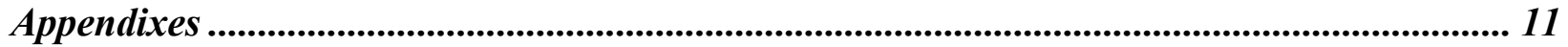

Appendix A - IIT Final Report for FY01 ........................................................................................... 11

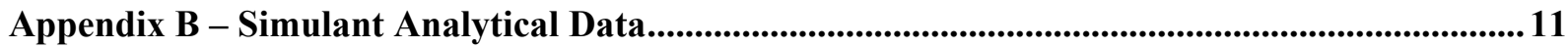




\section{Executive Summary}

The LAW evaporation processes currently being designed for the Hanford River Protection Project Waste Treatment Plant (RPP-WTP) are subject to foaming. Experimental simulant studies have been conducted in an effort to achieve an effective antifoam agent suitable to mitigate such foaming. Specifically, nine non-radioactive Hanford simulants were prepared by SRTC and shipped to Illinois Institute of Technology for foaming tests: AN105 (A), AN105 with entrained solids (A), AN107 (C), AN107 with entrained solids (C), AZ101 (B), AZ102 (B), AN104 (A), AN104 with entrained solids (A), and Pretreated AN107 (C). ${ }^{1}$ Each simulant went through a small-scale evaporation process (boiling) from which respective degrees of foaminess and foam textures were recorded. The waste simulants that were selected for evaporation testing are representative of the Phase 1 LAW feeds to the WTP. Phase 1 LAW feeds, instead of Phase 2 single-shell tank wastes, were selected because these wastes are better characterized and actual Phase 1 waste samples are available for comparison with the simulants.

Researchers at the Savannah River Technology Center (SRTC) and the Illinois Institute of Technology (IIT) jointly completed testing. A report was issued by the researchers at IIT (Attachment A). This document is designed to summarize the key results and explain the preparation of the simulants used in this testing.

Selected Hanford simulants were boiled and tested at different evaporation flux rates and at both atmospheric pressure and vacuum-760 mmHg and $110 \mathrm{mmHg}$, respectively. A vacuum of 110 $\mathrm{mmHg}$ was selected to simulate the operating temperature range $\left(50-60^{\circ} \mathrm{C}\right)$ expected to be encountered by the RPP-WTP evaporators. As the simulants' total solids concentrations increased, severe foaminess (650 to $800 \%$ at atmospheric pressure, $100 \%$ at vacuum) was observed in three of the nine simulant samples: AN107, AN107 with entrained solids, and Pretreated AN107, which exhibited the greatest amount of foam. All the remaining simulants, AN104, AN104 with entrained solids, AN105, AN105 with entrained solids, AZ101, and AZ102, produced less foam $(<71 \%)$ and thus, were not tested under vacuum (see Table 1$)$.

Mechanistically, foaming is particularly caused by precipitating solids and this process is encouraged by the presence of organic complexants. Maximum foaminess occurs when simulants' total solids concentrations are greater than $50 \mathrm{wt}$ \% (see Table 1), which is well beyond the saturation point for these simulants and beyond the desired concentration endpoint of the RPP evaporators. A review of the experiments conducted with Hanford tank sample 241AN102 shows that foaming occurred at a very low total solids concentration (approx. $30 \mathrm{wt} . \%, 5$ $\mathrm{M} \mathrm{Na}$ ), thus indicating that the mechanisms for foaming in the real waste may be much different than the mechanisms for the simulants.

A section of study was devoted to documenting the effects of separable organics, namely normal paraffin hydrocarbons (NPH) and tributyl phosphate (TBP), on LAW processes. The addition of $100 \mathrm{ppm}$ of NPH did not relieve foaming, but increased it by $25 \%$. On the contrary, the addition

\footnotetext{
${ }^{1}$ The designation AN105, AN107, etc., refers to a simulant designed to model the contents of Hanford waste tank 241-AN105, 241-AN107, etc. (A), (B), (C) refers to envelopes A, B, and C.
} 
of $100 \mathrm{ppm}$ of TBP did reduce foaminess by a factor of three. However, adding $300 \mathrm{ppm}$ of TBP to the simulants resulted in an increase in foaminess, suggesting a deminimus concentration for TBP somewhere between 100 and 300 ppm.

Dow-Corning Pulp Aid 3472 Concentrate and Dow-Corning Antifoam 1520-US were both tested as possible antifoam candidates. The effectiveness of 1520-US was poor. In contrast, antifoam agent Pulp Aid 3472 greatly reduced foaminess at low pressures by a factor of three. However, it is suggested that Pulp Aid 3472 be tested at higher evaporation fluxes. ${ }^{2}$

Future antifoam testing for the RPP will include surveying relevant literature and investigating the effect of trace surfactants known to be present in the 241-AN102 sample. Information found from the literature search concerning organics in Hanford waste simulants will be exploited with the goal of designing a better simulant. Experimentation to determine the impact on foaminess and foam stability when trace quantities of separable organics (TBP and NPH) are added to the simulants will also be performed and thus allow the RPP to determine the deminimus concentration of separable organics for the LAW evaporator. Modifications to the small-scale experimental rigs used by IIT will be made to increase the vapor flux during testing. Additionally, the consultants will continue testing using three commercial antifoams and final recommendation of the most effective antifoam will be given. Testing with the recommended antifoam will be conducted using actual radioactive, pilot scale Hanford tank samples.

Based upon IIT testing, selected LAW simulants with the antifoam agent will undergo pre- and post-irradiation testing to determine whether or not such a process is destructive to the antifoam. Testing using selected simulants and recommended antifoams will be conducted at the RPP design-basis evaporation flux rate. ${ }^{3}$

\section{Introduction and Background}

The River Protection Project Waste Treatment Plant (RPP-WTP) has identified a reference process for the treatment of low activity waste (LAW) solutions and high-level waste (HLW) slurries. $^{4}$ The reference process includes evaporation of LAW solutions and RPP-WTP recycle streams using forced circulation evaporators. The RPP-WTP is currently considering changing the design to also evaporate Envelope D HLW sludge stream and the associated supernate fraction. Since this design change is not yet finalized, the scope of design change has not been fully evaluated with respect to this task and will be considered in future efforts as requested by RPP-WTP R\&T.

\footnotetext{
${ }^{2}$ A. Nikolov, D. Wasan, K. Vijayaraghavan, Foaming in Hanford RPP-WTP LAW Evaporation Processes, AC19845S, Illinois Institute of Technology, 9/13/01.

${ }^{3}$ J. E. Josephs, T. B. Calloway, Jr., Task Technical and Quality Assurance Plan for-LAW Evaporation: Antifoam/Defoamer Testing for Low Activity Waste Solution, WSRC-RP-2001-00791, SRT-RPP-2001-00142 Rev. 0, Westinghouse Savannah River Company, 9/5/01.

${ }^{4}$ Waste Treatment Plant Request for Proposals Solicitation No. DE-RP27-00RV14136, August 31, 2000, section C.7, FACILITY SPECIFICATION, item (d)(iii) and (d)(iv), U. S. Department of Energy Office of River Protection, Richland, Washington.
} 
Excessive foaming during the evaporation of Envelope C (241-AN102) has been identified by SRTC. ${ }^{5}$ Excessive foaming in waste evaporators can cause carryover of radionuclides and other waste constituents, which could result in the process condensate exceeding waste acceptance criteria for the 200 Area Effluent Treatment Plant. The antifoams used at Hanford and tested by SRTC in Part B1 are known to degrade and become inactive in high pH solutions. ${ }^{6}$ Hanford wastes have been known to foam during operation of the 242-A evaporator causing excessive down time and processing delays. ${ }^{7}$

The DWPF and the SRS Alternative Salt Disposition programs have an ongoing antifoam research program. ${ }^{8}$ Researchers at SRTC in collaboration with Illinois Institute of Technology (IIT) have developed several antifoams for the DWPF ${ }^{9}$ and SRS Alternative Salt Disposition ${ }^{10}$ programs. The DWPF plans to deploy one of these antifoams in FY01. It is desirable for the RPP-WTP to leverage data and resources from the existing DOE antifoam development programs.

The RPP-WTP R\&T organization has requested SRTC to establish a contract with Illinois Institute of Technology to characterize the foaminess of the Hanford waste and to develop and optimize the existing commercial antifoam technology for the River Protection Project Waste Treatment Plant LAW Evaporators. The test specification/task plan for this task is contained in references. ${ }^{11,3}$ This report discusses the results and conclusions of the FY01 testing conducted at the SRTC and IIT laboratories. Specifically, this report partially completes item III.B in the referenced test specification. Item III.B was not completed because a simulant for AW101 and AN102 was not available by the end of FY01.

The overall objectives of the RPP-WTP antifoam program are:

-Evaluate the foaming tendencies of LAW Feed, LAW Melter Feed, and Eluate streams in the WTP conditions. In these tests, SRTC/Illinois Institute of Technology (IIT) will determine the foaming tendencies in the LAW evaporator systems.

\section{-Identify, through testing and analysis, a suitable antifoam reagent for use in plant}

\footnotetext{
${ }^{5}$ M. L. Crowder, C. L. Crawford, H. H. Saito and T. B. Calloway, Jr., Bench-Scale Evaporation of Large Hanford Envelope C Sample (Tank 241-AN102), WSRC-TR-2000-00469 (Draft), Westinghouse Savannah River Company, $12 / 15 / 00$.

${ }^{6}$ T. B. Calloway, "Verbal conversation with Dow-Corning Corporation Technical Services concerning Application of Dow 1520-US and Other Dow Antifoams to the RPP LAW Evaporators", Martin J. Hilger, Westinghouse Savannah Company, 12/1/00.

${ }^{7}$ M. D. Guthrie, 95-1 242-A Evaporator Campaign Post Run Document, WHC-SD-WM-PE-055 Rev. 0, Westinghouse Hanford Company, 2/7/96. The 242-A Evaporator was shutdown over four times during the campaign. Antifoam addition was increased from 300 to $600 \mathrm{ppm}$ to compensate for the excessive foaming. ${ }^{8}$ D. P. Lambert, Final Report: Illinois Institute of Technology Antifoam Recommendation to SRTC, WSRC-TR2000-00297 Rev. 0, Westinghouse Savannah River Company, 8/23/2000.

${ }^{9}$ D. C. Koopman, Comparison of Dow Corning 544 Antifoam to IIT747 Antifoam in the $1 / 240^{\text {th }}$ SRAT, WSRC-TR99-00377, Rev. 0, Westinghouse Savannah River Company, 12/17/1999.

${ }^{10}$ D. P. Lambert WSRC-TR-2001-00237, Revision 0, Illinois Institute of Technology Report: IITB52 Antifoamer for Alternative Salt Processes, 5/1/2001.

${ }^{11}$ M. E. Johnson, T. B. Calloway, LAW Evaporation: Antifoam/Defoamer Testing for Low Activity Waste Solution Test Specification, TSP-W375-00-00035, Rev. 0, Westinghouse Savannah River Company, 12/15/2000.
} 
evaporators. In these tests, SRTC/IIT will make an initial antifoam recommendation for the LAW evaporators.

\section{-Determine if tributyl phosphate (TBP) and normal paraffin hydrocarbons (NPH) create problems in evaporator operation and if so, at what concentration do these problems occur. In these tests, SRTC/IIT will determine the concentration of TBP and NPH that effect foaming in the evaporator.}

To achieve these objectives, the RPP-WTP R\&T organization via SRTC plan to conduct testing at beaker scale with simulants (this task and report), bench scale with simulants (with and without irradiation), bench scale with actual waste samples, and pilot scale testing.

The specific objectives of this portion of the work are:

- Identify the mechanism of foam formation and characterize the foaminess of selected Hanford waste simulants at various pressures. The specific intent will be to reduce the number of simulants (most of which will involve simulants of AN102) to be tested by future experiments.

- Characterize foaminess as a function of water evaporation flux rate.

- Characterize the foaminess of TBP and NPH with the intent to establish a deminimus concentration for future testing by SRTC.

- Characterize the performance of industry-recommended and available commercial antifoams.

\section{Experimental}

Nine Hanford simulants, which were previously developed and approved by the project, were prepared at SRS in accordance with the recipes outlined in reference. ${ }^{12}$ Pretreated AN107 was formulated from the AN107 recipe listed in reference 11 and was subjected to the $\mathrm{Sr} / \mathrm{Tru}$ precipitation/filtration process by the SRTC Thermal Fluid Laboratory. All nine simulants underwent analytical testing at the SRTC Laboratory for cation/anion concentrations. The instrument used for cation testing was the Varian Vista AX Inductively Coupled Plasma Atomic Emission Spectrometer (ICP-AES). The samples were aqueous so no sample preparation was necessary. A calibration was performed using $1 \mathrm{mg} / \mathrm{L}, 5, \mathrm{mg} / \mathrm{L}$ and $10 \mathrm{mg} / \mathrm{L}$ standards with the cations of interest. A 10X, 100X, 1000X, and 10,000X dilution was performed by volume on the original sample to bring the analytes of interest into the calibration range. The instrument used for anion determination was the Dionex DX-500 Ion Chromatograph. No sample prep was necessary. A calibration of 1,5 , and $10 \mathrm{mg} / \mathrm{L}$ was performed using the anions of interest. Dilutions of $100 \mathrm{X}, 1000 \mathrm{X}$, and 10,000X were performed by volume on the original sample to bring the analytes of interest into the calibration range.

\footnotetext{
${ }^{12}$ R.E. Eibling and C. A. Nash, Hanford Waste Simulants Created to Support the Research and Development on the River Protection Project - Waste Treatment Plant, WSRC-TR-2000-00338, SRT-RPP-2000-00017, Westinghouse Savannah River Company, February 2001.
} 
The predicted and actual chemical composition values of the nine Hanford simulants were recorded and percent target values were plotted in Microsoft ${ }^{\circledR}$ Excel. ${ }^{13}$ The percent target range $\mathrm{Na}$ (ICP-ES) concentration in all simulants was between 98.0 and $104.4 \%$ of target. However, in some simulants, the concentrations of $\mathrm{Al}, \mathrm{Ca}$, and $\mathrm{Si}$ were less than $50 \%$ of target. Also, in some simulants, concentrations of $\mathrm{F}, \mathrm{PO}_{4}, \mathrm{~K}$, and $\mathrm{Cr}$ were over $100 \%$ of target. It is suspected that the cause of such error in ion concentrations (e.g. Al) is due to misbatching. Low Ca concentrations in the simulants are due to the lack of complexants in several of the simulants. For example it is now known that the trace amounts of complexants are present in the Envelope A and B waste tanks. It is likely that the high dilution factors used for the analyses increased the analytical error for these elements (Appendix B).

Simulant samples were tested for foaminess during boiling. Several experiments were conducted in a laboratory set-up as shown in Figure 1. A specially designed heating jacket was installed around the beaker, which helped to increase the water evaporation rate of boiling. A digital camera was installed to monitor the foaming characteristics at varied temperatures and pressures. The foaming tests were conducted to identify the mechanism of foam formation so that a more effective antifoam agent could be selected. Additionally, these tests were conducted to reduce the number of simulants to be tested by future experiments.

In order to understand the effects of TBP and NPH on foaminess, small concentrations of normal paraffin hydrocarbons (NPH) and tributyl phosphate (TBP) were separately added to simulant samples. Adding $25 \mathrm{ppm}$ of NPH or TBP to the samples did not result in any notable effects on foaminess; therefore, research focused on using 100-ppm concentrations of NPH and TBP.

Using AN107, Pretreated AN107, and AN107 with entrained solids, the more severely foaming Hanford simulants, two commercial antifoams were selected for testing: Dow-Corning Antifoam 1520-US and Dow-Corning Pulp Aid 3472 Concentrate. ${ }^{14} 1400$ ppm of the 1520 -US antifoam was added to the samples prior to boiling as was Pulp Aid 3472 antifoam and the effectiveness of each was recorded (figures 28-33, Appendix A).

\footnotetext{
${ }^{13}$ Pretreated AN107 was excluded from the spreadsheet since no predicted values existed for this simulant.

${ }^{14} 1520$-US antifoam is used at the Hanford 242-A evaporator. Pulp Aid 3472 antifoam, suggested by Dow, is used by paper industries for processes of high alkaline conditions.
} 
WSRC-TR-2001-00561

SRT-RPP-2001- 00211

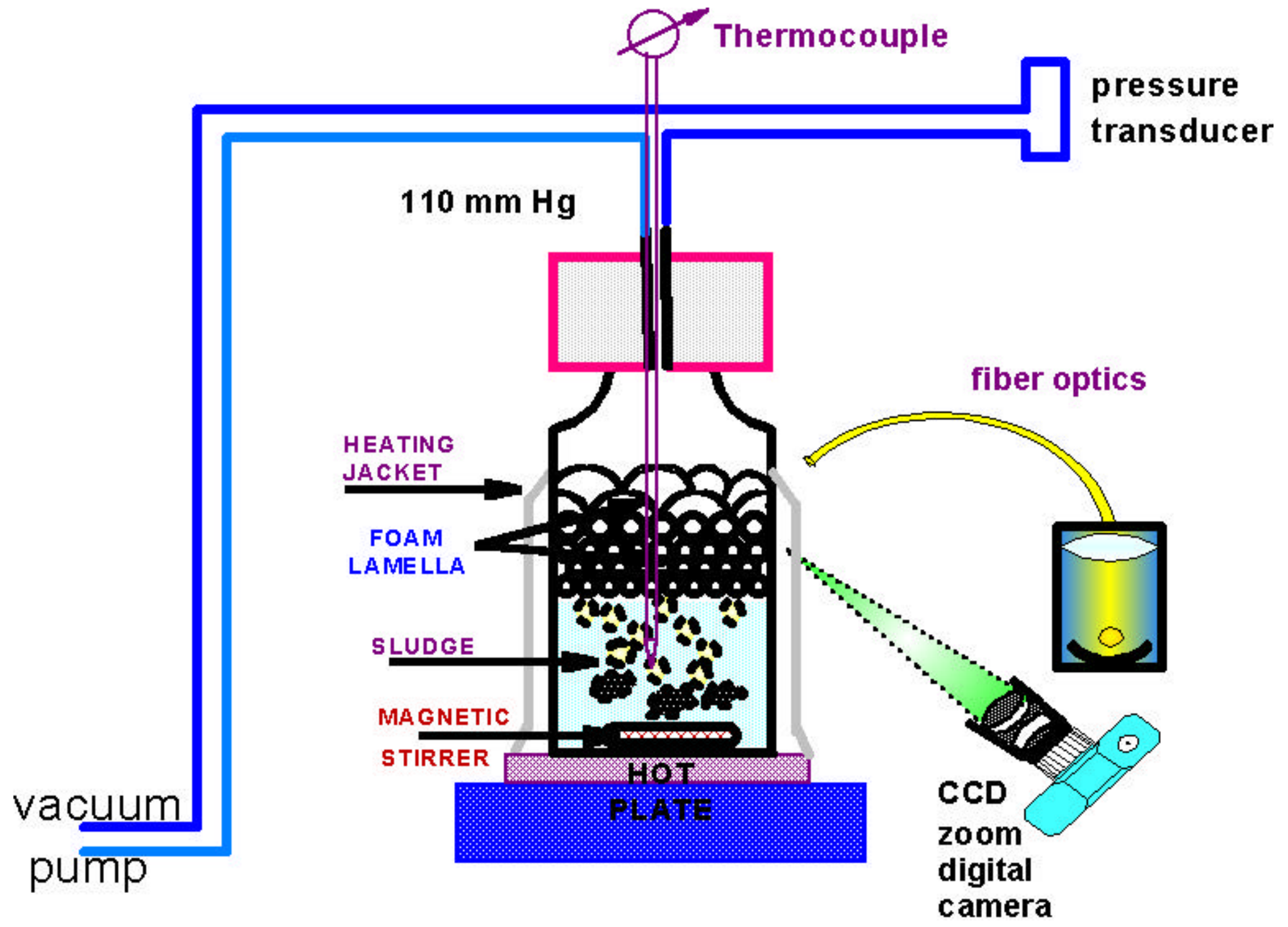

Figure 1 - Experimental Set-Up To Study Foaminess Of Sludge Simulants During Boiling Using Vacuum 


\section{Results}

There were essentially four main experimental studies carried out by IIT that focused upon the Hanford simulants AN105, AN105 with entrained solids, AN107, Pretreated AN107, AN107 with entrained solids, AZ101, AZ102 envelope B, AN104, and AN104 with entrained solids. These were (1) foaminess at atmospheric pressure and vacuum, (2) foaminess at various evaporation flux rates, (3) foaminess as a function of TBP and NPH concentrations, and (4) foaminess in the presence of a commercial antifoam. Table 1 gives a summary of the simulants' characteristics and chemistry.

1) Less foam is produced at vacuum rather than at atmospheric pressure. For samples AN107 with entrained solids, AN107, and Pretreated AN107, Figures 16-18 in Appendix A show how lowering the pressure to which a simulant is exposed while boiling can significantly decrease foaminess. Experimental testing at standard atmospheric pressure also indicated that the amount of foam produced correlated to the amount of water evaporated during boiling. As sample volumes decreased over time from the evaporation of water, its total solids concentration increased linearly (Appendix A, figures 3a-11a) and in turn, foaming potential greatly increased (see figures $3 \mathrm{~b}-11 \mathrm{~b}$ in Appendix A).

2) Higher evaporation flux will result in higher foaminess. For tested simulants AN107 with entrained solids, AN107, and Pretreated AN107, data clearly indicate that a high water evaporation flux rate $\left(0.09 \mathrm{ml} / \mathrm{min} \mathrm{cm}^{2}\right)$ will result in a greater amount of foaminess. For instance, when the flux rate was increased from 0.05 to $0.09 \mathrm{ml} / \mathrm{min} \mathrm{cm}^{2}$, the amount of foam drastically increased by an average factor of nearly 15 (see Appendix A, figures 19-21).

3) Studies concerning the concentration of TBP and NPH in Hanford simulants yielded contrasting results. The presence of NPH led to more foam while TBP acted as an antifoamer at low concentration and lead to more foam at high concentrations.

Consequently, the greatest reductions in foaminess were observed with the addition of 100 ppm of TBP to simulants that were at a low pressure of $110 \mathrm{mmHg}$.

4) Use of the 1520-US antifoam did not result in a relatively significant foam reduction (see Appendix A, figures 28-30) whereas the Pulp Aid 3472 antifoam did indeed reduce the amount of foam produced during boiling by a factor of 3-4 (see Appendix A, figures 31-33). The evaporation flux rate was $0.04 \mathrm{ml} / \mathrm{min} \mathrm{cm}^{2}$ for experimental tests concerning 1520 -US antifoam whereas the evaporation flux rate was $0.09 \mathrm{ml} / \mathrm{min} \mathrm{cm}^{2}$ for tests concerning Pulp Aid 3472 antifoam. 
WSRC-TR-2001-00561

SRT-RPP-2001- 00211

Table 1: Summary of Hanford Simulant Characteristics and Chemistry

\begin{tabular}{|c|c|c|c|c|c|c|c|c|c|}
\hline \multirow[t]{2}{*}{ Name of Simulant } & \multirow[t]{2}{*}{$\begin{array}{l}\text { Weight of } \\
\text { solids (g) } \\
\text { \% TOC } \\
\end{array}$} & \multicolumn{2}{|c|}{$\begin{array}{c}\text { \% foaminess as a } \\
\text { function of pressure }^{\mathrm{a}, \mathrm{b}, \mathrm{c}}\end{array}$} & \multicolumn{3}{|c|}{$\begin{array}{c}\text { \% foaminess as function of total solids } \\
\text { conc. and } \mathrm{Na} \text { molarity }\left(\text { at } 0.04 \mathrm{ml} / \mathrm{min} \mathrm{cm}^{2}\right. \\
\text { and } 760 \mathrm{mmHg})^{\mathrm{a}}\end{array}$} & \multirow[t]{2}{*}{$\mathbf{p} \mathbf{H}^{\mathrm{d}}$} & \multirow[t]{2}{*}{$\begin{array}{l}\% \mathrm{NaNO}_{3} \\
/ \mathrm{NaNO}_{2}^{\mathrm{d}}\end{array}$} & \multirow[t]{2}{*}{ Color $^{\mathrm{d}}$} \\
\hline & & $\begin{array}{c}760 \\
\mathrm{mmHg}\end{array}$ & $\begin{array}{c}110 \\
\mathrm{mmHg}\end{array}$ & $\begin{array}{l}\text { Total solids } \\
\text { conc. (wt \%) }\end{array}$ & $\begin{array}{l}\text { Na conc. } \\
\text { (M) }\end{array}$ & $\begin{array}{c}\% \\
\text { foaminess }\end{array}$ & & & \\
\hline Pretreated AN107 & 2.49 & 800 & 100 & 60 & $>9.7$ & 800 & 14 & $3.5 / 1$ & Blackish Red \\
\hline $\begin{array}{c}\text { AN107 with } \\
\text { Entrained Solids }\end{array}$ & 2.49 & 650 & 100 & 80 & $>11.7$ & 633 & 12 & $3.5 / 1$ & Brown \\
\hline AN107 3M & 2.49 & 700 & 100 & 70 & $>10.3$ & 660 & 12 & $8 / 2.7$ & Brick Red \\
\hline $\begin{array}{c}\text { AN104 with } \\
\text { Entrained Solids }\end{array}$ & 0.48 & $\mathrm{~N} / \mathrm{A}$ & $\mathrm{N} / \mathrm{A}$ & 55 & $>8.6$ & 70 & 14 & $4.4 / 3.3$ & Green \\
\hline AN104 3M & 0.48 & $\mathrm{~N} / \mathrm{A}$ & $\mathrm{N} / \mathrm{A}$ & 60 & $>10.1$ & 35 & 14 & $6.3 / 4.3$ & Green \\
\hline AN105 3M & 0.50 & $\mathrm{~N} / \mathrm{A}$ & $\mathrm{N} / \mathrm{A}$ & 60 & $>9.8$ & 50 & 14 & $6.3 / 4.3$ & Green \\
\hline $\begin{array}{l}\text { AN105 3M with } \\
\text { Entrained solids }\end{array}$ & 0.50 & $\mathrm{~N} / \mathrm{A}$ & N/A & 60 & $>9.0$ & 25 & 14 & $6.3 / 4.3$ & Yellow \\
\hline AZ101 & 0 & $\mathrm{~N} / \mathrm{A}$ & N/A & 65 & $>10.3$ & 30 & 14 & $3.5 / 3.8$ & Yellow \\
\hline AZ102 & 0.30 & N/A & $\mathrm{N} / \mathrm{A}$ & 55 & $>9.7$ & 55 & 14 & $1.0 / 3.0$ & Yellow \\
\hline
\end{tabular}

${ }^{a}$ Data transcribed from graphs in Appendix A (figures 3b-11b)

${ }^{\mathrm{b}}$ At evaporation flux rate of $0.05 \mathrm{ml} / \mathrm{min} \mathrm{cm}^{2}$

" "N/A" signifies that test was not conducted with simulant

${ }^{\mathrm{d}}$ Data copied from Table 1 in Appendix A 
Mechanistically, it is suggested that foam stability is more dependent on physical (formation due to precipitating solids) rather than chemical attributes of the foam. ${ }^{15}$ For instance, foam collapsed shortly after a simulant was removed from the hot plate. Had surfactants been the primary constituent in a simulant's foaming capability, the foam should have remained for a longer period of time. Moreover, maximum foaminess occurs when simulants' total solids concentrations are greater than $50 \mathrm{wt}$ \% (see Table 1), which is well beyond the saturation point for these simulants and beyond the desired concentration endpoint of the RPP evaporators. However, Pretreated AN107, AN107 with entrained solids, and AN107, all of which exhibited the greatest amount of foaming, contained a significantly greater concentration of organic complexants ${ }^{12}$ (see Table 1 ) than the other simulants, thus undermining a purely physical-based mechanism. Furthermore, a review of the experiments conducted with Hanford tank sample 241-AN102 shows that foaming occurred at a very low solids concentration (approx. 30 wt. \%, 5 $\mathrm{M} \mathrm{Na}$ ), thus indicating that the mechanisms for foaming in the real waste may be very different than with simulants. Examination of the video results for the evaporation of Hanford tank sample 241-AN102 leads to the hypothesis that foaming in this sample may be due to surfactants that are present in the waste.

\section{Conclusion}

Studies were completed by SRTC/IIT that characterized the foaminess of Hanford simulants AN105 (A), AN105 with entrained solids (A), AN107 (C), AN107 with entrained solids (C), AZ101 (B), AZ102 (B), AN104 (A), AN104 with entrained solids (A), and Pretreated AN107 (C) at atmospheric and vacuum conditions. The following can be summarized from experimental results:

- Foaminess in all the Hanford waste simulants occurs due to the formation of particles (precipitated salt species) that occur when the solution reaches saturation. The precipitated salt particles stabilize the foam by preventing the liquid from draining through each foam lamella. The particles attach themselves to the bubble and create a stabilization barrier creating stable foam surfaces. Foam occurred in the 241-AN102 sample at a relatively low total solids content ( 31.5 wt. \% total solids, $<0.002 \mathrm{wt}$ \% insoluble solids). Foams in the Hanford waste simulants only occurred after bulk saturation was reached $(\sim 40 \mathrm{wt} . \%)$ and significant quantities of salt particles began to form. Therefore, the mechanism for foam formation in the Hanford simulant is very different from the actual 241-AN102 tested by SRTC in the B1 phase. It is known that various salt species (e.g. sodium carbonate) experience retrograde solubility when the temperature is increased. Therefore, it is likely that the foaminess of Hanford waste simulants is related to the chemical composition and morphology of the particle formed in the solution.

- Lowering the pressure during the evaporation process can reduce foaminess. Table 1 compares the amount of foaminess at both atmospheric pressure and at a vacuum pressure of $110 \mathrm{mmHg}$ and clearly shows that such a lower pressure will greatly reduce the amount of foaminess during boiling of the simulant.

\footnotetext{
${ }^{15}$ See Appendix A (p. 13) for proposed mechanism of foam stability.
} 
- The foaminess of all the simulants decreased significantly when evaporated under vacuum conditions and even more so with a low vapor flux rate of $0.05 \mathrm{ml} / \mathrm{min} \mathrm{cm}^{2}$ (see Table 1). Essentially, a higher vapor flux rates always increases foaming potential at a given solids concentration. Testing at the design basis vapor flux is needed to determine the foaminess under actual evaporator conditions.

- The addition of $25 \mathrm{ppm}$ of normal paraffin hydrocarbons (NPH) and tributyl phosphate (TBP) did not affect the foaminess of the AN107 with entrained solids or the AN107 pretreated simulants. Higher additions $(100 \mathrm{ppm})$ of TBP resulted in a decrease in foaminess by a factor of three. However, with additions of $300 \mathrm{ppm}$ of TBP, the foaminess was increased. Foaminess may have increased due to the decomposition of TBP into organic and inorganic components. The decomposed organic component (dibutyl phosphate-DBP) may lead to an increase in foaminess of the simulant. Addition of $100 \mathrm{ppm}$ of NPH increases the foaminess by $25 \%$. Since the effects of TBP (and DBP) and NPH on foaminess are different and non-linear in nature, further work needs to be conducted to define a deminimus level for separable organics.

- Currently, Dow-Corning Pulp Aid 3472 Concentrate seems to be a much more effective antifoam agent than Dow-Corning Antifoam 1520-US. Even though Pulp Aid 3472 antifoam was tested at a higher flux rate than 1520-US, it still outperformed 1520-US and decreased foaminess by a factor of 3-4.

Future antifoam testing for the RPP will include surveying relevant literature and investigating the effect of trace surfactants known to be present in the 241-AN102 sample. Information found from the literature search concerning organics in Hanford waste simulants will be exploited with the goal of designing a better simulant. Experimentation to determine the impact on foaminess and foam stability when trace quantities of separable organics (TBP and NPH) are added to the simulants will also be performed and thus allow the RPP to determine the deminimus concentration of separable organics for the LAW evaporator. Modifications to the small-scale experimental rigs used by IIT will be made to increase the vapor flux during testing. Additionally, the consultants will continue testing using three commercial antifoams and final recommendation of the most effective antifoam will be given. Testing with the recommended antifoam will be conducted using actual radioactive, pilot scale Hanford tank samples.

Based upon IIT testing, selected LAW simulants with the antifoam agent will undergo pre- and post-irradiation testing to determine whether or not such a process is destructive to the antifoam. Testing using selected simulants and recommended antifoams will be conducted at the RPP design-basis evaporation flux rate. ${ }^{16}$

\footnotetext{
${ }^{16}$ J. E. Josephs, T. B. Calloway, Jr., Task Technical and Quality Assurance Plan for-LAW Evaporation: Antifoam/Defoamer Testing for Low Activity Waste Solution, WSRC-RP-2001-00791, SRT-RPP-2001-00142 Rev. 0, Westinghouse Savannah River Company, 9/5/01.
} 


\section{References}

See footnotes.

\section{Appendixes}

Appendix A - IIT Final Report for FY01

Appendix B - Simulant Analytical Data 
FINAL REPORT ON SUBCONTRACT NO: AC19845S

\author{
FOAMING IN HANFORD RPP-WTP LAW \\ EVAPORATION PROCESSES
}

By

\begin{abstract}
Alex Nikolov, Darsh Wasan and Krishna Vijayaraghavan Department of Chemical and Environmental Engineering Illinois Institute of Technology Chicago, Illinois 60616
\end{abstract}

September 13, 2001 


\section{EXECUTIVE SUMMARY}

A program was implemented at IIT to develop a basic understanding of the severe foaming experienced in Hanford River Protection Project Waste Treatment Plant (RPP-WTP) evaporation processes. A study, to understand foaminess, was carried out using simple experiments with nine Hanford sludge simulants. Foaminess and foam textures were monitored during boiling of the simulants. Results of foaminess of nine non-radioactive Hanford simulants are summarized as follows:

Foaminess during boiling of Hanford sludge simulants was tested at both atmospheric pressure $(760 \mathrm{~mm} \mathrm{Hg})$ and at low pressure $(110 \mathrm{~mm} \mathrm{Hg})$ (only for simulants showing severe foaminess). The foaminess of all the simulants goes to a maximum at higher solid concentration $(>50 \%)$. At atmospheric pressure $(760 \mathrm{~mm} \mathrm{Hg})$ severe foaminess $(>600 \%)$ was observed in sludge samples AN-107 with entrained solids, AN-107 3M and pretreated AN-107 at the maximum in foaminess. Less Foaminess at atmospheric pressure $(760 \mathrm{~mm}$ $\mathrm{Hg}$ ) was observed in sludge samples AN-104 3M, AN-104 with entrained solids, AN-105 3M with entrained solids, AN-105 3M, AZ-101 and AZ-102.

The increase in water evaporation flux rate enhances foaminess. Experiments were carried out at both atmospheric $(760 \mathrm{~mm} \mathrm{Hg})$ and low pressure $(110 \mathrm{~mm}$ $\mathrm{Hg}$ ) to understand its effect on foaminess. Significantly less foaminess occurred at low pressure $(110 \mathrm{~mm} \mathrm{Hg})$ and low water evaporation flux (0.05 
$\mathrm{ml} / \mathrm{min}$ sq.cm). However, at low pressure and high evaporation flux rate (0.09 $\mathrm{ml} / \mathrm{min}$ sq.cm.) the maximum in foaminess was about $1200 \%$. This shows that foaminess increases with increasing water evaporation flux. Extrapolated data for water evaporation flux $(0.56 \mathrm{ml} / \mathrm{min}$ sq. $\mathrm{cm})$ simulated at Hanford plant show severe foaminess $(>1500 \%)$ at low solid concentration $(<40 \%)$.

The addition of $25 \mathrm{ppm}$ of normal paraffin hydrocarbon (NPH) and tributyl phosphate (TBP) to the sludge samples with severe foaminess did not show reduction in foaminess. However, addition of $100 \mathrm{ppm}$ of NPH increases foaminess at maximum by $25 \%$ and addition of $100 \mathrm{ppm}$ of TBP reduces foaminess by a factor of three at maximum. A detailed study of effect of TBP on foaminess needs to be done at higher water evaporation fluxes.

The antifoaming efficiency of two antifoamers (DOW PULPAID CONCENTRATE 3472 and DOW 1520 US) was tested. The antifoaming performance of DOW 1520 US was poor. Antifoamer DOW PULPAID CONCENTRATE 3472 reduces the foaminess at low pressures by a factor of three (at foaminess corresponding to maximum). However its antifoaming efficiency needs to be studied at higher evaporation fluxes. 


\section{INTRODUCTION}

Hanford wastes have been known to foam during operation of the 242-A Evaporator causing excessive down time and processing delays ${ }^{1}$. The Savannah River Technology Center (SRTC) found that severe foaminess occurred during the continuous bench scale evaporation of the Envelope $\mathrm{C}$ tank (sludge sample 241-AN102) and during the small beaker evaporation of simulated 241-AN107 without SR/TRU pretreatment ${ }^{2,3}$. Foaming in waste evaporators can cause excessive carryover of radionuclides and nonradioactive waste constituents to the condensate system. The antifoamer (DOW-1520 US) used at Hanford and tested by SRTC is known to decompose and become inactive in high $\mathrm{pH}$ solutions ${ }^{1}$. Therefore, a fundamental research program was initiated by the IIT researchers (Nikolov and Wasan) with the three main objectives: 1) To develop a basic understanding of the mechanisms of foaminess in the RPP Evaporation process; 2) To identify the key phenomena which aggravate foaming; and 3) To identify a more effective means to eliminate or mitigate foaming

1 M.D.Guthrie, 95-1 242-A Evaporator Campaign Post Run Document, WHC-SD-WM-PE-055 Rev. 0 , Westinghouse Hanford Company, 2/7/96.

${ }^{2}$ M.L.Crowder, C.L.Crawford, H.H.Saito and T.B.Calloway, Jr., Bench Scale Evaporation of Large Hanford Envelope C (Tank 241-AN102). WSRC-TR- 2000-00469 (Draft), Westinghouse Savannah River Company, 12/15/00.

${ }^{3}$ T.B.Calloway and A.Burk, Foam Tests using Simulated Hanford Law solutions, WSRC-NB-9900073, Westinghouse Savannah River Company, 9/15/2000. 
In the initial phase of the research program, nine non-radioactive simulants of Hanford salt solution prepared by SRTC were supplied to the IIT researchers to conduct foaming tests during boiling.

- Laboratory tests were conducted at both atmospheric $(760 \mathrm{~mm} \mathrm{Hg})$ and below atmospheric pressure $(110 \mathrm{~mm} \mathrm{Hg})$.

- Foaming tests were also conducted when trace quantities of separable organics such as tributyl phosphate (TBP) and normal paraffin hydrocarbons (NPH) were added to the simulants with entrained solids.

- The performance of the commercially available antifoamers DOW PULPAID CONCENTRATE 3472 and DOW-1520 US was tested (the Hanford 242-A evaporator currently uses DOW-1520 US antifoamer).

\section{EXPERIMENTAL}

Nine sludge samples simulating Hanford nuclear waste sludges were tested for foaminess during boiling. The foaming experiments were conducted in a laboratory set-up as shown in Figure 1. A specially designed heating jacket was installed around the beaker, which helped in increasing the water evaporation rate of the boiling sludge samples. The arrangement included specially designed fiber optics and a digital camera to monitor the degree of foaminess and the foam lamella texture at different temperatures and pressures (see Figure 1). The foaming tests were conducted to understand the foaming mechanisms, and to select the potential antifoamers. The foaming 
tests were conducted at both atmospheric $(760 \mathrm{~mm} \mathrm{Hg})$ and below atmospheric pressure $(110 \mathrm{~mm} \mathrm{Hg})$. The set up for the experiments conducted below atmospheric pressure $(110 \mathrm{~mm} \mathrm{Hg})$ is shown in Figure 2.

A $300 \mathrm{ml}$ of the sludge sample was placed in a beaker with a diameter of about $9 \mathrm{~cm}$ and height $22 \mathrm{~cm}$. The boiling temperature of the sludge at atmospheric pressure $(760 \mathrm{~mm} \mathrm{Hg})$ was approximately $98^{\circ} \mathrm{C}$. Several minutes after the beaker was placed on the hot plate the sludge sample began to boil, typically after 10-12 minutes. To eliminate overheating of the sludge sample and creation of local hot spot areas, small amount of boiling chips were added to the sludge in the beaker. To homogenize the sludge sample in the beaker a magnetic stirrer was placed inside the beaker. The $\mathrm{pH}$ of the simulants was measured using a $\mathrm{pH}$ paper and the results are presented in Table 1.

In order to study the effect of the water evaporation flux on foaminess, the hot plate temperature and the efficiency of heating were controlled. The boiling water evaporation flux for each of the sludge sample was calculated from the measurement of the volume of water evaporated from the sludge in the known time interval. It is important to note that after stopping the boiling the foam collapses in 10-15 seconds. So foaminess was observed only during boiling of the simulant. The volume of liquid remaining in the sludge was measured by removing the sludge from the hot plate and allowing foam to collapse. The change in the liquid level during the known interval of time divided by the 
evaporating area of the beaker gave the water evaporation rate for that simulant. During boiling the volume of foam starts increasing which is measured at regular interval. Without boiling the foam collapses and sludge volume was measured after the foam collapsed by removing the beaker from the hot plate. The difference in the volume with and without boiling gives the volume of foam during boiling. Foaminess was calculated as the percentage of foam volume to the stationary liquid volume.

To investigate the effect of sludge particle concentration on foaminess, approximately $15 \mathrm{~g}$ of sludge sample was taken in a plastic cup and weighed to measure the soluble solid concentration. The simulant contained both the insoluble as well as the soluble solids, which could be summed up as the total solids in the simulant. The cups were then kept at room temperature for evaporation and sludge samples were weighed after every 6 hrs. After about 48-60 hours the dried sludge samples were weighed and the percentage of total solid concentration of the simulant was calculated. The initial solid concentration was measured by taking the weight fraction of solids in the sludge sample to the total weight of the sludge sample containing both the liquid as well as the solids.

\section{Foaminess at atmospheric pressure $(760 \mathrm{~mm} \mathrm{Hg})$}

Foaming of sludge samples was studied at the atmospheric pressure $(760 \mathrm{~mm}$ $\mathrm{Hg}$ ). The heat input to the water evaporation rate was monitored by measuring 
the temperature of the hot plate using a thermocouple. The heating temperature of the hot plate was kept at $400 \pm 10^{\circ} \mathrm{C}$ with a flux rate of 0.04 $\mathrm{ml} / \mathrm{min}$ sq.cm. During the boiling, water evaporated and the concentration of the total solids (soluble and insoluble solids) in the sludge increased. The rate of water evaporation and the foaminess were monitored for each sludge samples. Figures $3 \mathrm{a}$ to $11 \mathrm{~b}$ show the effect of solid concentration on the foaminess and the evaporation rate of the simulant for experiments carried out at $400{ }^{\circ} \mathrm{C}$. All the results reported in the figures $3 \mathrm{a}$ to $11 \mathrm{~b}$ were conducted with the first batch of simulants. In order to investigate the effect of flux on foaminess, the temperature of the hot plate was increased from 400 to $450{ }^{\circ} \mathrm{C}$. The plot showing the effect of water evaporation flux on foaminess is shown in figure 12. The evaporation flux rate for experiments carried out at $450{ }^{\circ} \mathrm{C}$ with the heating jacket was $0.08 \mathrm{ml} / \mathrm{min}$ sq. $\mathrm{cm}$ for the tested sludge samples. The comparative plots for the water evaporation rate from 0.04 to 0.08 $\mathrm{ml} / \mathrm{min}$ sq.cm is shown in figures $13-15$ for the simulants AN-107 with entrained solids, AN-107 3M and Pretreated AN-107. The results clearly show that as the water evaporation rate increases the foaminess also increases.

\section{Foaminess at low pressure $(110 \mathrm{~mm} \mathrm{Hg})$}

The effect of low pressure $(110 \mathrm{~mm} \mathrm{Hg})$ on the foaminess of the Hanford simulants was also investigated. Figure 2 shows the experimental set-up used to achieve the low pressure. The experiments were carried out at below the 
atmospheric pressure of $110 \mathrm{~mm} \mathrm{Hg}$, which was obtained by using a water pump to remove vapor from the headspace above the boiling surface. The beaker containing the sludge sample was covered with a specially made rubber enclosure to eliminate any leaks and a small pipe was connected to the water pump in order to achieve the below atmospheric pressure. Mercury manometers were used to calibrate the pressure transducers, which was then used to measure pressure below atmospheric. The foaminess and the foam texture of the sludge sample during boiling were monitored using the video camera. The water evaporation rate for the experiments carried out at $400{ }^{\circ} \mathrm{C}$ was $0.05 \mathrm{ml} / \mathrm{min}$ sq.cm for the tested sludge samples. Figures $16-18$ show the effect of low pressure on foaminess for the simulants AN-107 with entrained solids, AN-107 3M and Pretreated AN-107. The experiments were carried out with the first batch of simulants. The result of all the three samples depicts that foaminess decreased significantly with decreasing of pressure e.g. for the simulant Pretreated AN-107 the maximum foaminess decreases by about 10 times. (See the movie clip).

\section{Foaminess at higher flux and low pressure}

A heating jacket was specially designed so that higher water evaporation flux value could be obtained. Using a camera and fiber optics the foaminess of the boiling sludge sample was monitored. Applying a low pressure $(110 \mathrm{~mm} \mathrm{Hg})$ in conjunction with the heating jacket the water evaporation flux value could be increased from $0.05 \mathrm{ml} / \mathrm{min}$ sq. $\mathrm{cm}$ to $0.09 \mathrm{ml} / \mathrm{min} \mathrm{sq} . \mathrm{cm}$ for the tested 
sludge samples. Figures 19-21 shows the effect of higher water evaporation rate on foaminess for the samples AN-107 with entrained solids, AN-107 3M and Pretreated AN-107.

In order to evaluate the foaminess at conditions consistent with Hanford water evaporation rate at about $0.56 \mathrm{ml} / \mathrm{min} \mathrm{sq} . \mathrm{cm}$, we extrapolated the value of foaminess at a higher water evaporation rate value. Figures 22-24 show the extrapolated values of foaminess for the simulants AN-107 with Entrained Solids, AN-107 3M and Pretreated AN-107. Extrapolated values of foaminess show that for the conditions consistent with Hanford, the foaminess values are about $1500 \%$.

\section{Foaminess with addition of TBP and NPH}

It is known in the literature that tributyl phosphate (TBP) helps in reducing the foaminess and acts as an antifoamer. So in order to understand the effect of TBP on foaminess, experiments were carried out using $25 \mathrm{ppm}$ and 100 ppm of TBP with the sludge samples. By using $25 \mathrm{ppm}$ of the TBP no notable effect on foam reduction was found and so our research focused on using 100 ppm of TBP in order to study the effect on foaminess (figures 25-27).

Experiments were also carried out to study the effect of normal paraffin hydrocarbons (NPH) on the foaminess of the boiling sludge sample. Trace quantities (25 ppm) of NPH were added to the boiling sludge samples. It was found that $25 \mathrm{ppm}$ of the NPH did not show notable effect on foaminess and it 
was decided that a minimum amount of NPH would be required in order to have any effect on the foaminess. So after a number of experiments $100 \mathrm{ppm}$ of the NPH was found to show some effect on foaminess (Figures 25-27). In summary it was observed that low pressure $(110 \mathrm{~mm} \mathrm{Hg})$ and $100 \mathrm{ppm}$ TBP sufficiently reduces the maximum foaminess by a factor of three. From the figures we can conclude that TBP shifts the maximum in foaminess towards the higher concentration.

\section{Foaminess in the presence of antifoamer}

In the study of the foaminess of the boiling sludge samples, our observations clearly showed that at higher flux for both low pressure $(110 \mathrm{~mm} \mathrm{Hg})$ and atmospheric pressure $(760 \mathrm{~mm} \mathrm{Hg})$ foaminess of the simulants was very severe. To reduce foaminess two commercial antifoamers provided by SRTC were tested. The two commercial antifoamers studied were DOW-1520 US and the DOW PULPAID CONCENTRATE 3472. Due to the severe foaminess of the simulant, a large volume of the antifoamer such as $1400 \mathrm{ppm}$ was added to the boiling sludge samples. In the experimental study we first added $1400 \mathrm{ppm}$ of DOW-1520 US as an antifoamer to the sludge sample right from the start of the experiment and the effect of the antifoamer was monitored (Figures 28-30). The value of the water evaporation rate was 0.05 $\mathrm{ml} / \mathrm{min}$ sq.cm. for these experiments. The antifoamer DOW PULPAID CONCENTRATE 3472 was tested at a higher vapor flux value of 0.09 $\mathrm{ml} / \mathrm{min}$ sq.cm. (Figures 31-33). The antifoamer DOW PULPAID 
CONCENTRATE 3472 reduces the maximum foaminess by a factor of about 3-4. (See figures 31-33, which compares the foaminess with and without the antifoamer)

\section{RESULTS AND DISCUSSION}

With the evaporation of water the solid concentration in the simulant increases, which was monitored along with the foaminess of the sludge samples. Figures 3a, 4a, 5a, 6a, 7a, 8a, 9a, 10a and 11a show the rate of change of sludge volume at a hot plate temperature of $400{ }^{\circ} \mathrm{C}$ and an atmospheric pressure of $760 \mathrm{~mm} \mathrm{Hg}$ (water evaporation flux $0.04 \mathrm{ml} / \mathrm{min}$ sq.cm) for the sludge samples Pretreated AN-107, AN-107 with entrained solids, AN-107 3M, AN-104 with entrained solids, AN-104 3M, AN-105 3M, AN-105 3M with entrained solids, AZ-101 and AZ-102. The figures show that the rate of water evaporation is constant e.g. the sludge volume decreases linearly with time. As a result of the linear decrease in volume of the sludge the concentration of solids increases linearly with time. Figures $3 b, 4 b, 5 b, 6 b$, $7 \mathrm{~b}, 8 \mathrm{~b}, 9 \mathrm{~b}, 10 \mathrm{~b}$ and $11 \mathrm{~b}$ show the dependence of foaminess on the concentration of solids for the sludge samples pretreated AN-107, AN-107 with entrained solids, AN-107 3M, AN-104 with entrained solids, AN-104 3M, AN-105 3M, and AN-105 3M with entrained solids, AZ-101 and AZ102. 
For all the Hanford simulants during boiling we observed a maximum in foaminess with concentration. The data shown in the above figures clearly indicate that for the Hanford sludge samples, the maximum foaminess occurs at a more than $50 \mathrm{wt} \%$ solid concentration. Multiple tests were conducted to ensure the reproducibility of the trends in foaminess as a function of solid concentration (Figures 3b, 4b, 5b, 6b, 7b, 8b, 9b, 10b and 11b). We have observed that during the boiling experiments at low solid concentrations (less than $30 \mathrm{wt} \%$ ) the foam cells are spherical in shape. The foam lamella was only a few millimeters in size and the lamella increases in size as the solid concentration increases. At higher solid concentrations, the foam lamella was several centimeters in size and its texture changed dramatically. It is important to note that the foam collapses shortly after the boiling sludge sample was removed from the hot plate, thereby suggesting that the foam stability is not due to the presence of surfactants, because in the presence of surface active materials the foam will be stable. Table 1 shows the Hanford Low Activity Waste chemistry, the type of the simulants, the compositions and the maximum of foaminess of the simulants that were studied.

Based on the results for foaminess during boiling, the Hanford sludge samples are categorized into two major categories i.e. sludge samples showing a higher foaminess (700-800 \%) and sludge samples showing a lower foaminess $(<100 \%)$. The Hanford simulants pretreated AN-107, AN-107 with entrained solids and AN-107 3M showed a higher degree of foaminess (Figures 3b, 4b, 5b) while AN-104 with entrained solids, AN-104 3M, AN- 
105 3M, and AN-105 3M with entrained solids, AZ-101 and AZ-102 showed a lower degree of foaminess. Our subsequent tests focussed on the three sludge samples, which showed higher foaminess.

The mechanism of stability of the foam lamella in sludge samples with severe foaming is discussed below.

During boiling of the sludge sample, the water evaporates and the sludge is concentrated. At a certain temperature and concentration, the sludge becomes even over saturated and fine crystals or nuclei are formed. These fine crystals (solids) attach to the bubble surfaces generated during boiling. The process of crystal formation was also observed on the walls/surface of the glass beaker. The crystals (solids attached to the bubble surface) provide a structural stabilization barrier, which prevents adjacent bubbles from coalescing, and, thereby, stabilizes the foam lamella and increases the foaminess. When the boiling is stopped the particles drain from the foam lamella and the foam lamella collapses. This mechanism of foam stabilization formed by the structural stabilization barrier was discussed in our previous report using the acidified SRTC sludge with PHA ${ }^{4}$. The main difference between the Hanford and the STRE sludge samples is that the Hanford simulants before boiling contain much less insoluble solids ( $\supseteq<1 \mathrm{wt} \%)$ while the SRTC acidified sludge contained 7-10 wt \% insoluble solids. As a result of the high concentration of insoluble solids in the SRTC acidified sludge, the foaminess started when the sludge sample was concentrated to about 15 wt \% solids 
during boiling, and had a maximum at about $18-23$ wt \% solids. Based on this difference in the initial concentration of insoluble solids, one can expect the foaminess for the Hanford simulants to begin when the concentration of the insoluble solids (crystals) becomes higher than $15 \mathrm{wt} \%$. So the concentration of the total solids (crystals and soluble solids) becomes higher than about $40 \mathrm{wt} \%$. The maximum in foaminess was visually observed when the solid concentration is about 50-60\%, e.g. for the case AN-107 with entrained solids the maximum occurs at solid concentration at $75 \%$ while for the AN-107 3M it occurs $70 \%$ and for pretreated AN-107 it occurs at $60 \%$. The reason for maximum in foaminess is due to the competition of two major phenomena: the structural stabilization barrier and the flocculation (attractiondepletion) mechanisms ${ }^{4}$. At higher concentration of particles (crystals) due to the flocculation (aggregation), particles cannot form the structural stabilization barrier.

In our future study, we need to investigate the factors like boiling temperature and solid concentration of the sludge, which affect the nucleation and crystal growth processes (particle formation), as well as factors such as crystal size and morphology, surface active agents and sludge composition on foam lamella stability and foaminess. 


\section{Effect of Water evaporation flux on foaminess}

To study the effect of water evaporation flux on foaminess of the sludge samples AN-107 with entrained solids, experiments were carried out at two different temperatures i.e. $400{ }^{\circ} \mathrm{C}$ and $450{ }^{\circ} \mathrm{C}$. The flux rate for the experiment where the temperature was increased from 400 to $450{ }^{\circ} \mathrm{C}$ was 0.06 $\mathrm{ml} / \mathrm{min}$ sq.cm. From Figure 12 it is clear that at higher water evaporation flux the foaminess at a fixed solid concentration increases significantly. The maximum in foaminess at higher water evaporation flux occurs at a slightly lower solid concentration. Therefore, we can conclude higher foaminess is observed at higher water evaporation rate. In the following section we discuss the effect of pressure on foaminess, because the water evaporation flux also depends on pressure.

\section{Effect of water evaporation rate on foaminess at atmospheric pressure (760 mm Hg)}

The experiments were carried out over a range of $0.04 \mathrm{ml} / \mathrm{min}$ sq. $\mathrm{cm}$ to 0.08 $\mathrm{ml} / \mathrm{min} \mathrm{sq} . \mathrm{cm}$ in order to study the effect of water evaporation flux on foaminess at atmospheric pressure. The water evaporation flux rate at $400{ }^{\circ} \mathrm{C}$ was $0.04 \mathrm{ml} / \mathrm{min}$ sq.cm at atmospheric pressure conditions $(760 \mathrm{~mm} \mathrm{Hg})$ and increased to $0.08 \mathrm{ml} / \mathrm{min}$ sq.cm at $450{ }^{\circ} \mathrm{C}$ with the heating jacket. Figures 13,14 and 15 show the effect of the water evaporation rate on the foaminess 
for the sludge AN-107 with Entrained solids, AN-107 3M and Pretreated AN107 for the experiments carried out at $760 \mathrm{~mm} \mathrm{Hg}$. The three sludge samples show the increase in foaminess with the increase in water evaporation rate at atmospheric pressure (boiling point $98^{\circ} \mathrm{C}$ ). The reason for this increase is the decrease in surface tension with the increase in the temperature and more bubbles are generated, and consequently foaminess increases.

\section{Effect of water evaporation rate on foaminess at low pressure (110 mm Hg)}

The effect of low pressure $(110 \mathrm{~mm} \mathrm{Hg})$ on foaminess was studied for the three sludge samples which showed severe foaminess namely AN-107 with entrained solids, AN-107 3M and pretreated AN-107 (Figures 16-18). The water evaporation rate was at a constant value of $0.04 \mathrm{ml} / \mathrm{min} \mathrm{sq} . \mathrm{cm}$ for these experiments. It is evident that pressure below the atmospheric conditions (110 $\mathrm{mm} \mathrm{Hg}$ ) reduces the foaminess for AN-107 with entrained solids, AN-107 $3 \mathrm{M}$ and pretreated $\mathrm{AN}-107$ to a large extent (figures 34-36). For the case of $\mathrm{AN}-1073 \mathrm{M}$ the low pressure reduces the foaminess by a factor of 10 (e.g., see the movie clip for the effect of pressure on foaminess for the simulant pretreated AN-107). At low pressure the solubility of the sludge solids (particles) is higher. Due to this the concentration of sludge solids in the simulant is lower and hence foaminess of the simulant is much lower. 
Our study also investigated the foam lamella structure and its size in these experiments. As the pressure is decreased the foaminess decreases dramatically (Figures 16-18). We observed that in the case when initial boiling experiment of the sludge was conducted at atmospheric pressure, and then the pressure was decreased for a while, the foaminess increased dramatically, and this effect is due to the gas solubility in sludge simulant (see video clip). It was seen that at low pressure the foam lamella was of the order of a few centimeters, was highly unstable and it collapsed very quickly. At higher pressure the gas solubility is high, more gas is contained in the sludge and when the pressure is reduced from high to low the gas solubility decreases and for a short period of time many bubbles are generated.

\section{Effect of low pressure $(110 \mathrm{~mm} \mathrm{Hg})$ and higher vapor flux on foaminess}

The experiments were carried out over a range of $0.05 \mathrm{ml} / \mathrm{min}$ sq.cm to 0.09 $\mathrm{ml} / \mathrm{min}$ sq. $\mathrm{cm}$ in order to characterize the effect of water evaporation rate on foaminess. The water evaporation rate at $400{ }^{\circ} \mathrm{C}$ and low pressure was 0.05 $\mathrm{ml} / \mathrm{min}$ sq.cm and it increases to $0.09 \mathrm{ml} / \mathrm{min}$ sq.cm at $450{ }^{\circ} \mathrm{C}$ with the heating jacket at low pressures. Figures 19-21 shows the effect of the water evaporation rate on the foaminess for the sludge AN-107 with entrained solids, $\mathrm{AN}-1073 \mathrm{M}$ and pretreated $\mathrm{AN}-107$ for the conditions of $110 \mathrm{~mm} \mathrm{Hg}$. It is evident that with the increase in the water evaporation rate the foaminess also increased. At low pressure and low evaporation flux the solubility of the 
sludge solids (less particles are formed) is higher and so foaminess of the sludge simulant is lower. But by increasing the water evaporation rate (increasing the boiling temperature) and the solid particles, more gas is generated and more bubbles are formed. Due to this, the particles attach themselves to the bubble and create the stabilization barrier creating stable foam and one can expect higher foaminess with the increase in water evaporation rate. In summary, at low pressures and high evaporation fluxes foaminess is higher.

In order to simulate the operation conditions (low pressure and high water evaporation flux) at Hanford it was necessary to extrapolate the data for the water evaporation rate value of $0.56 \mathrm{ml} / \mathrm{min} \mathrm{sq} . \mathrm{cm}$. and at total solid concentration level of 40-50\%. We extrapolated our data for foaminess as a function of evaporation flux $(0.56 \mathrm{ml} / \mathrm{min} \mathrm{sq} . \mathrm{cm}$.) for the case of $40 \mathrm{wt} \%$ solids using a LINEAR relation (Figures 22-24). From the calculations the foaminess was in the range of $1500 \%$.

\section{Effect of Hydrocarbons and tributyl phosphate on foaminess}

A study was carried out to check the impact of normal paraffin hydrocarbon (NPH) and tributyl phosphate (TBP) on foaminess of the Hanford sludge samples. It was noted that addition of $25 \mathrm{ppm}$ concentration of the NPH and TBP each did not affect the foaminess (Figures 34-36). To see the effect of 100 ppm of TBP and NPH each on foaminess experimental runs were carried 
out with the simulant. The results for the degree of foaminess during boiling of the sludge samples with and without the NPH and TBP each are shown in the figures 25-27. It is evident that in the presence of the hydrocarbons the foaminess increases by about $25 \%$. From the figures $25-27$ it is evident that by adding $100 \mathrm{ppm}$ of TBP the foaminess decreases by a factor of three for the simulants AN-107 with entrained solids, AN-107 3M and Pretreated AN107.

In summary, with the addition of $100 \mathrm{ppm}$ of NPH the foaminess increases by $25 \%$ at the concentration corresponding to a maximum in foaminess. However, with the addition of $100 \mathrm{ppm}$ of TBP the maximum foaminess decreases by a factor of three and shifts the maximum in the foaminess to a higher solid concentration.

In order to understand the effect of TBP on foaminess, three different levels (50, 100 and $300 \mathrm{ppm}$ ) of TBP were added. The results (Figure 37) show that with 50 and 100 ppm concentration of TBP foaminess decreases, however with the addition of $300 \mathrm{ppm}$ foaminess increases. This kind of effect on foaminess as a function of solid concentration needs a further study. A possible explanation of the increase in foaminess with the concentration of TBP is due to the decomposition of TBP into organic and inorganic components. The decomposed organic component of TBP leads to an increase in the foaminess of the simulant. 


\section{Effect of Antifoamer on foaminess}

The efficiency of two commercial antifoamers (DOW-1520 US and DOW PULPAID CONCENTRATE 3472) on the Hanford higher foaminess sludge samples were tested. Due to the severe foaminess of the simulants a large volume of antifoamer (1400 ppm) was added to the simulants before boiling. The results for the antifoamer DOW 1520 US performance are as shown in the Figures 28-30 for the sludge samples AN-107 with entrained solids, AN$1073 \mathrm{M}$ and pretreated AN-107, respectively. It was observed that for the sludge samples AN-107 with entrained solids and AN-107 3M, the antifoamer did show a small change in reducing the degree of foaminess. The maximum of foaminess occurred at a lower solid concentration, than for experiments performed without the antifoamer. The antifoamer did have some effect on the pretreated AN-107 sludge sample. The maximum of foaminess decreased from $800 \%$ to $700 \%$ for the pretreated $\mathrm{AN}-107$ sludge sample and it showed a shift towards the higher solid concentration. Overall, it can be concluded that the antifoamer did not show good antifoaming performance.

The other commercial antifoamer (DOW PULPAID CONCENTRATE 3472) provided by SRTC was tested. Experiments were conducted by adding 1400 ppm of the antifoamer to the sludge simulant before boiling. Figures 31-33 show the effect of the antifoamer on the foaminess. The maximum in foaminess is about $300 \%$ for the case of the $\mathrm{AN}-107$ with entrained solids 
(Figure 31). Although the antifoamer reduced the foaminess of the simulant sufficiently further testing has to be done at higher water evaporation flux value where the foaminess is expected to be higher. So, either the concentration of the antifoamer may have to be increased or a new commercial antifoamer may have to be tested.

\section{RECOMMENDATIONS}

The following additional experiments need to be performed to better understand foaminess in the Hanford simulants.

- It was observed that, at a higher water evaporation rate, the foaminess increased. Studies have to be carried out for the Hanford simulants at a rate at least twice or three times the present water evaporation rate of 0.09 $\mathrm{ml} / \mathrm{min}$ sq.cm. This study requires a new design of the sludge heating elements and use of a special heating jacket in order to achieve higher evaporation rates.

- It is seen that $1400 \mathrm{ppm}$ of the commercial antifoamer DOW PULPAID CONCENTRATE 3472 reduces the maximum foaminess upto three times. However the maximum in foaminess for the boiling sludge with the antifoamer is $300 \%$. Studies need to be carried out at higher concentration 
levels of antifoamer to efficiently reduce foaminess. However it has to be determined whether this antifoamer is efficient at higher evaporation fluxes.

- In the case of sludge simulant the foaminess is due to the particle structural stabilization barrier. To reduce the foaminess the particle surface properties (interactions between particles) have to be modified as was done for the case of acidified SRTC sludge with PHA.

- The commercial antifoamers, which have been tested, normally perform only when the foaming is caused by surfactants. Foaming in the Hanford simulants is caused by sludge solids (particles). So we need to select a commercial antifoamer which will reduce structural barrier caused by the particles and not by the surfactants.

- Microscopic properties of the particles (surface size and biphilicity) in the simulant under low pressure conditions need to be studied. It is necessary to understand the effects of nucleation, crystal growth, size and shape of the particles on foam lamella stability and foaminess.

- Due to the unavailability of an AN102 simulant, testing was not completed. Since the radioactive AN102 sludge sample tested by SRTC shows a higher degree of foaminess, studies with an AN102 simulant need to be completed before recommending final antifoam to the RPP-WTP. 
- Studies need to be performed using the mixed simulants such as the mixture of envelope $\mathrm{A}$ and envelope $\mathrm{C}$ simulants and mixtures of RPP recycles with LAW simulants. 
Table 1: Hanford Low Activity Waste Chemistry

\begin{tabular}{|c|c|c|c|c|c|c|c|c|c|}
\hline \multirow[t]{2}{*}{$\begin{array}{l}\text { Name of } \\
\text { simulant }\end{array}$} & \multicolumn{2}{|c|}{$\begin{array}{c}\text { Weight of } \\
\text { solids } \\
\text { (g) }\end{array}$} & $\begin{array}{c}\text { Total weight } \\
\text { of solids } \\
\text { (g) }\end{array}$ & $\begin{array}{c}\text { Foaminess } \\
\%\end{array}$ & $\mathbf{p H}$ & Color & $\begin{array}{c}\text { Hydroxide } \\
\%\end{array}$ & $\begin{array}{c}\text { Acids } \\
\%\end{array}$ & $\begin{array}{c}\% \mathrm{NaNO}_{3} \\
/ \mathrm{NaNO}_{2}\end{array}$ \\
\hline & TOC & TIC & & & & & & & \\
\hline $\begin{array}{c}\text { Pretreated } \\
\text { AN-107 }\end{array}$ & 115 & 857 & 4620 & 825 & 14 & Blackish Red & $1.5 / 0$ & --- & $3.5 / 1$ \\
\hline $\begin{array}{l}\text { AN-107 with } \\
\text { Entrained } \\
\text { Solids }\end{array}$ & 115 & 857 & 4620 & 750 & 12 & Brown & $1.5 / 0$ & $\begin{array}{l}-- \\
\end{array}$ & $3.5 / 1$ \\
\hline AN-107 3M & 115 & 857 & 4620 & 725 & 12 & Brick Red & $1.0 / 0$ & $\begin{array}{l}\text { 2-Glycolic acid } \\
1.2 \text { Citric acid }\end{array}$ & $8 / 2.7$ \\
\hline $\begin{array}{l}\text { AN-104 with } \\
\text { Entrained } \\
\text { Solids }\end{array}$ & 22 & 845 & 4612 & 75 & 14 & Green & $4 / 2.3$ & --- & $4.4 / 3.3$ \\
\hline AN-104 3M & 22 & 845 & 4612 & 75 & 14 & Green & $4 / 2.3$ & --- & $6.3 / 4.3$ \\
\hline AN-105 3M & 23 & 892 & 4612 & 55 & 14 & Green & $3.2 / 2.2$ & --- & $6.3 / 4.3$ \\
\hline $\begin{array}{c}\text { AN-105 3M } \\
\text { with } \\
\text { Entrained } \\
\text { solids }\end{array}$ & 23 & 892 & 4612 & 35 & 14 & Yellow & $3.2 / 2.2$ & --- & $6.3 / 4.3$ \\
\hline AZ-101 & $\mathbf{0}$ & 592 & 4396 & 40 & 14 & Yellow & $1.5 / 1.2$ & -- & $3.5 / 3.8$ \\
\hline AZ-102 & 13 & 517 & 4396 & 45 & 14 & Yellow & $0.8 / 0.1$ & --- & $1.0 / 3.0$ \\
\hline
\end{tabular}




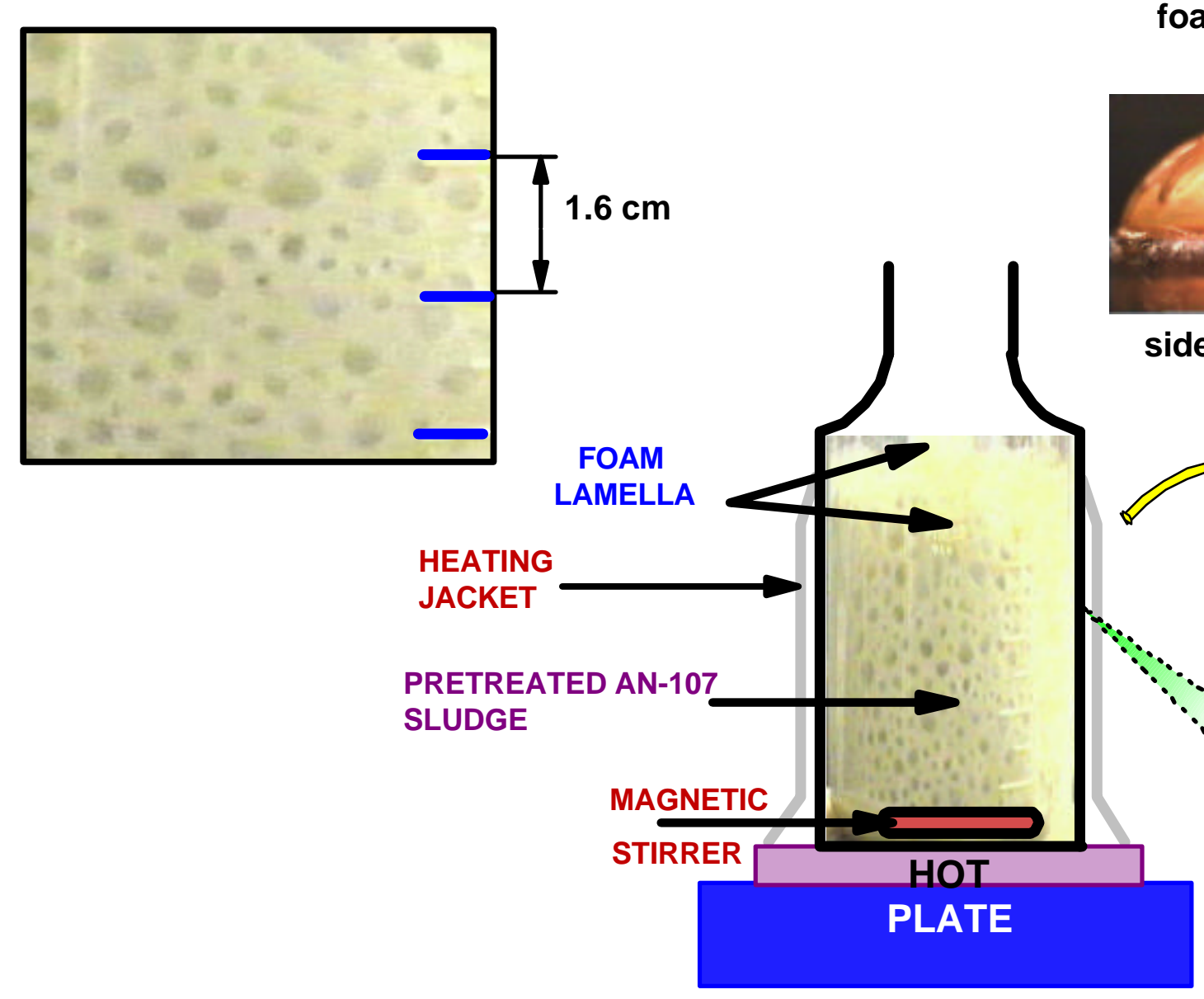

foam lamella stabilized by particles

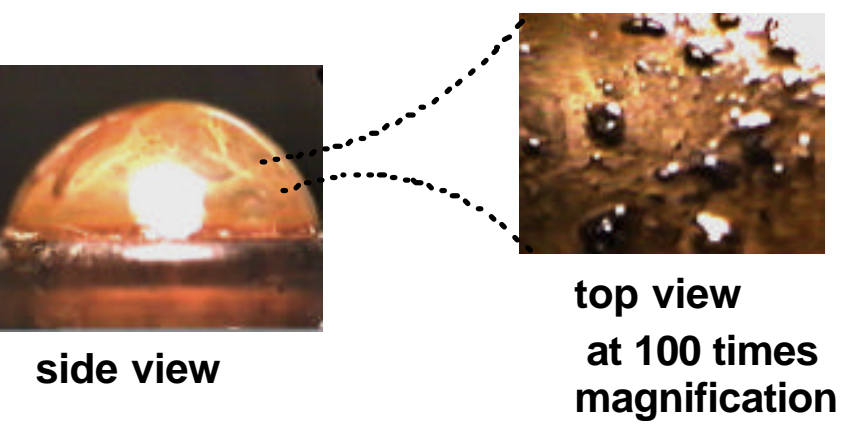

Figure 1 EXPERIMENTAL SET-UP TO MONITOR LAMELLA TEXTUREDURING SLUDGE BOILING

zoom digital camera 


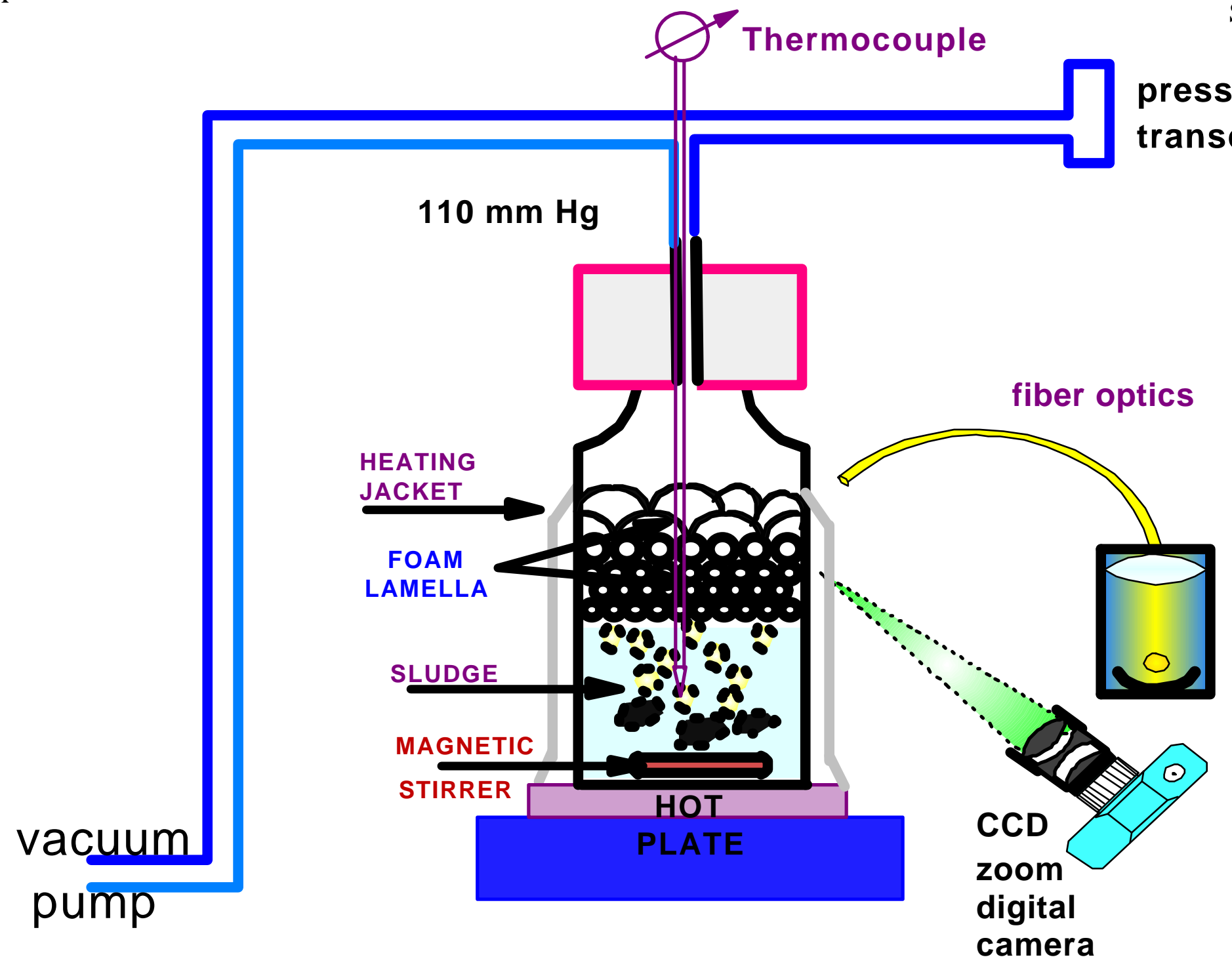

Figure 2 EXPERIMENTAL SET-UP TO STUDY FOAMINESS OF SLUDGE SIMULANTS DURING BOILING USING VACUUM 


\section{PRE TREATED AN-107 (ENVELOPE C) \\ (FIRST BATCH OF SIMULANTS)}

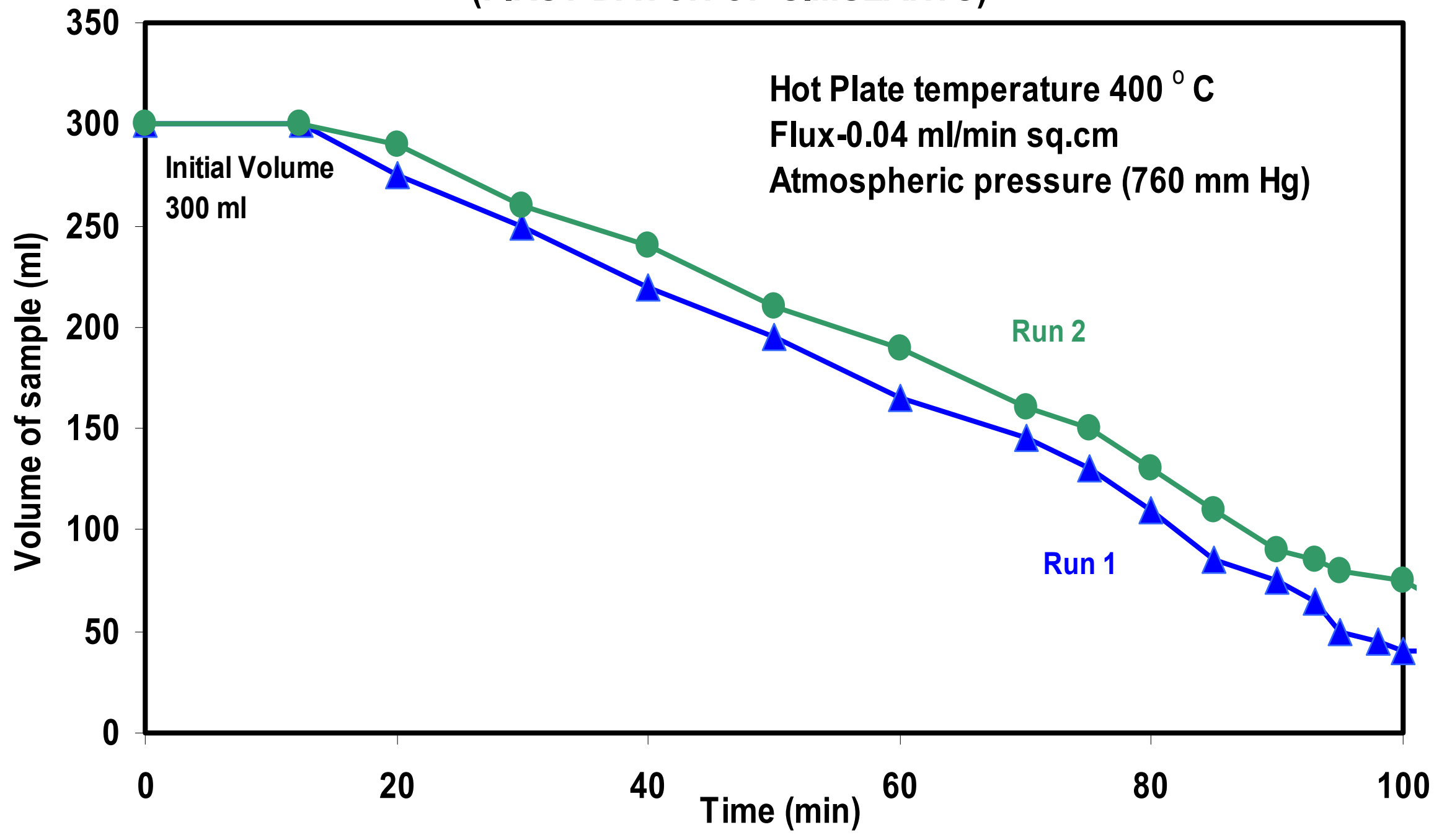

Figure 3a: Water evaporation flux with time 
(FIRST BATCH OF SIMULANTS)

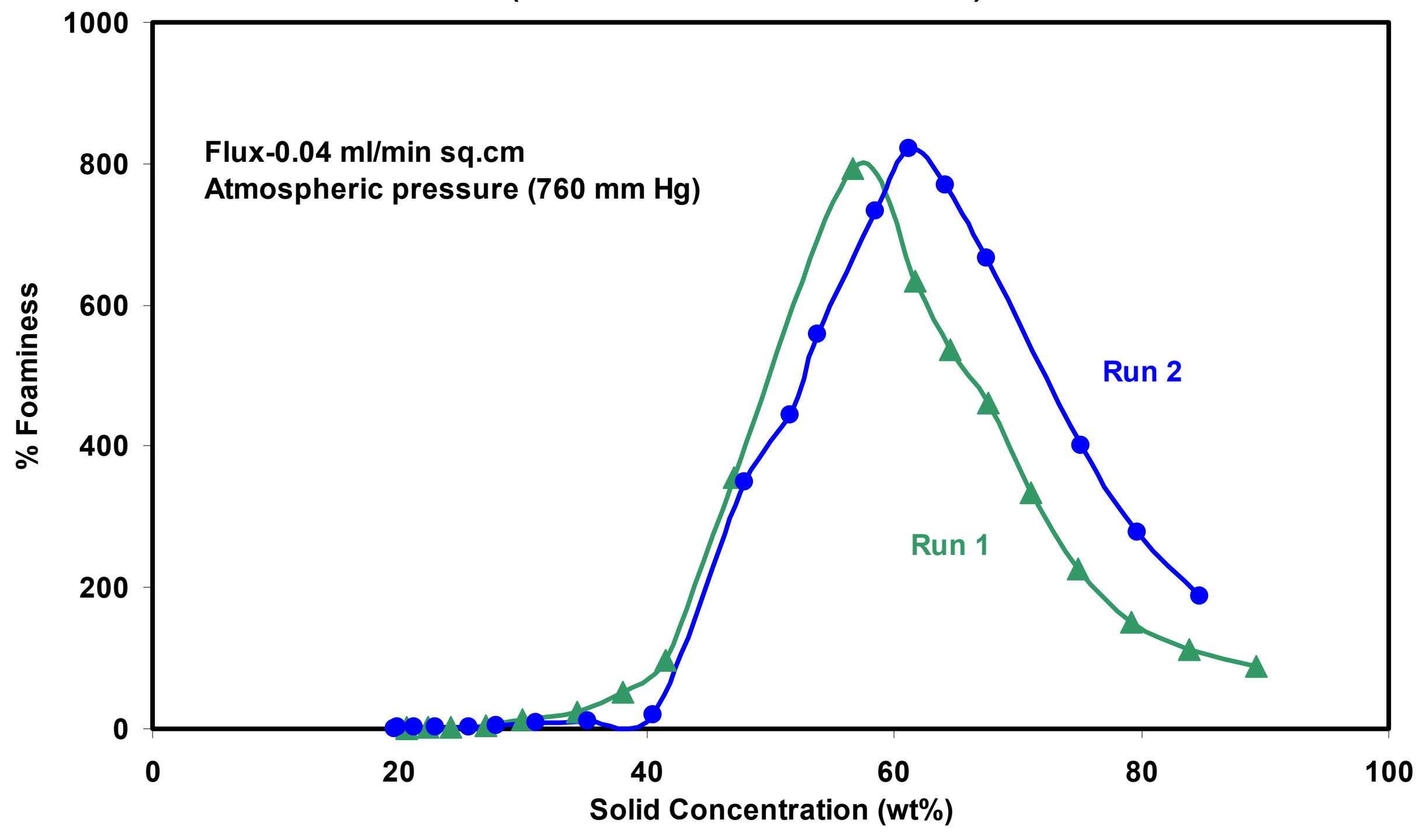

Figure 3b: \% Foaminess vs Solid Concentration 
AN-107 with Entrained Solids (ENVELOPE C)

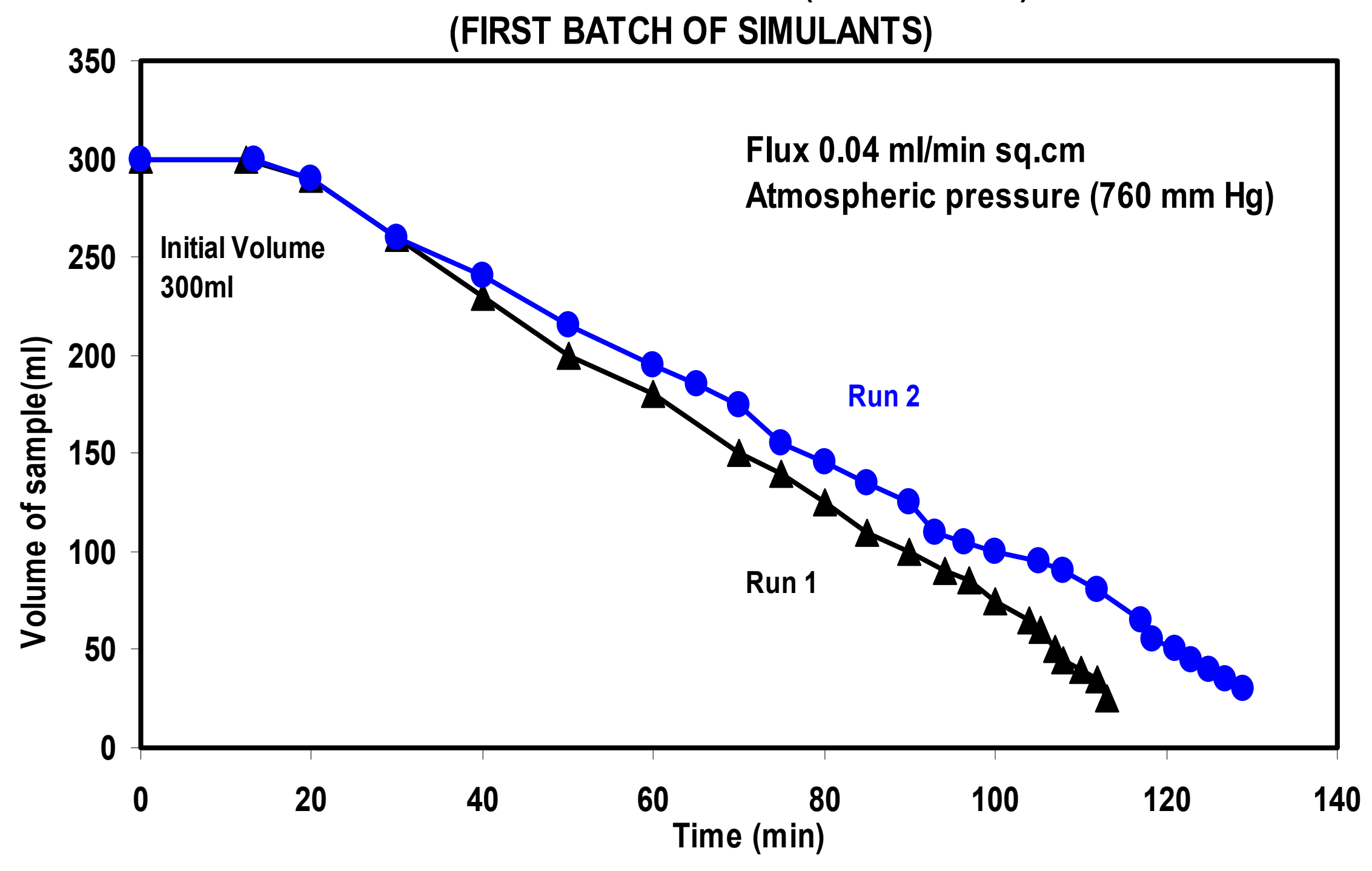

Figure 4a: Water evaporation flux with time 


\section{AN-107 with Entrained Solids (ENVELOPE C)}

(FIRST BATCH OF SIMULANTS)

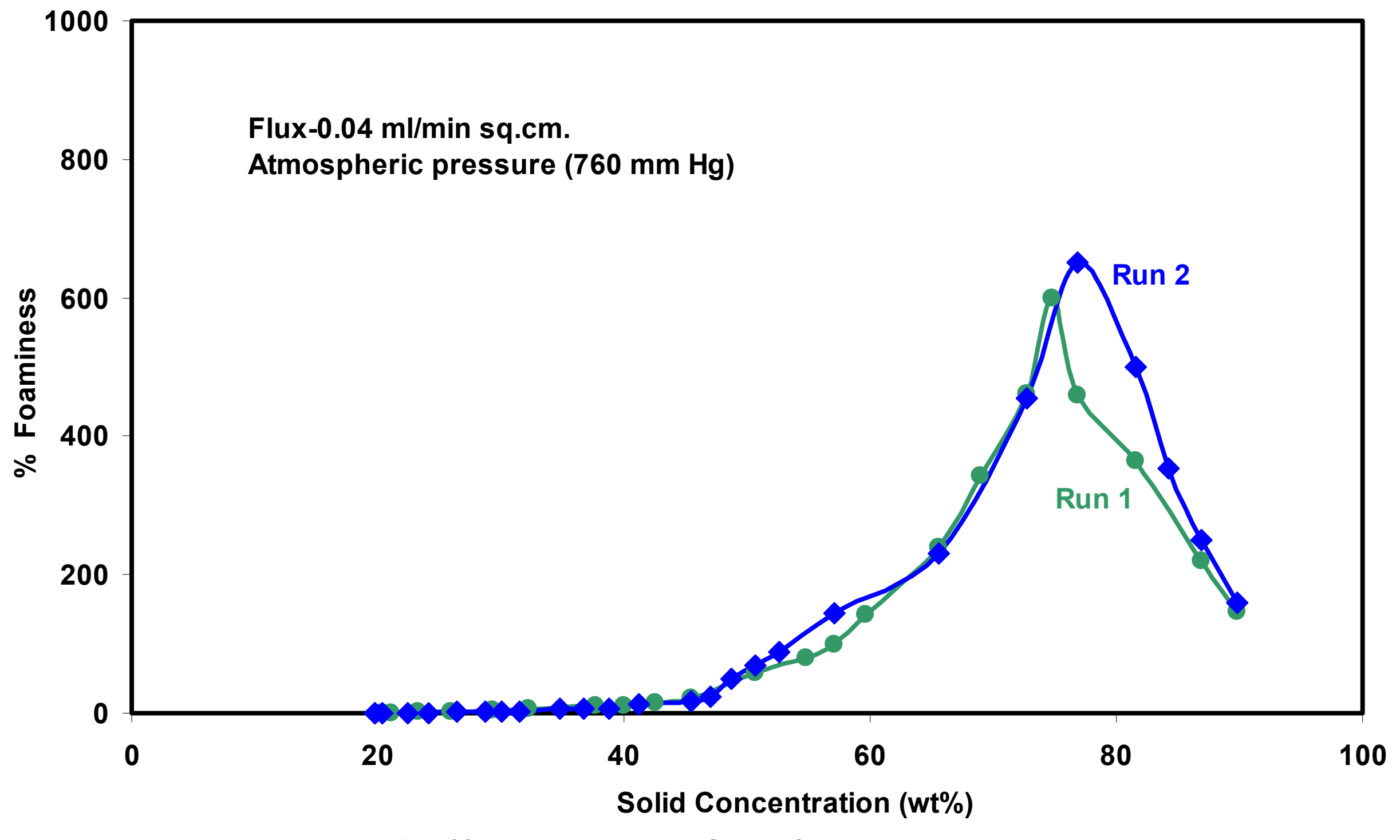

Figure 4b: \% Foaminess vs Solid Concentration 


\section{AN-107 3M (ENVELOPE C)}

(FIRST BATCH OF SIMULANTS)

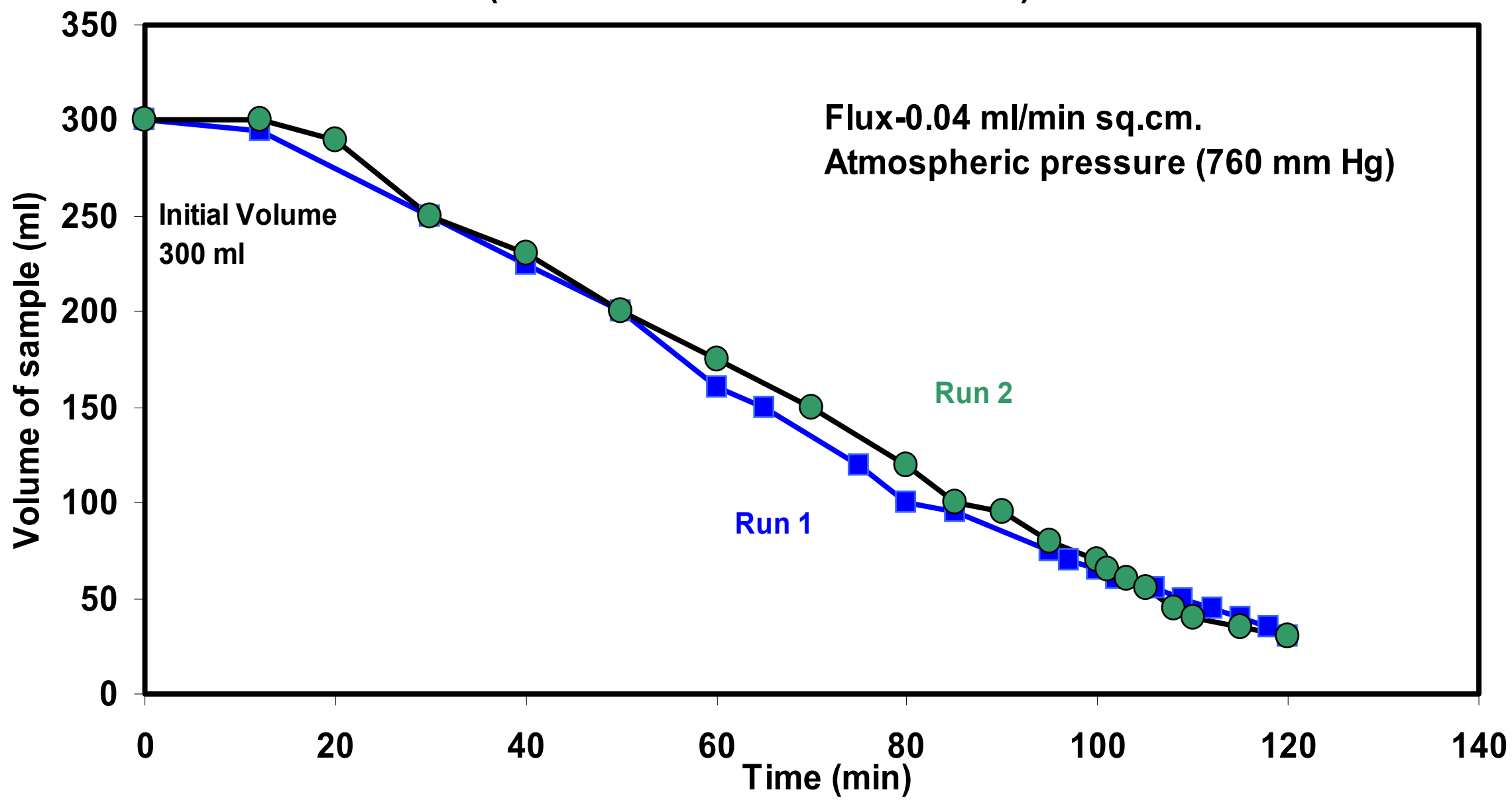

Figure 5a: Water evaporation flux with time 


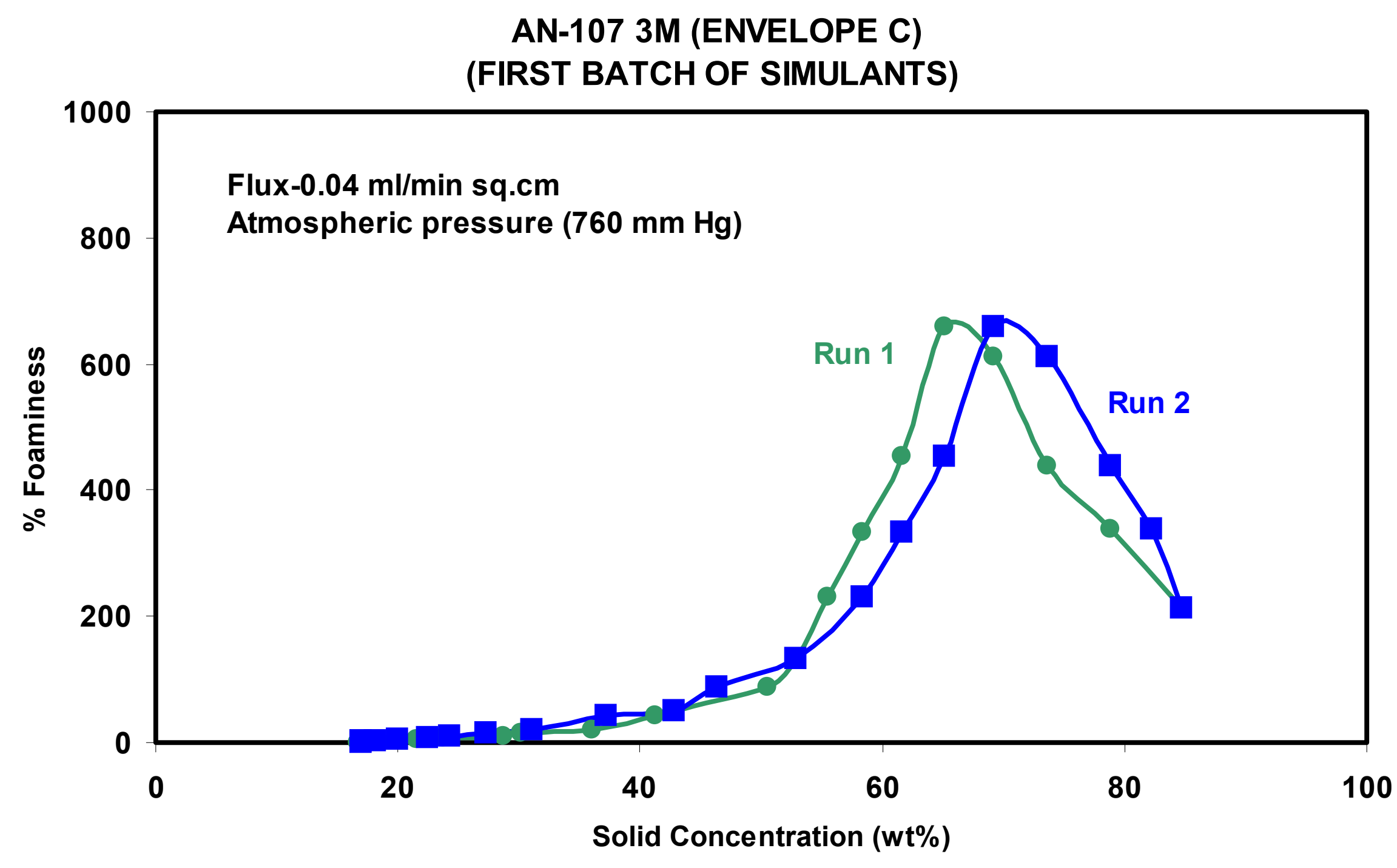

Figure 5b: \% Foaminess vs Solid Concentration 


\section{AN-104 with Entrained Solids}

(FIRST BATCH OF SIMULANTS)

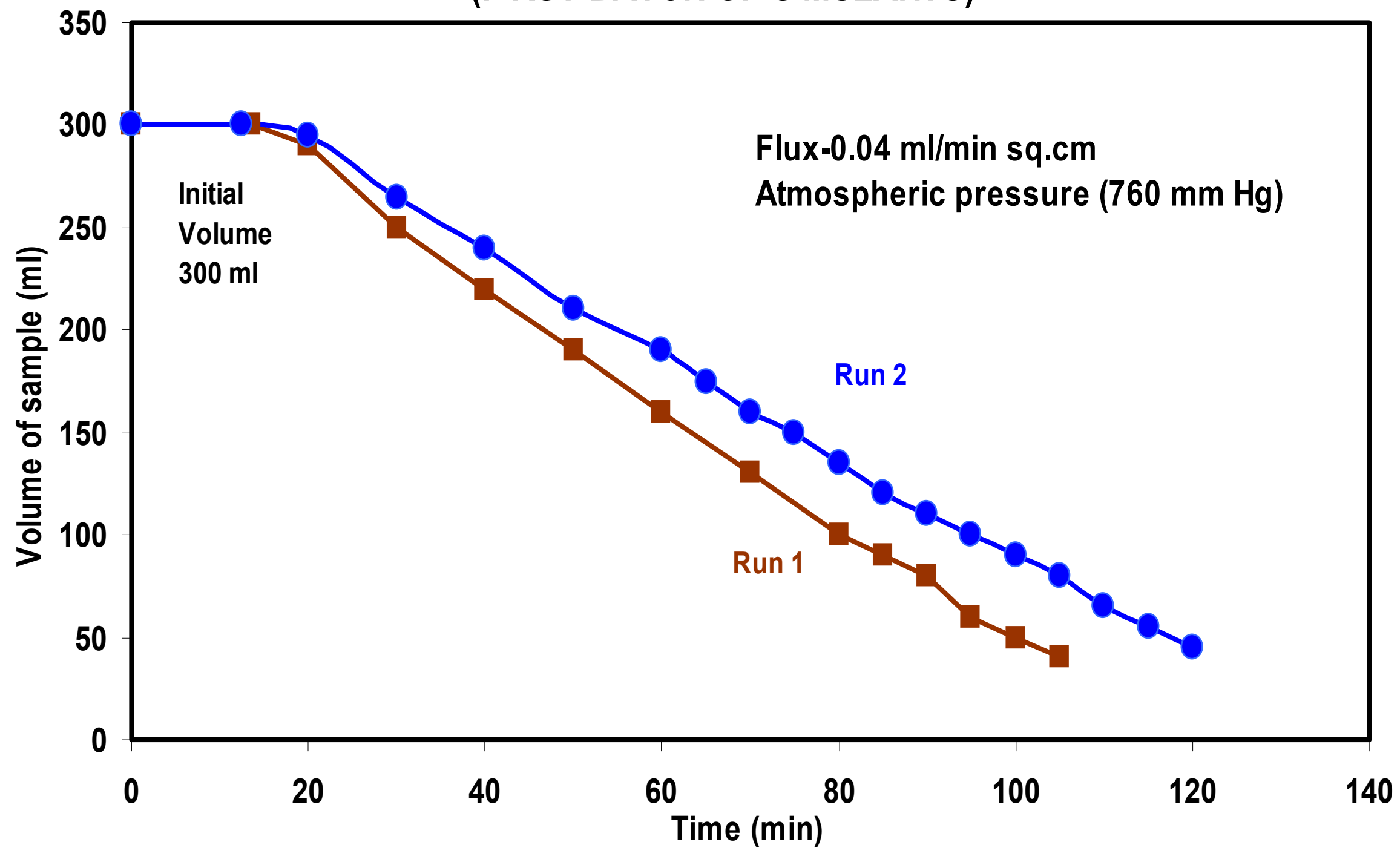

Figure 6a: Water evaporation flux with time 


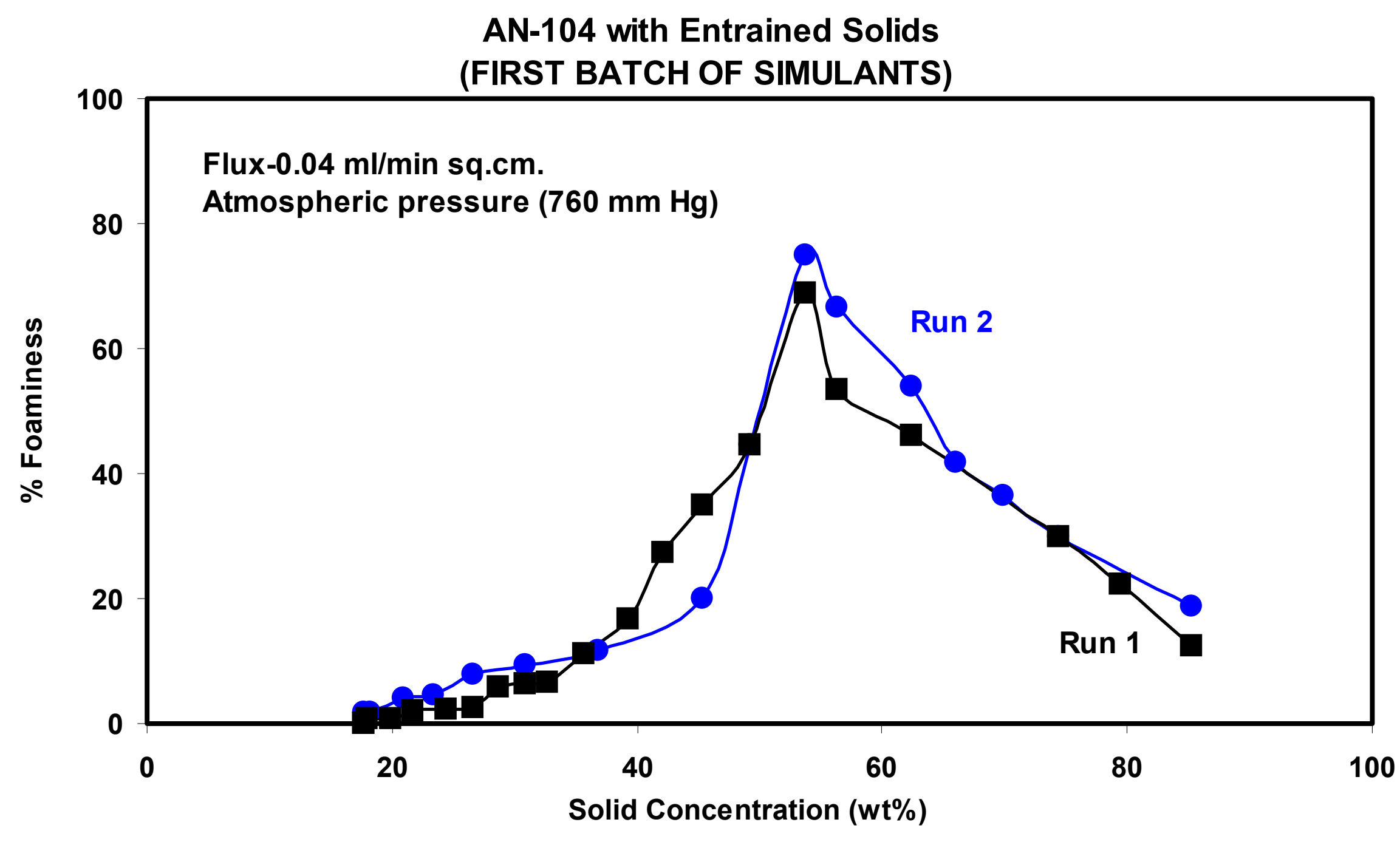

Figure 6b: \% Foaminess vs Solid Concentration 


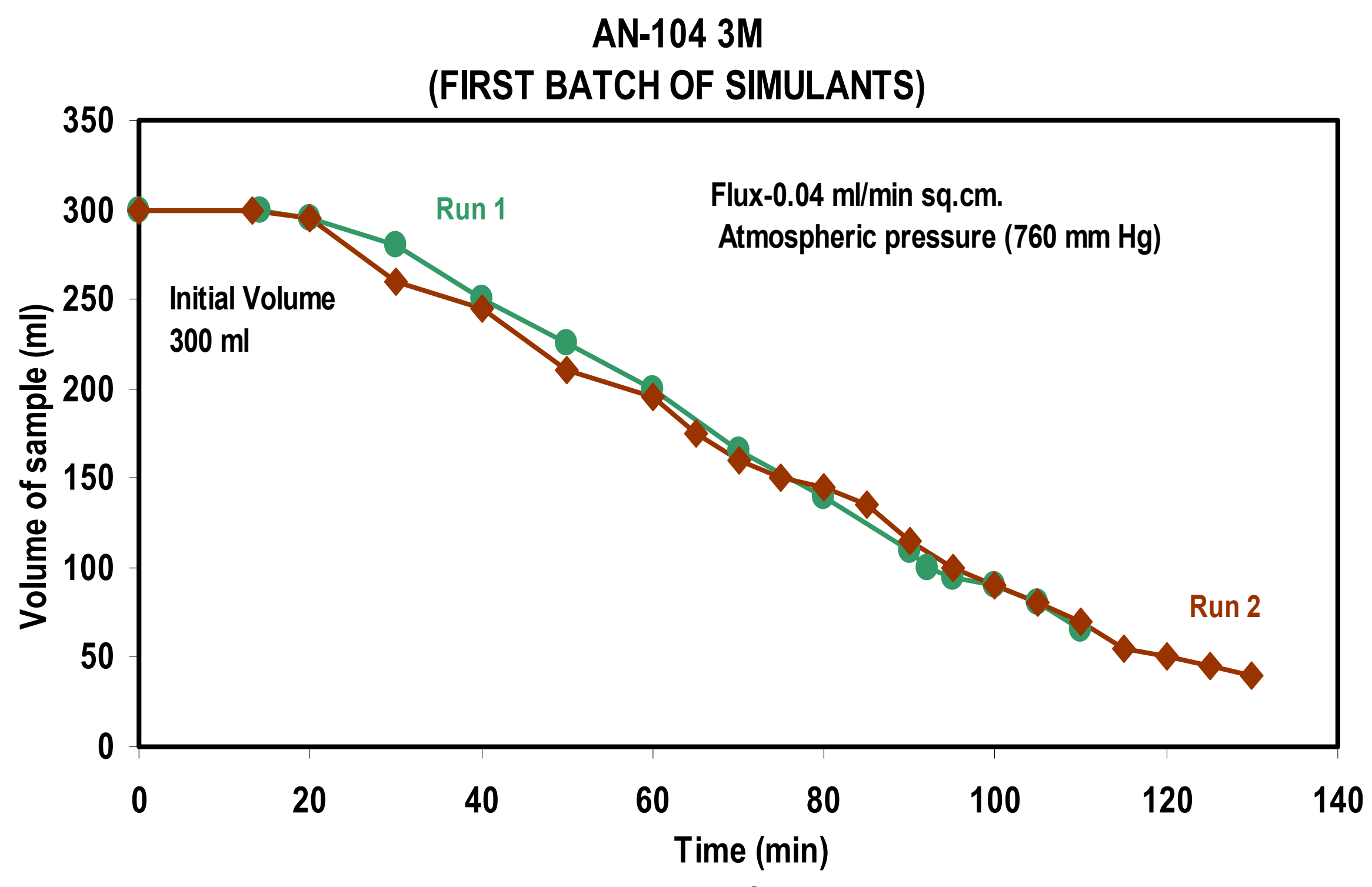

Figure 7a: Water evaporation flux with time 


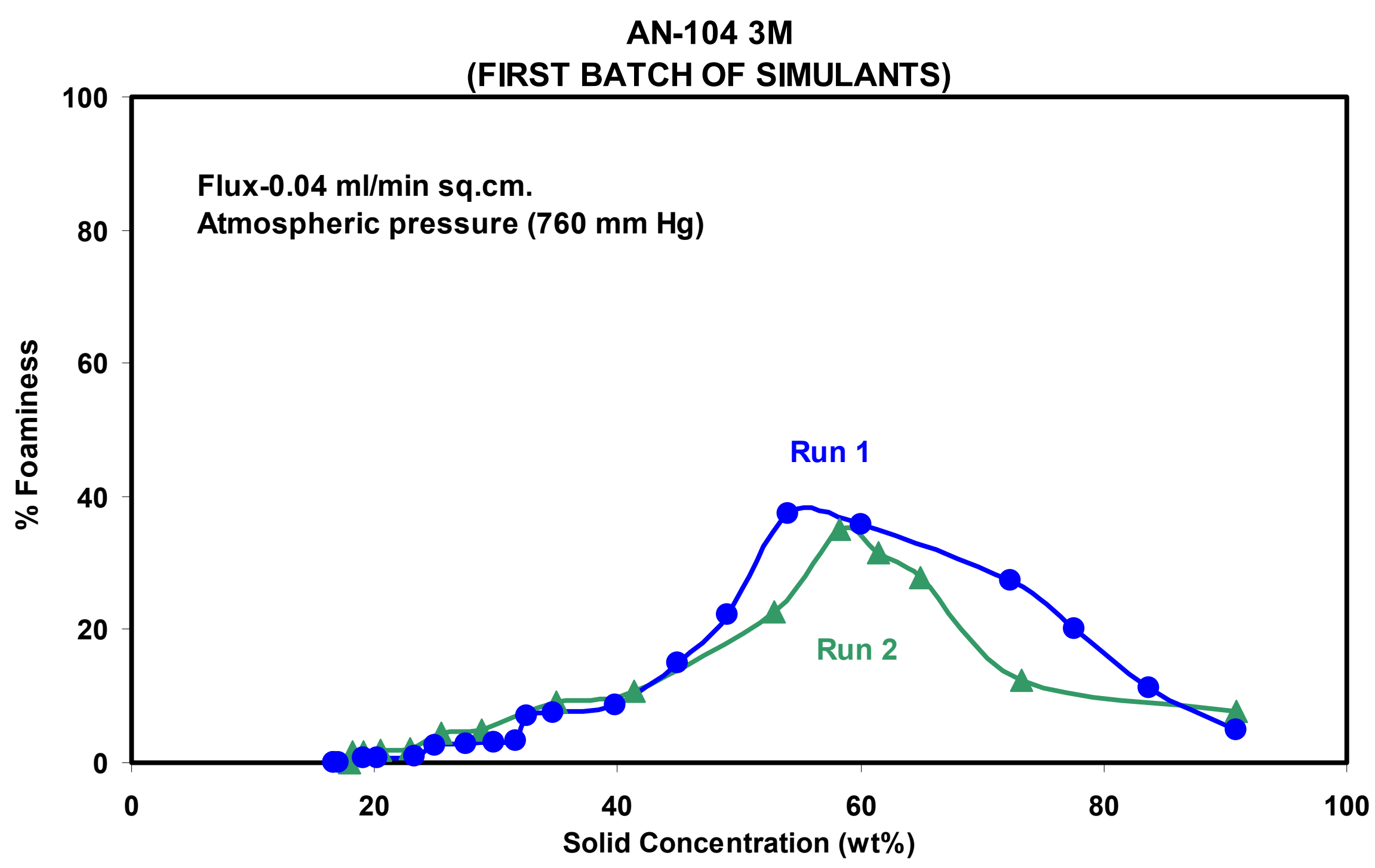

Figure 7b: \% Foaminess vs Solid Concentration 


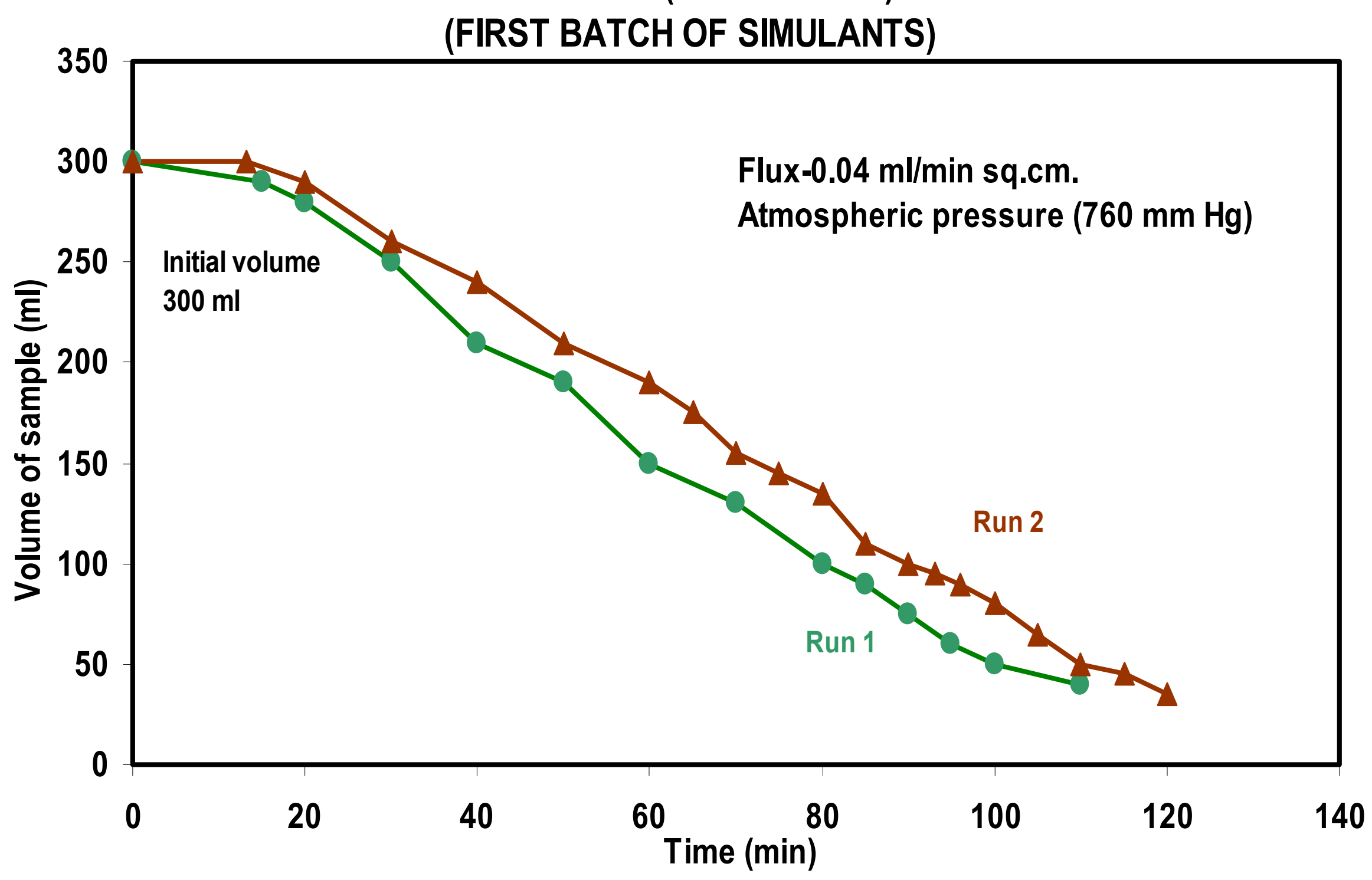

Figure 8a: Water evaporation flux with time 


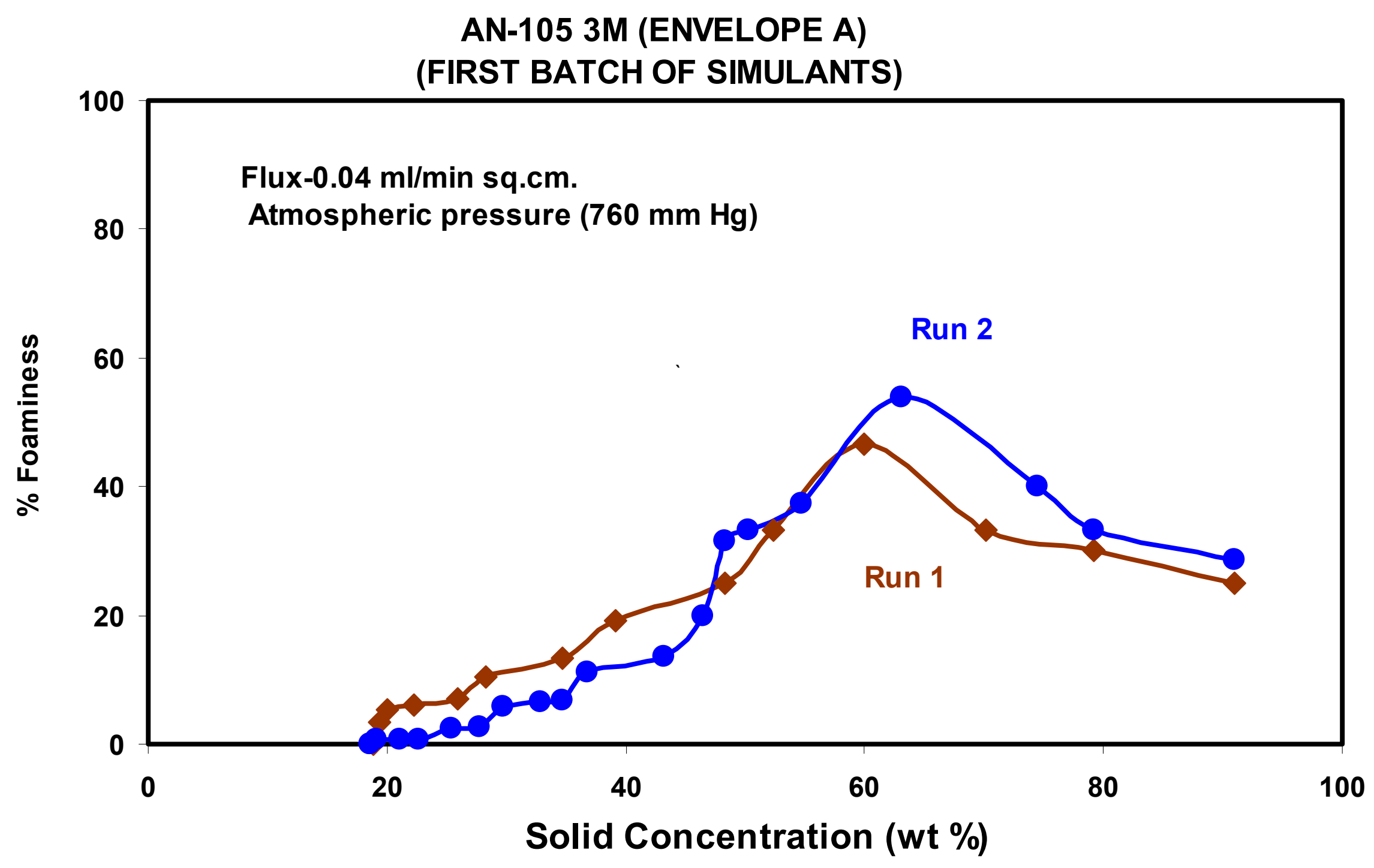

Figure 8b: \% Foaminess vs Solid Concentration 
AN-105 3M with Entrained Solids (ENVELOPE A) (FIRST BATCH OF SIMULANTS)

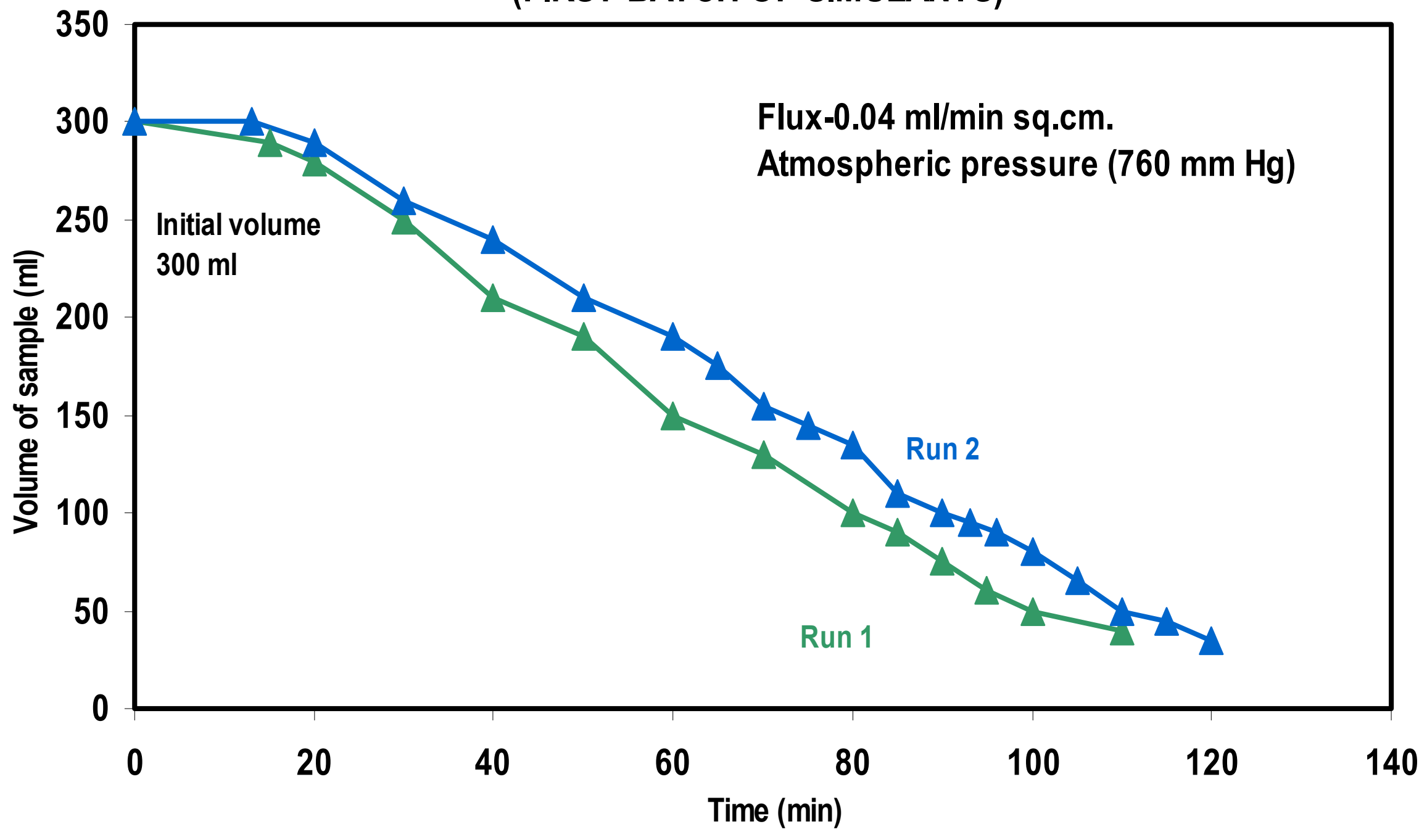

Figure 9a: Water evaporation flux with time 


\section{AN-105 3M with ENTRAINED SOLIDS (ENVELOPE A)} (FIRST BATCH OF SIMULANTS)

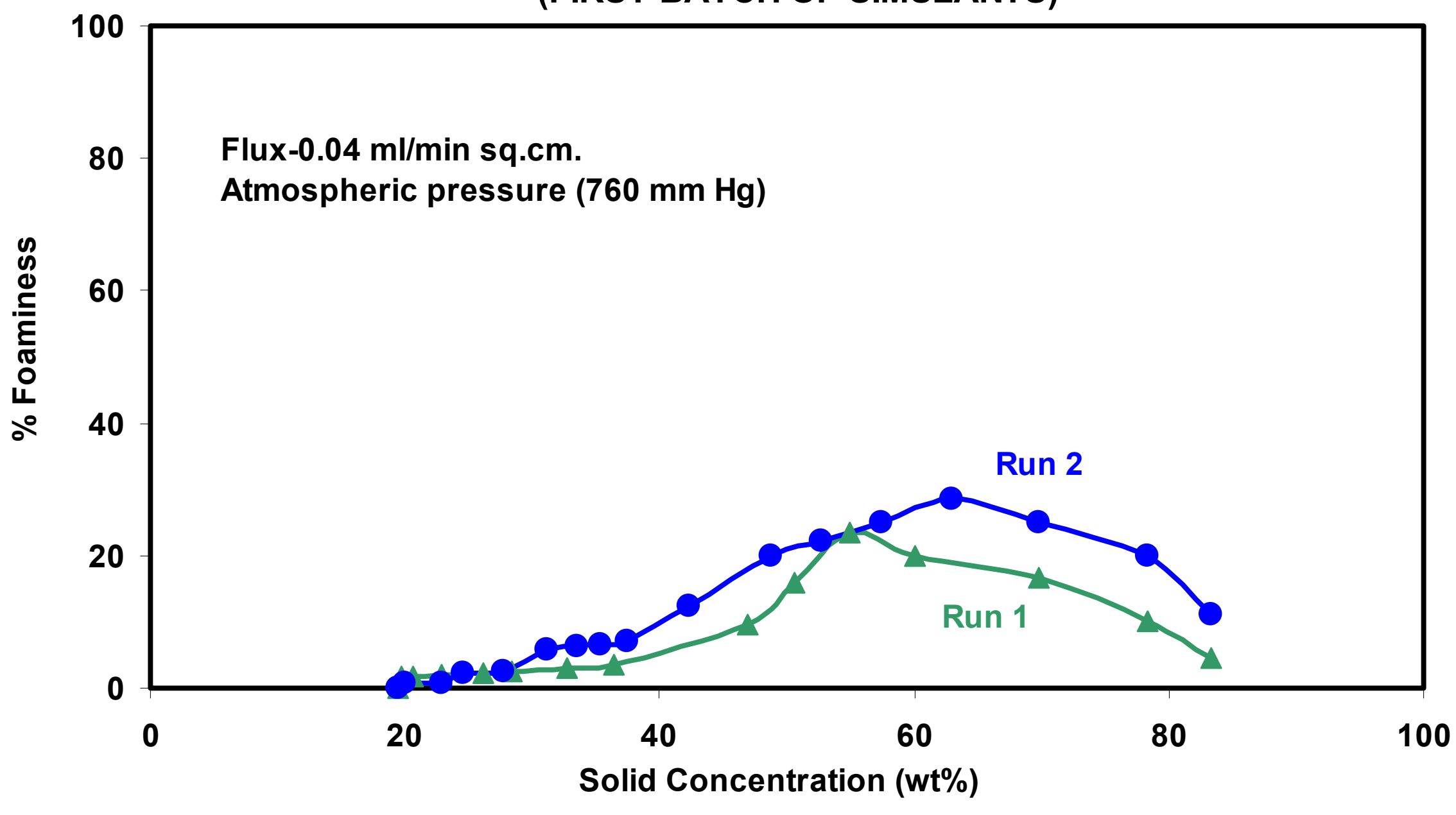

Figure 9b: \% Foaminess vs Solid Concentration 


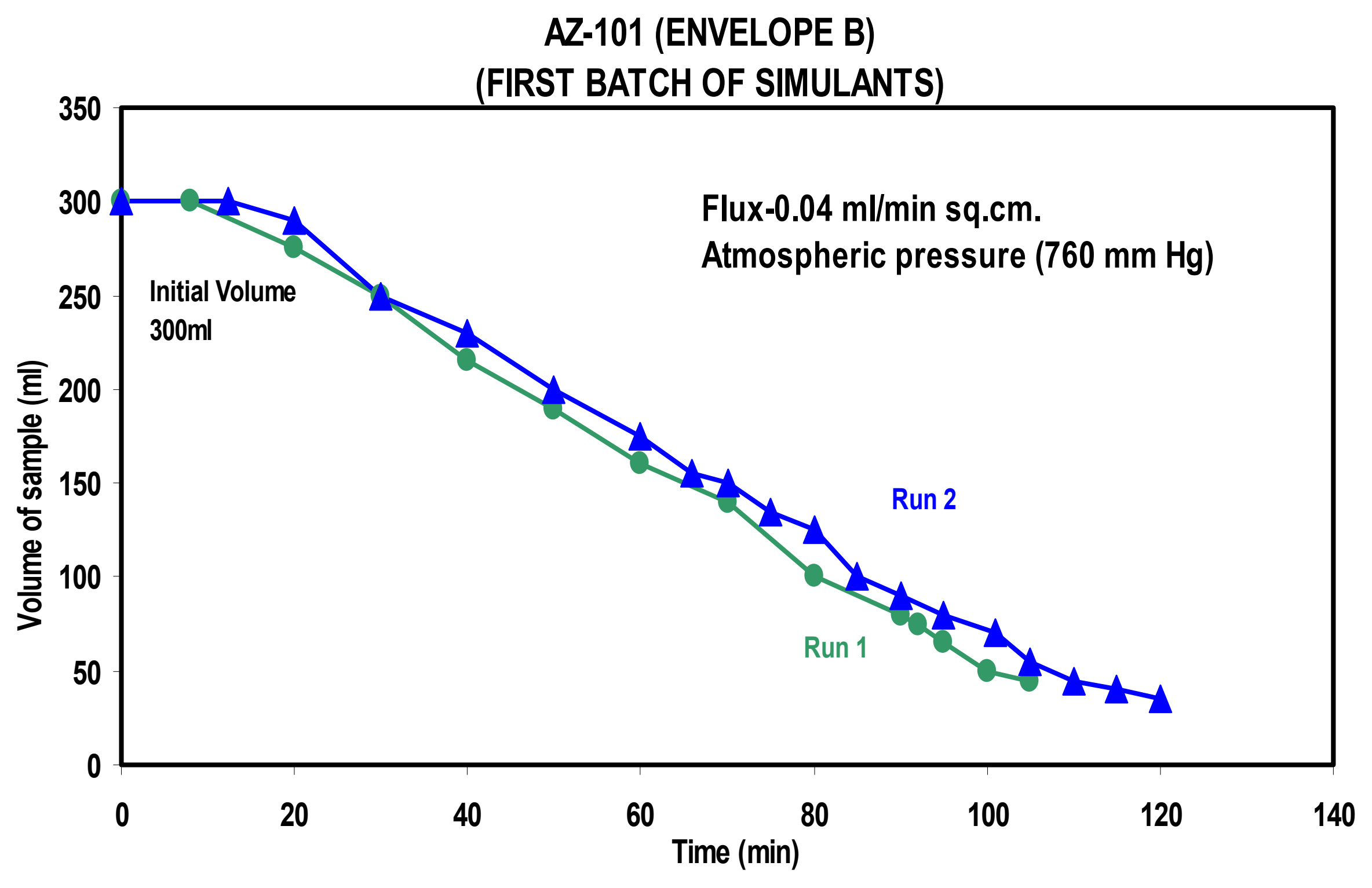

Figure 10a: Water evaporation flux with time 


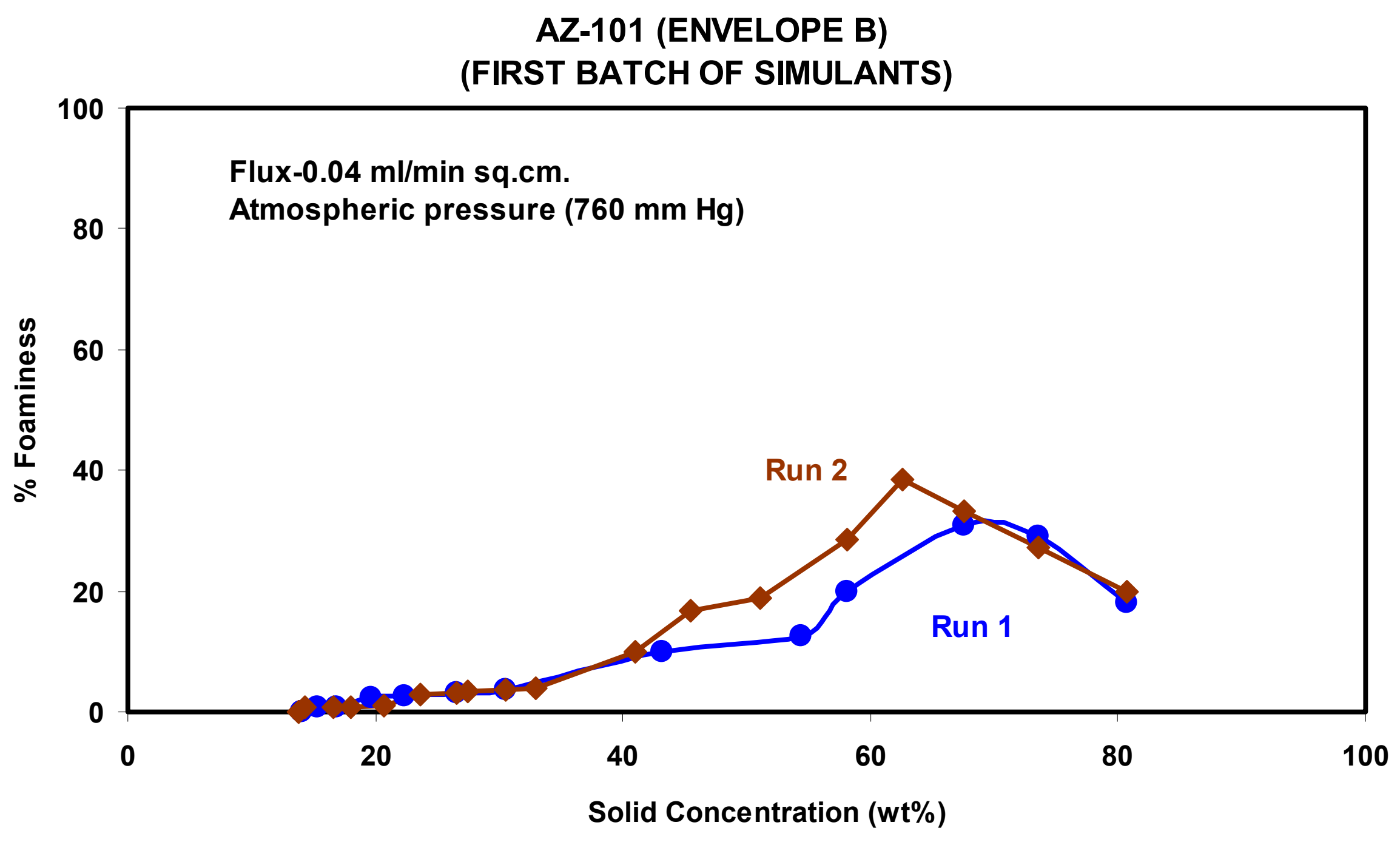

Figure 10b: \% Foaminess vs Solid Concentration 


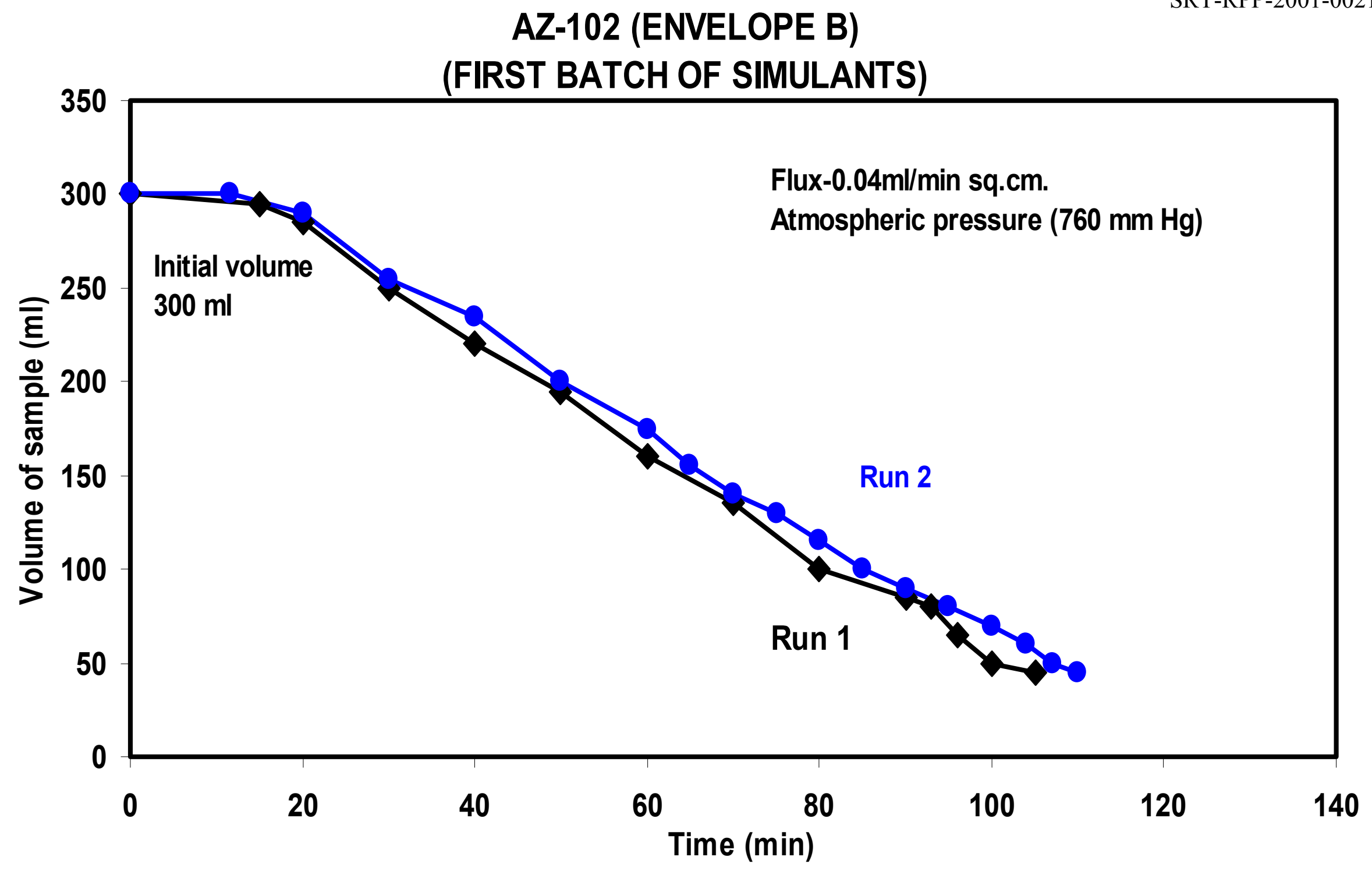

Figure 11a: Water evaporation flux with time 


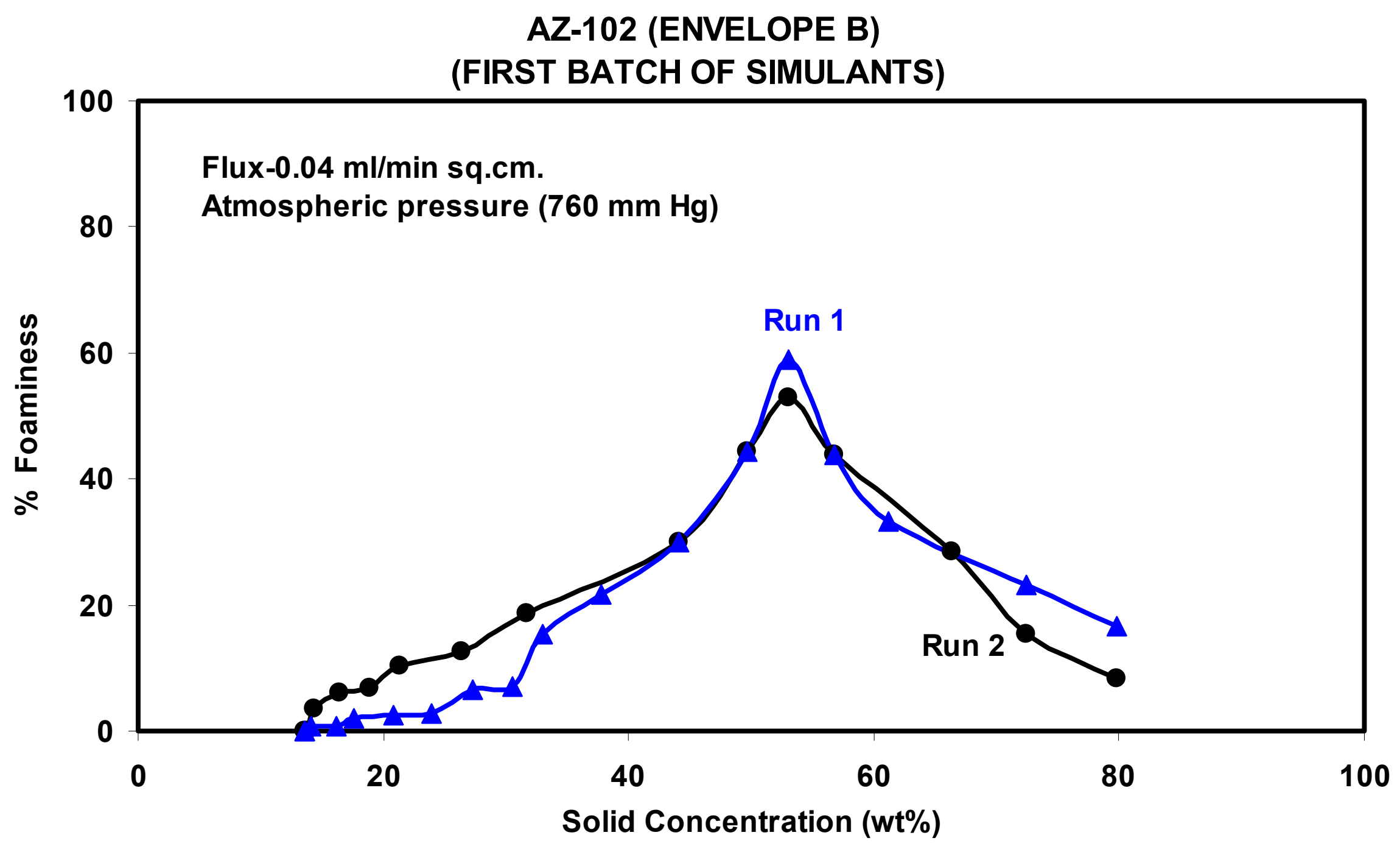

Figure 11b: \% Foaminess vs Solid Concentration 
AN-107 with Entrained Solids (ENVELOPE C) (FIRST BATCH OF SIMULANTS)

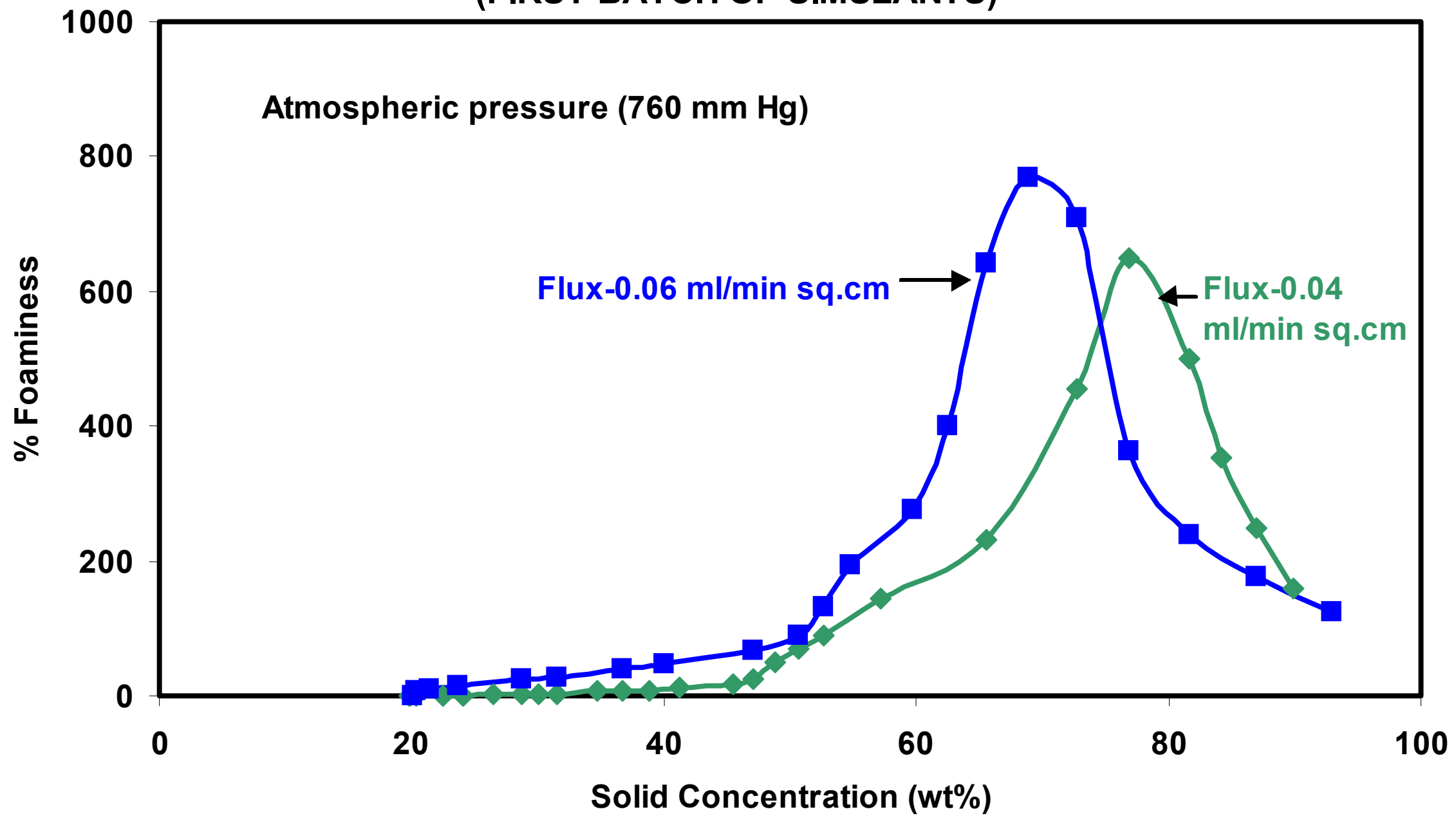

Figure 12: Effect of water evaporation flux on foaminess at atmospheric pressure $(760 \mathrm{~mm} \mathrm{Hg})$ 


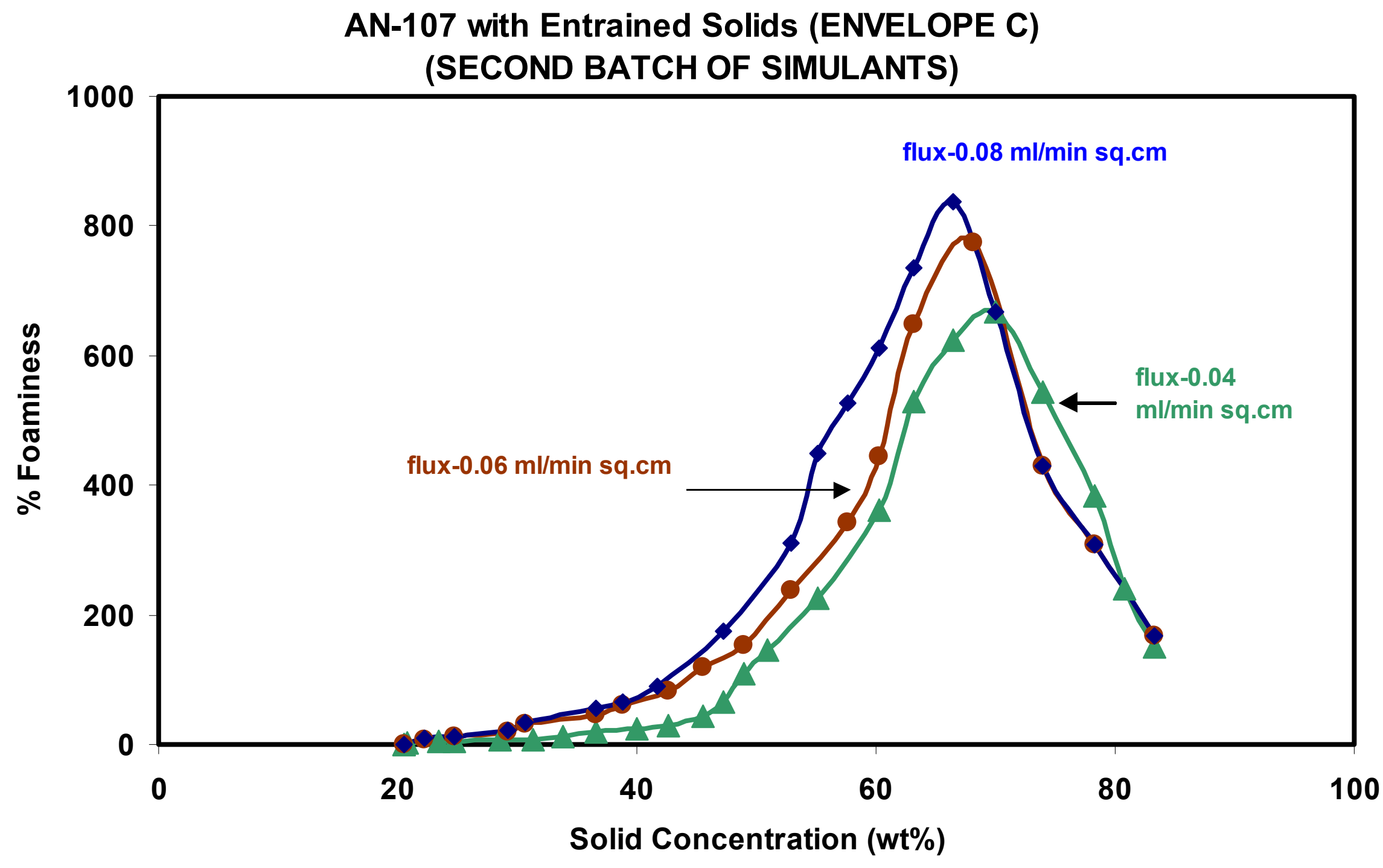

Figure 13: Effect of water evaporation flux on foaminess at atmospheric pressure (760 $\mathrm{mm} \mathrm{Hg})$ 


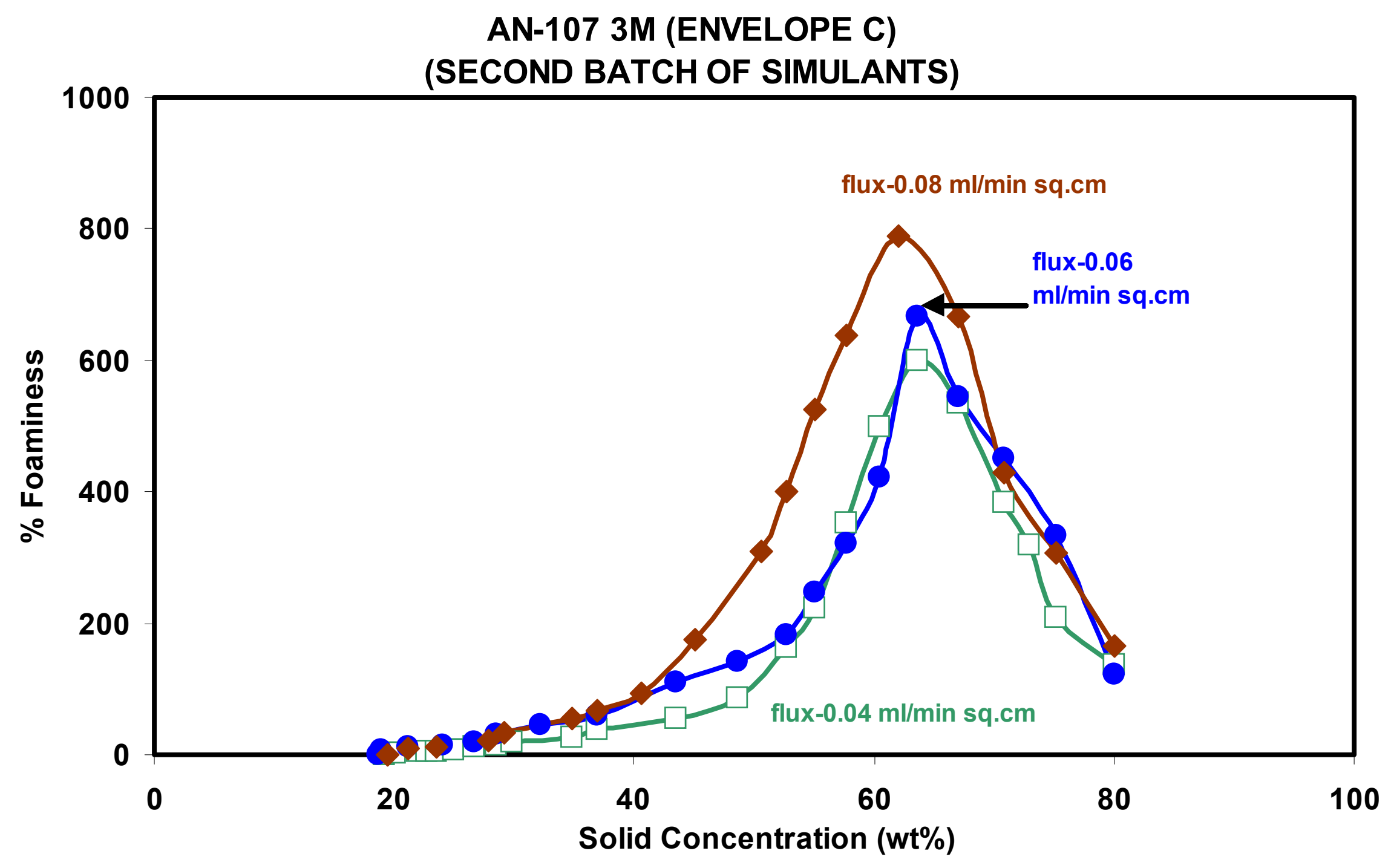

Figure 14: Effect of water evaporation flux on foaminess at atmospheric pressure (760 $\mathrm{mm} \mathrm{Hg})$ 


\section{PRETREATED AN-107 (ENVELOPE C)}

(SECOND BATCH OF SIMULANTS)

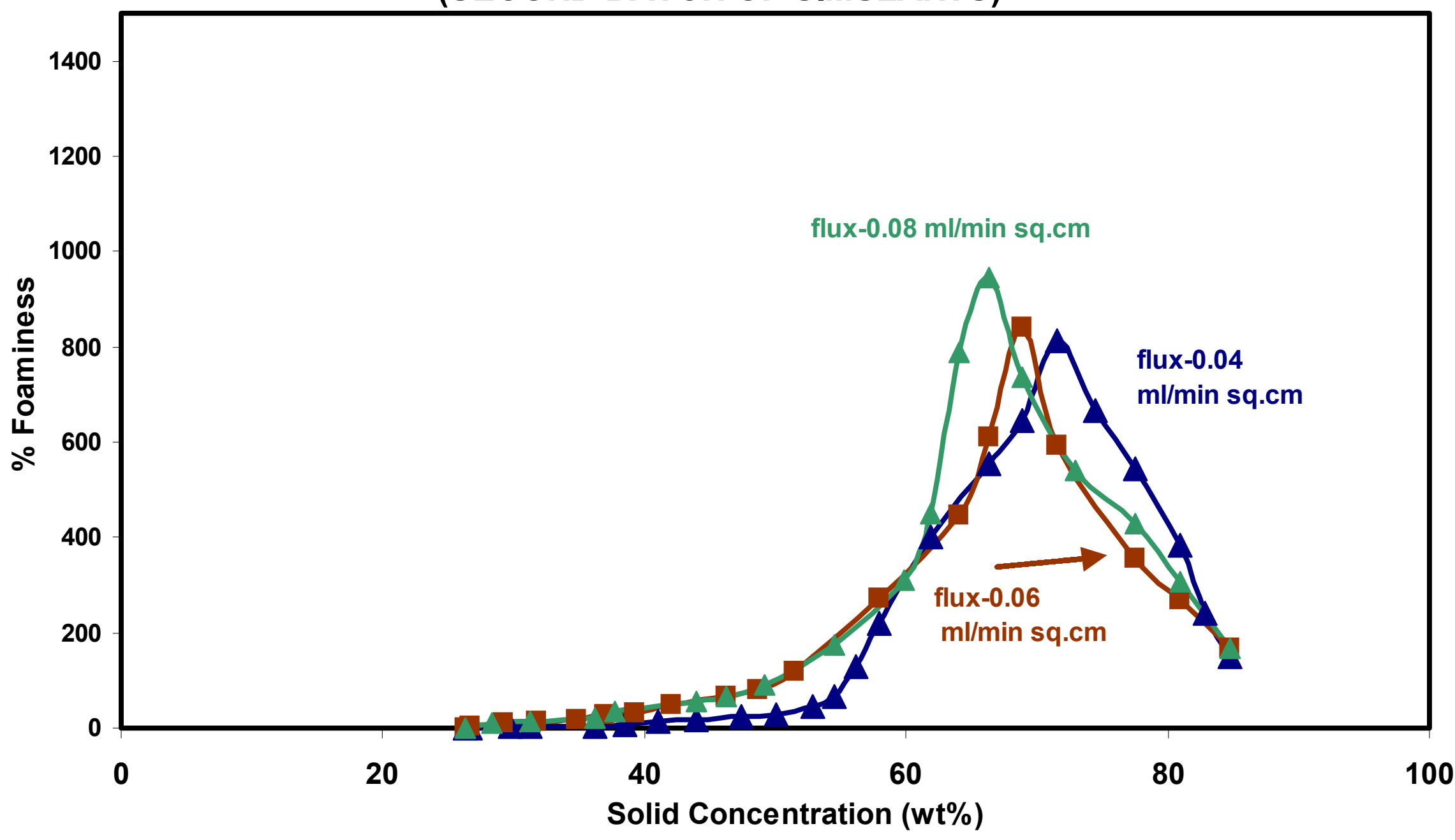

Figure 15: Effect of water evaporation flux on foaminess at atmospheric pressure $(760 \mathrm{~mm} \mathrm{Hg})$ 
AN-107 with Entrained Solids (ENVELOPE C)

(FIRST BATCH OF SIMULANTS)

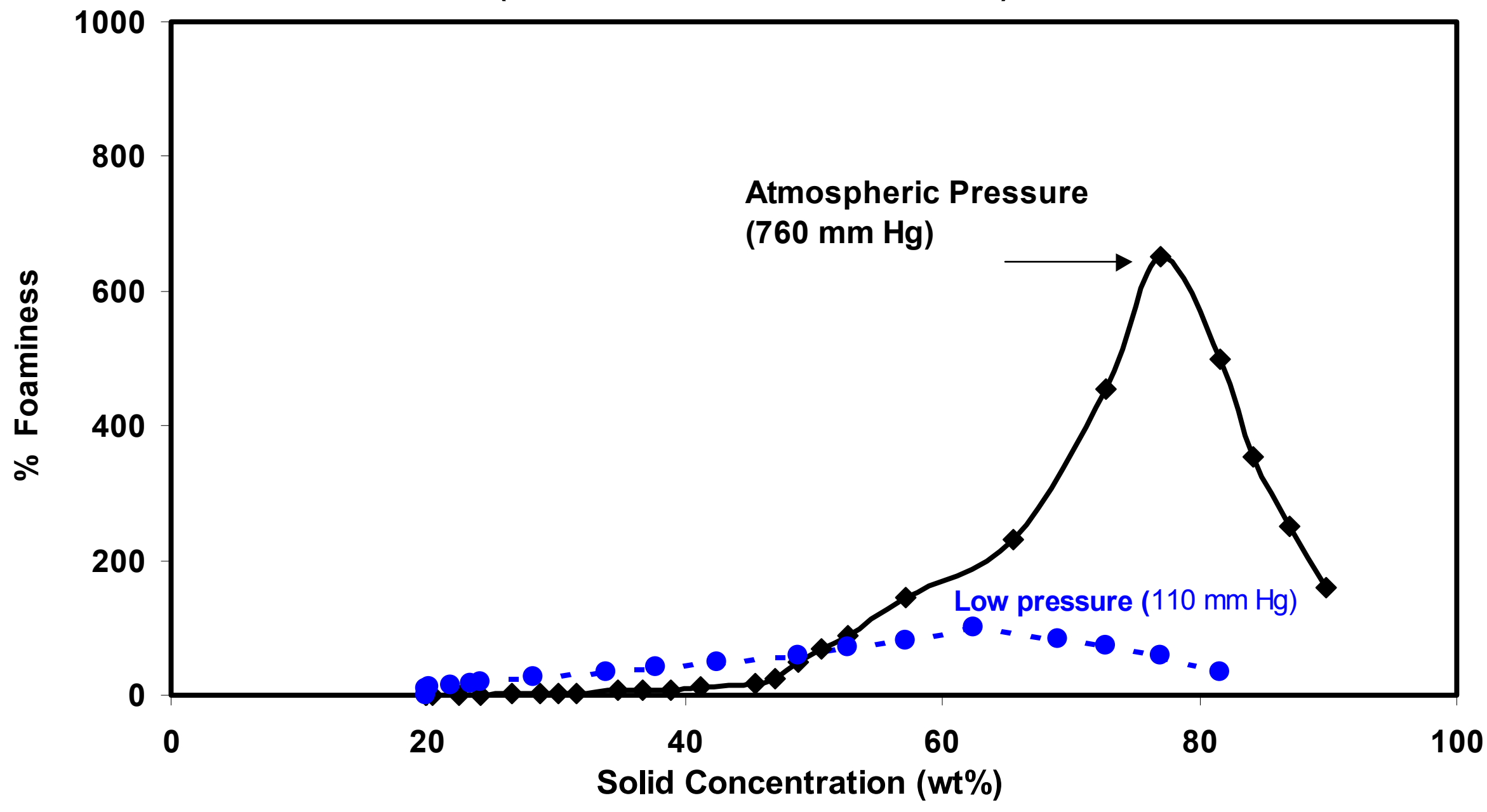

Figure 16: Effect of pressure on foaminess at water evaporation flux $(0.05 \mathrm{ml} / \mathrm{min}$ sq.cm) 


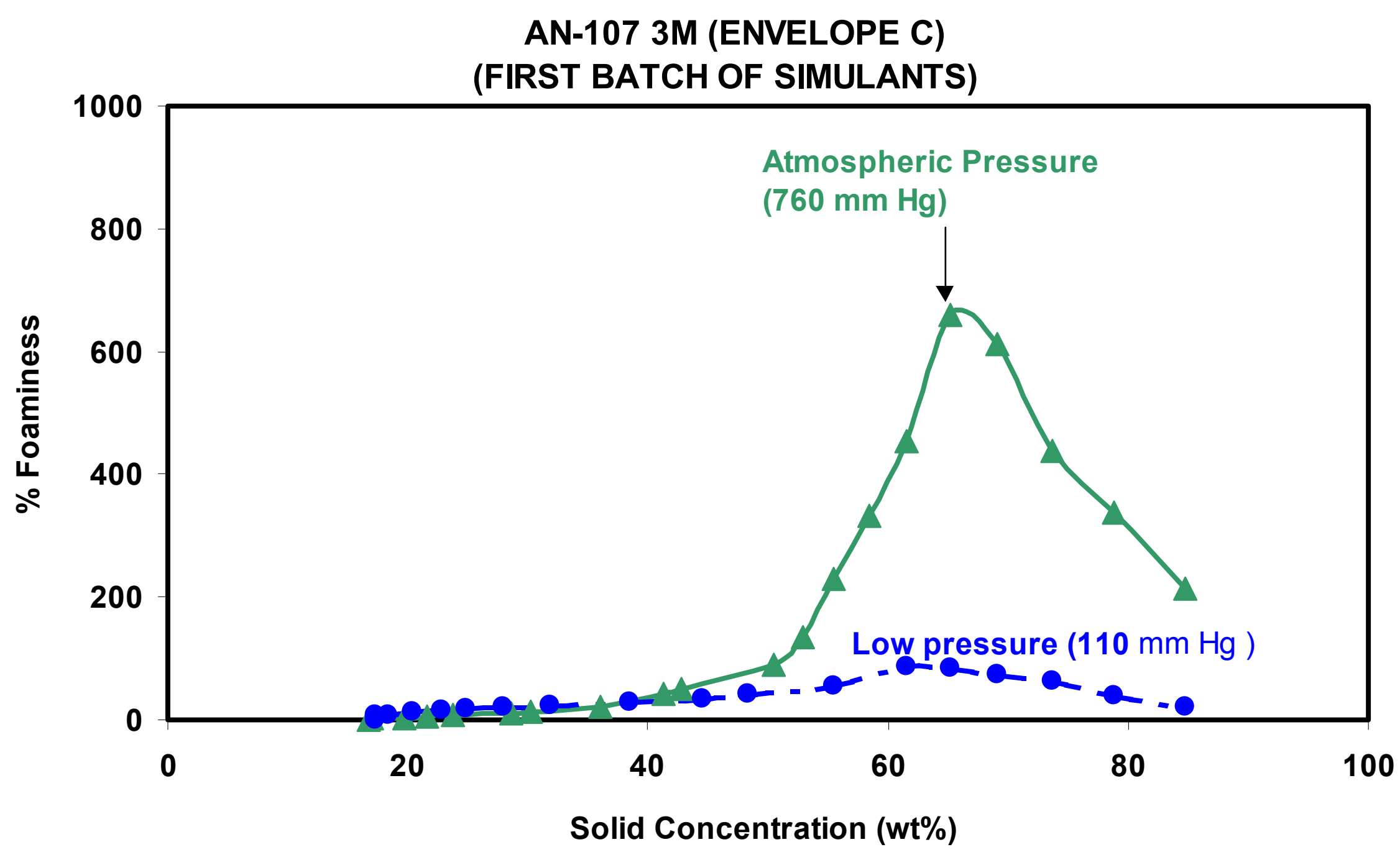

Figure 17: Effect of pressure on foaminess at water evaporation flux $(0.05 \mathrm{ml} / \mathrm{min} \mathrm{sq} . \mathrm{cm}$.) 


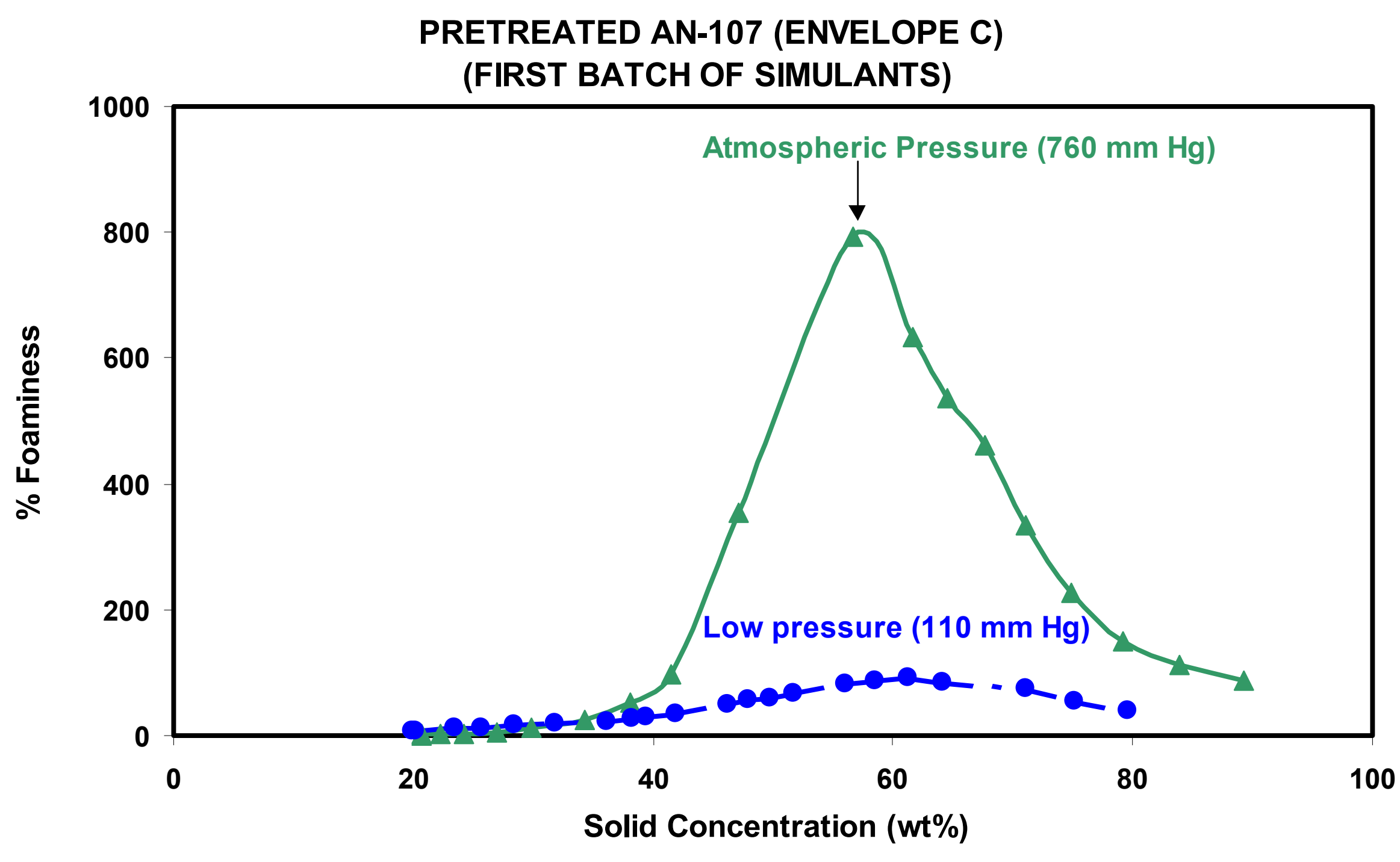

Figure 18: Effect of pressure on foaminess at water evaporation flux $(0.05 \mathrm{ml} / \mathrm{min} \mathrm{sq} . \mathrm{cm})$ 


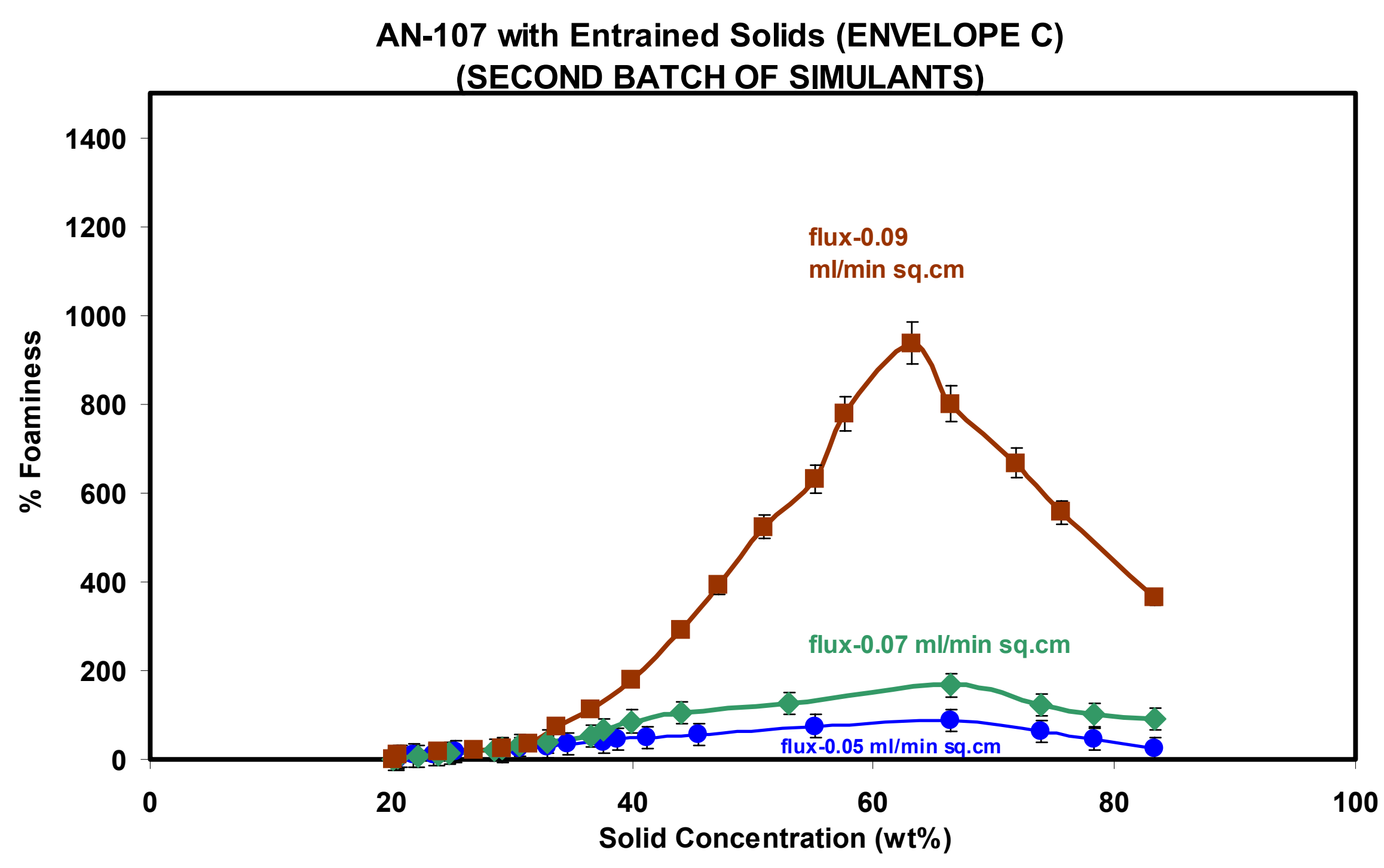

Figure 19: Effect of water evaporation flux on foaminess at low pressure $(110 \mathrm{~mm} \mathrm{Hg})$ 


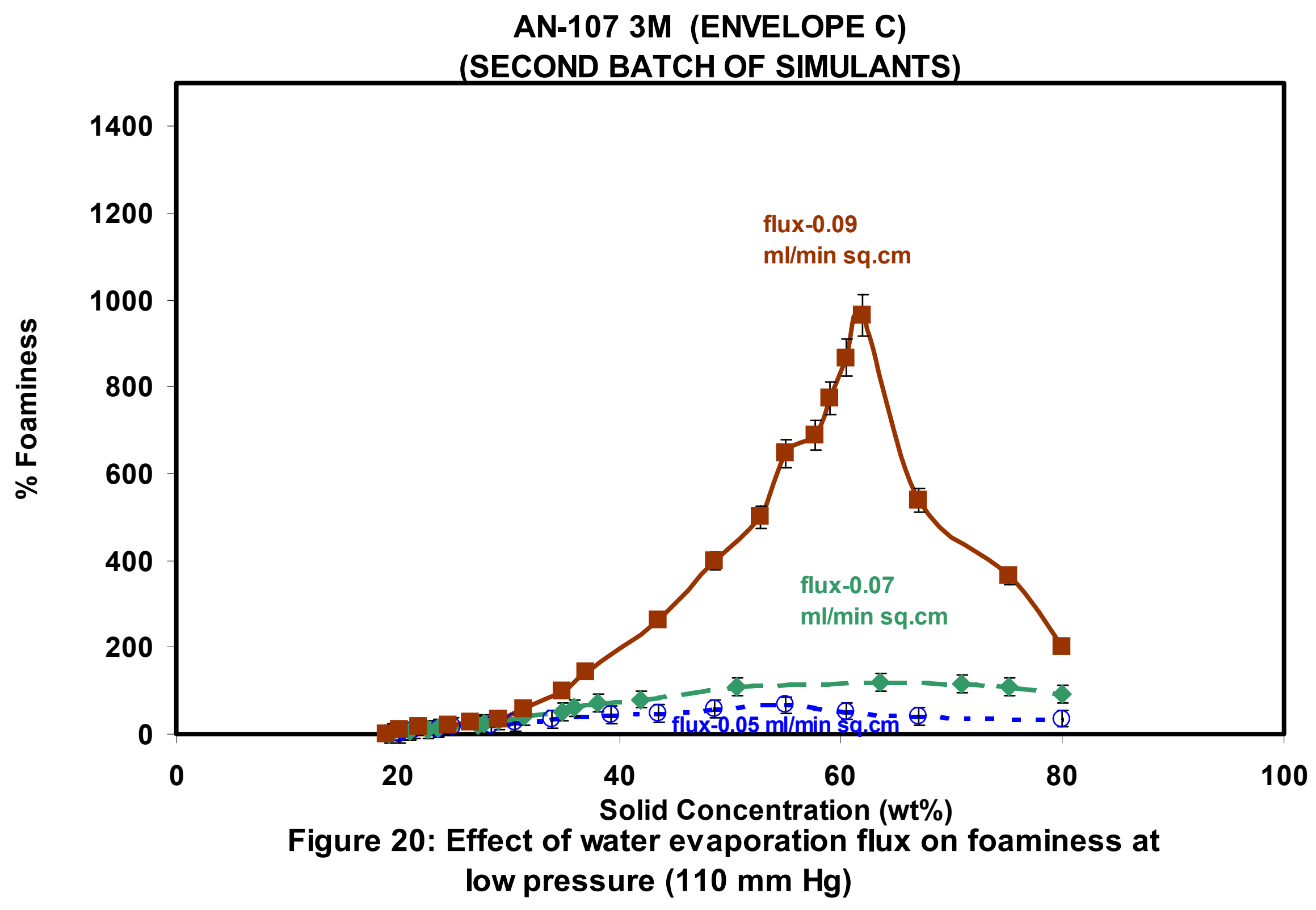


PRE TREATED AN-107(ENVELOPE C) (SECOND BATCH OF SIMULANTS)

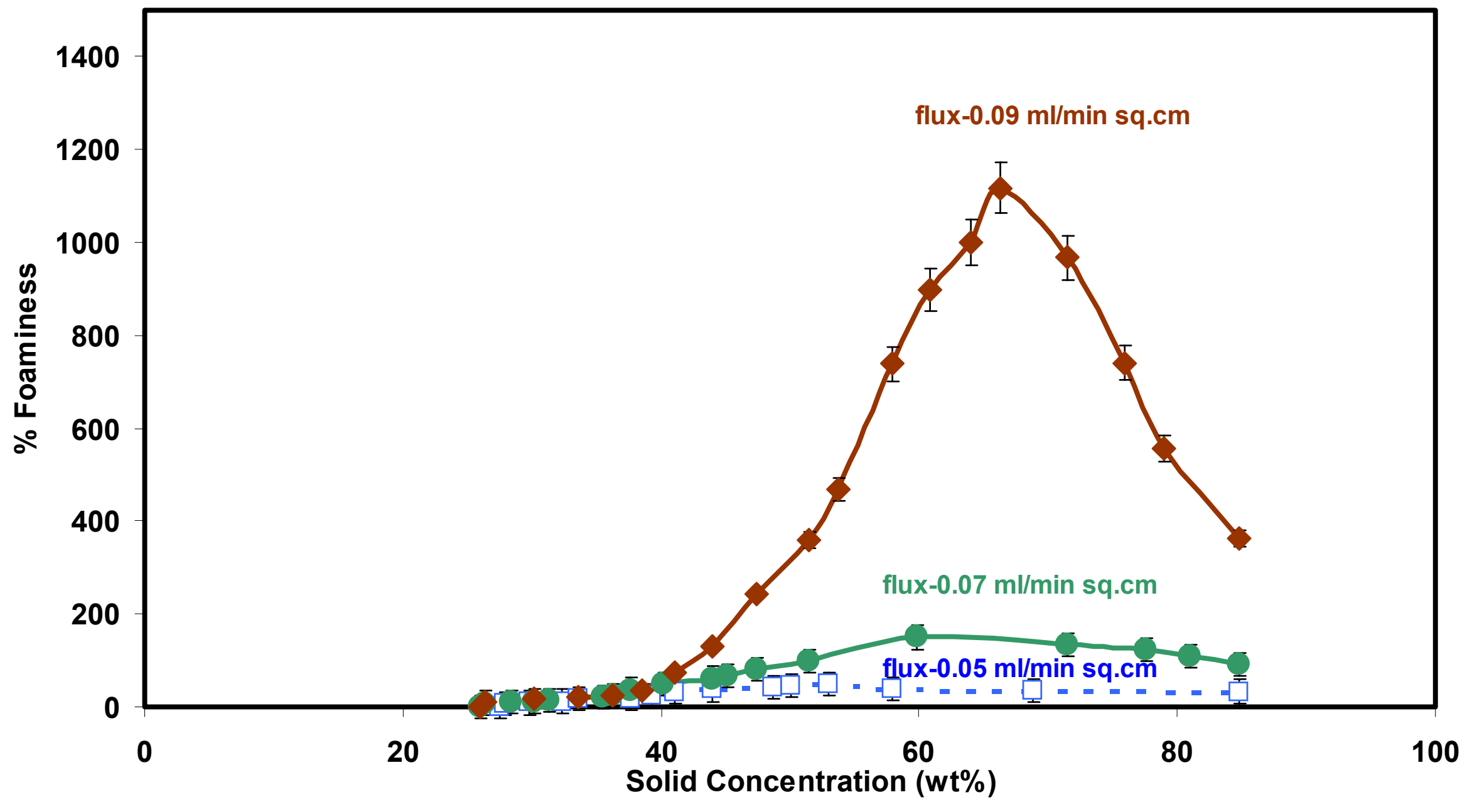

Figure 21: Effect of water evaporation flux on foaminess at low pressure $(110 \mathrm{~mm} \mathrm{Hg}$ ) 


\section{AN-107 with Entrained Solids (ENVELOPE C) (SECOND BATCH OF SIMULANTS)}

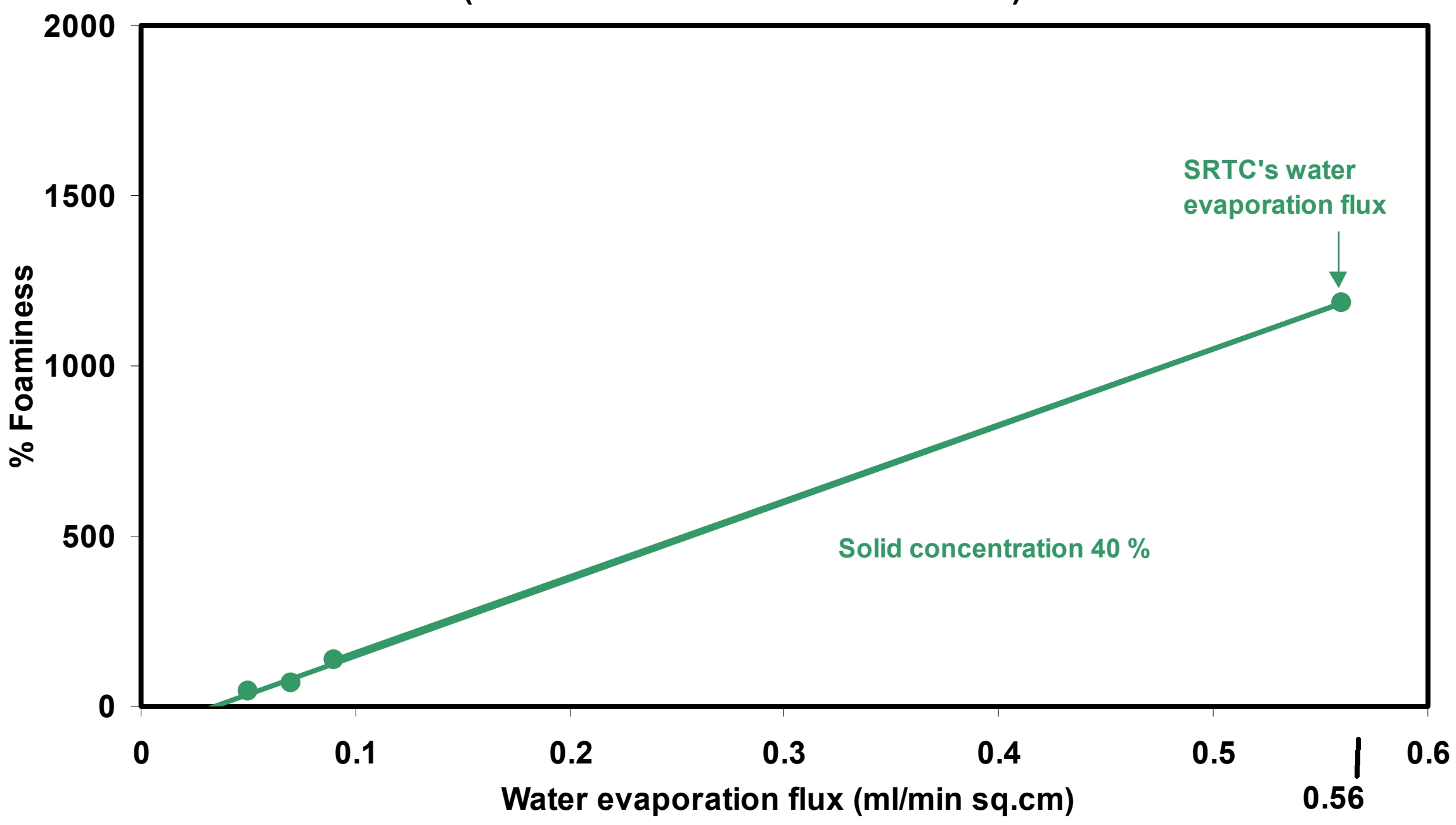

Figure 22 : Predicted foaminess at SRTC's water evaporation flux pressure $110 \mathrm{~mm} \mathrm{Hg}$ ) 


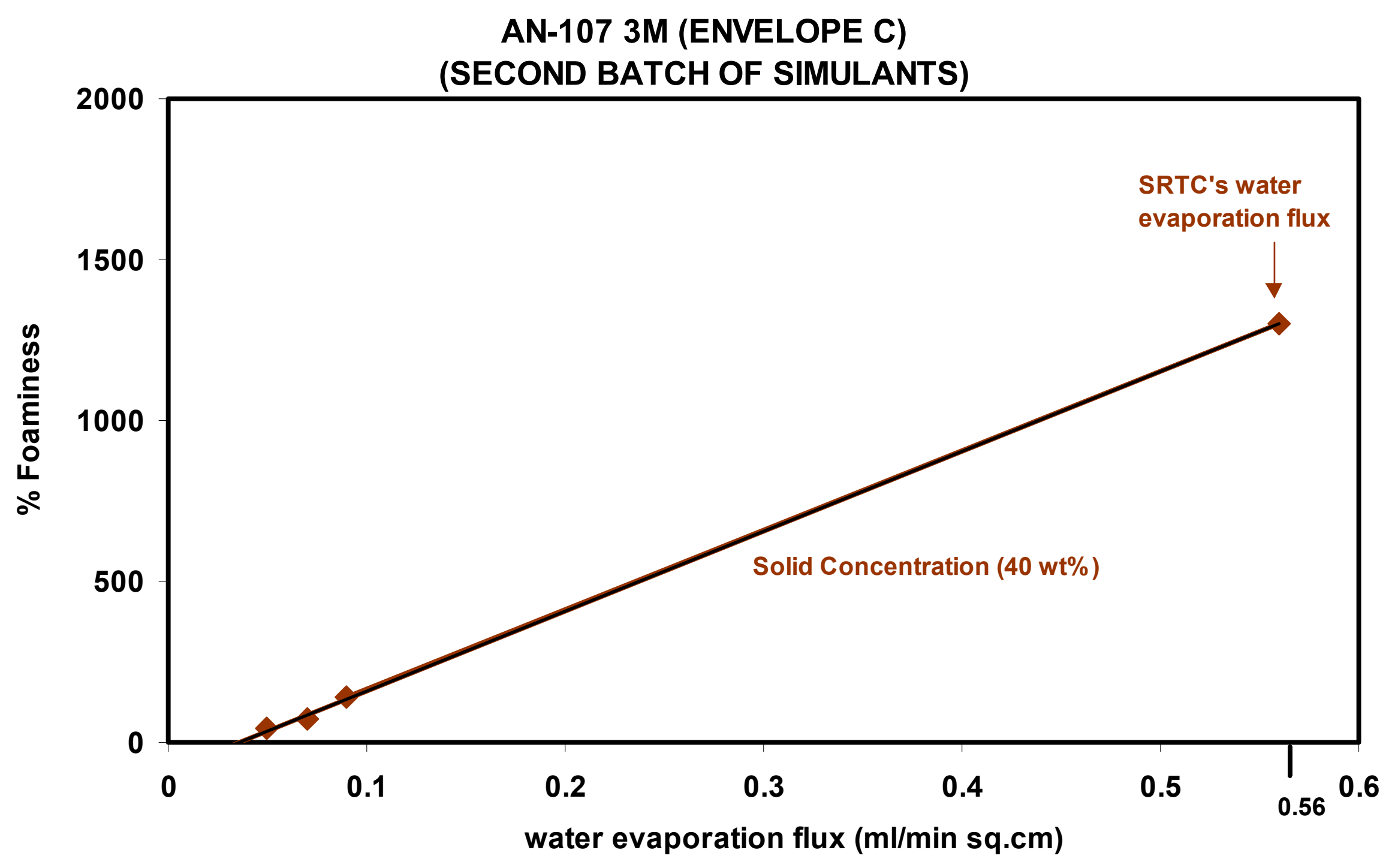

Figure 23: Predicted foaminess at SRTC's water evaporation flux (pressure $110 \mathrm{~mm} \mathrm{Hg}$ ) 


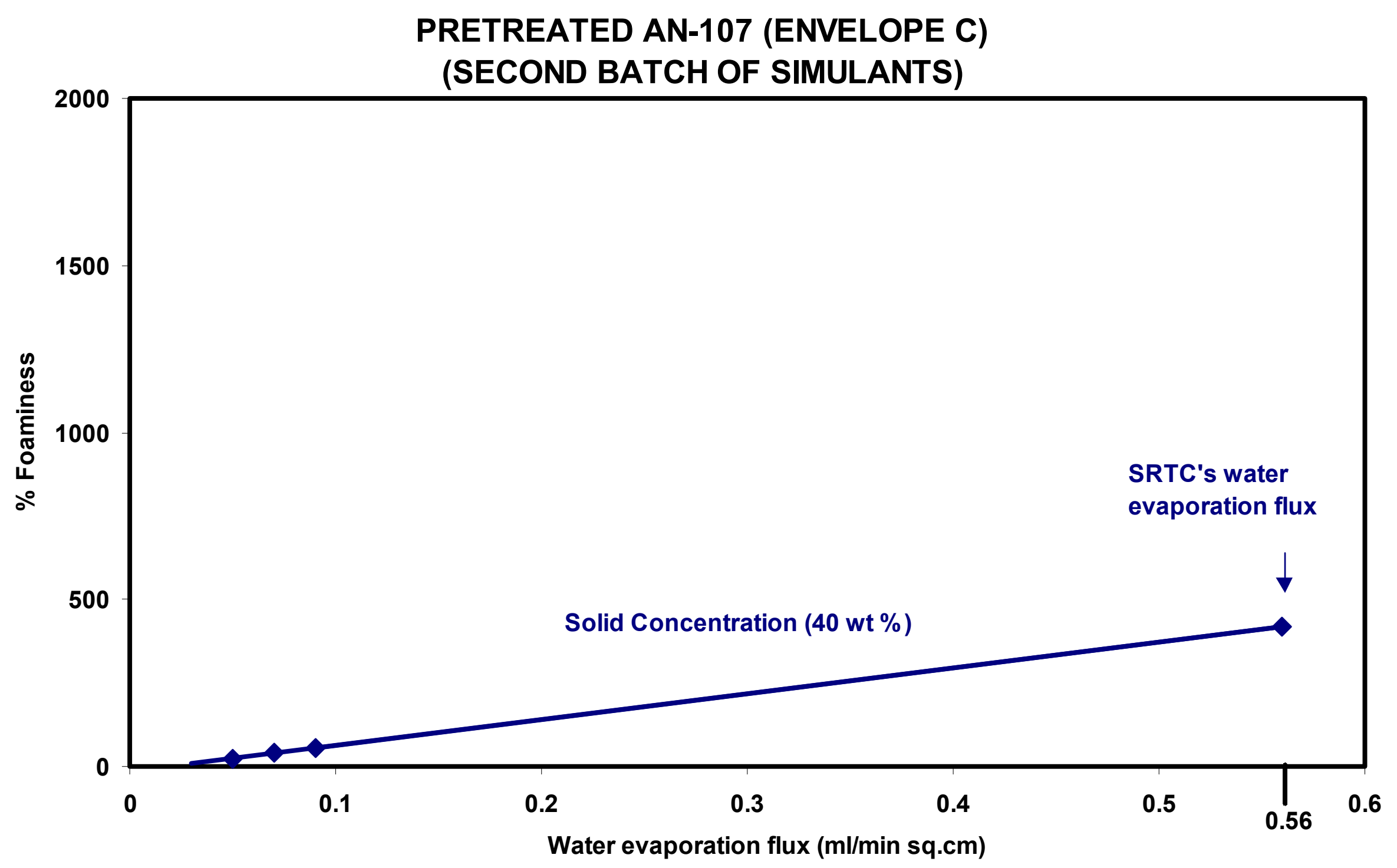

Figure 24: Predicted foaminess at SRTC's water evaporation flux (pressure $110 \mathrm{~mm} \mathrm{Hg}$ ) 
AN-107 with Entrained Solids (ENVELOPE C) (SECOND BATCH OF SIMULANTS)

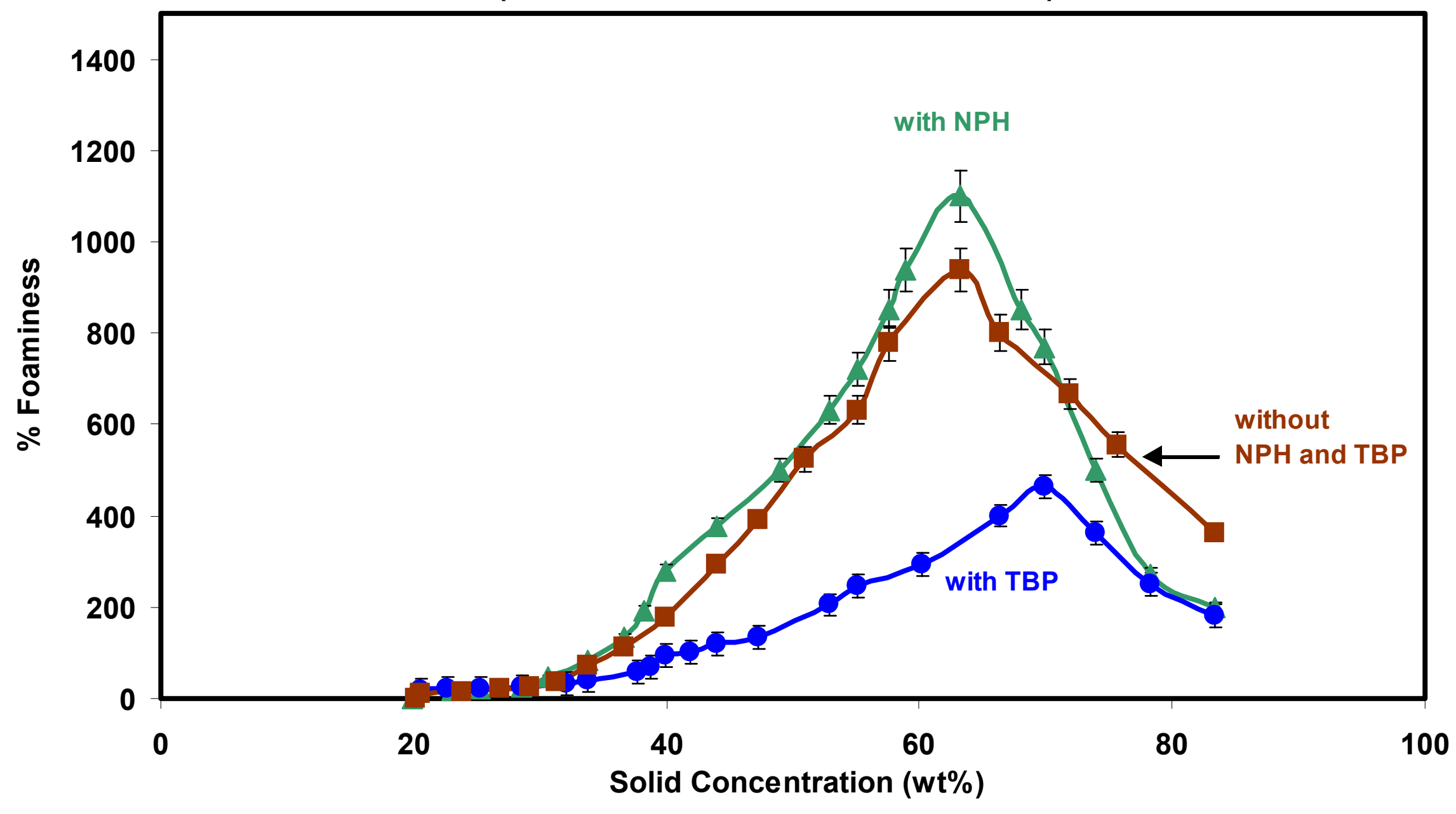

Figure 25: Effect of NPH (100 ppm) and TBP (100 ppm) on foaminess at pressure $(110 \mathrm{~mm} \mathrm{Hg})$ and water evaporation flux $(0.09 \mathrm{ml} / \mathrm{min} \mathrm{sq} . \mathrm{cm})$ 


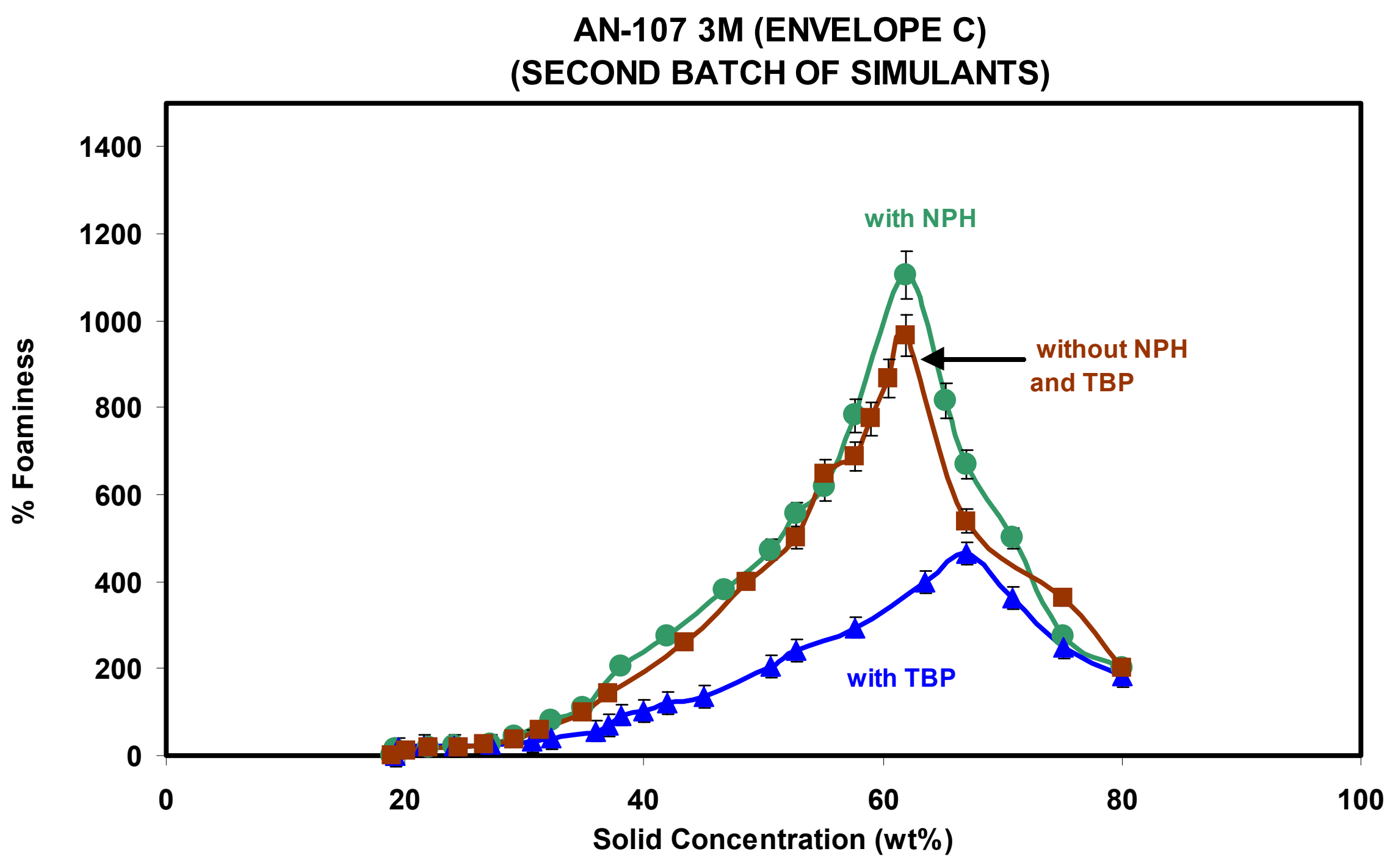

Figure 26: Effect of NPH (100 ppm) and TBP (100 ppm) on foaminess at pressure $(110 \mathrm{~mm} \mathrm{Hg})$ and water evaporation flux $(0.09 \mathrm{ml} / \mathrm{min} \mathrm{sq} . \mathrm{cm})$ 


\section{PRE TREATED AN-107 (ENVELOPE C) (SECOND BATCH OF SIMULANTS)}

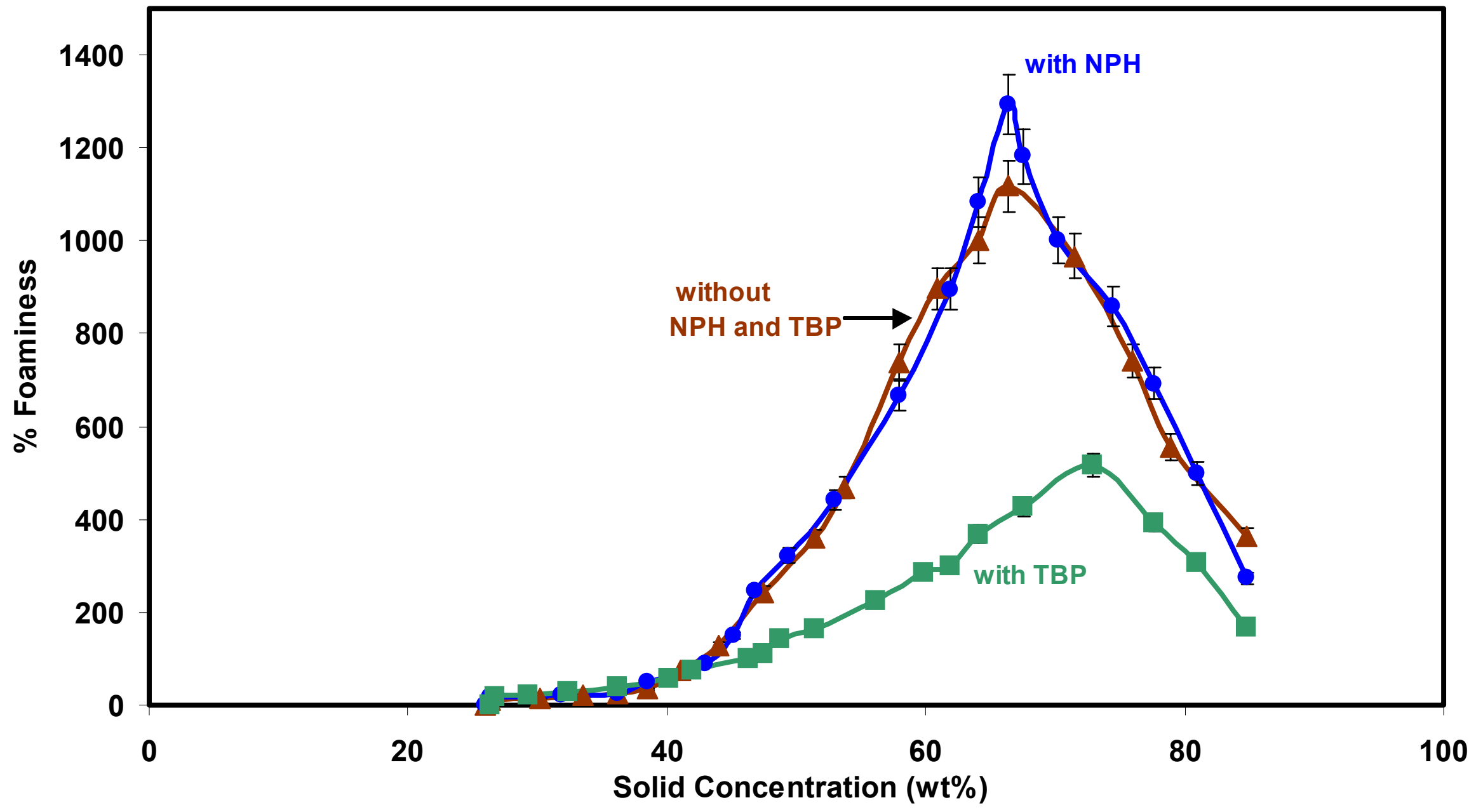

Figure 27: Effect of NPH (100 ppm) and TBP (100 ppm) on foaminess at pressure $(110 \mathrm{~mm} \mathrm{Hg})$ and water evaporation flux $(0.09 \mathrm{ml} / \mathrm{min}$ 


\section{AN-107 with Entrained Solids (ENVELOPE C) (FIRST BATCH OF SIMULANTS)}

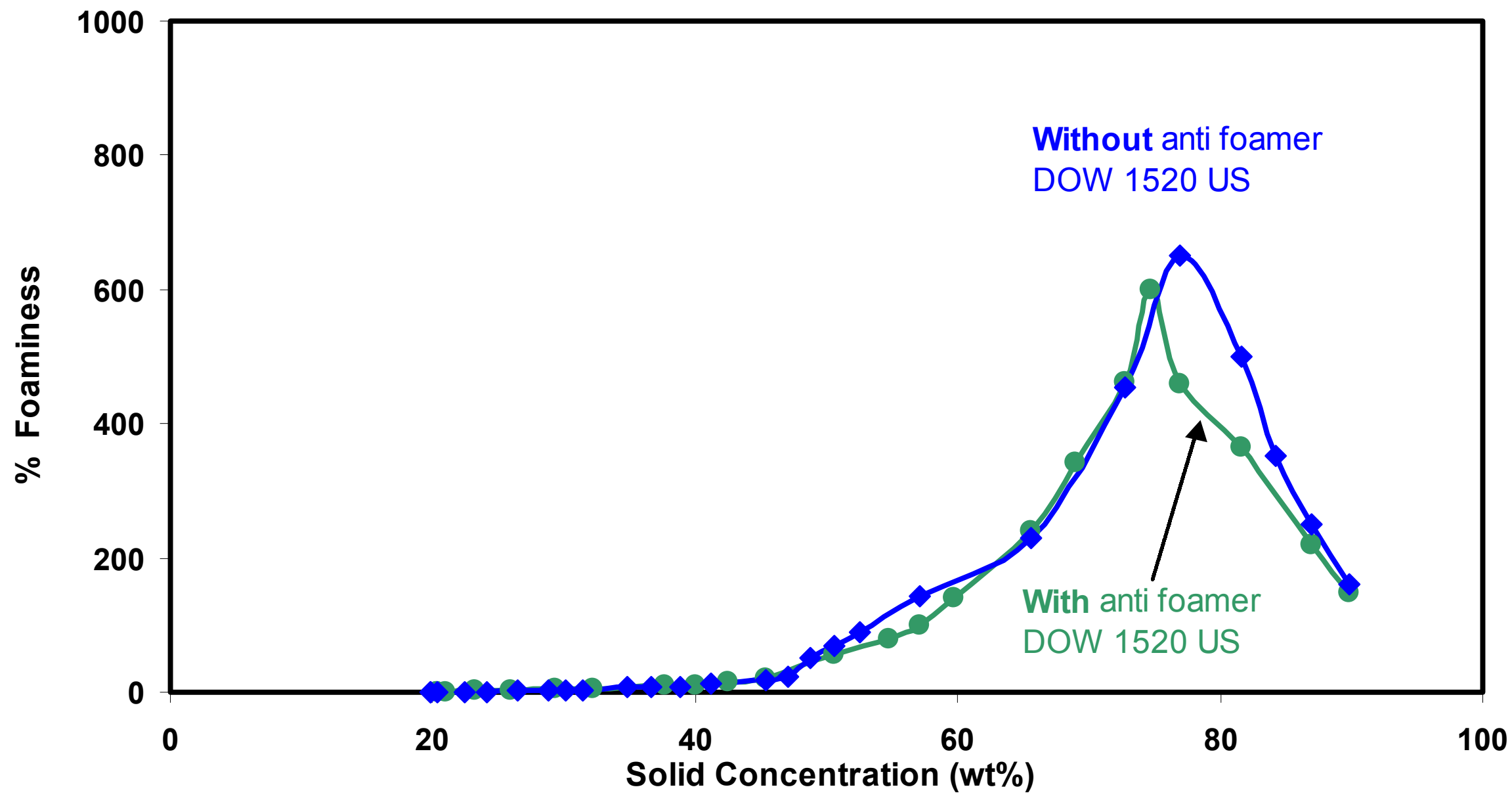

Figure 28: Effect of antifoamer (DOW 1520 US, 1400 ppm) on foaminess at atmospheric pressure $(760 \mathrm{~mm} \mathrm{Hg})$ and water evaporation flux $(0.04 \mathrm{ml} / \mathrm{min} \mathrm{sq.cm}$.) 


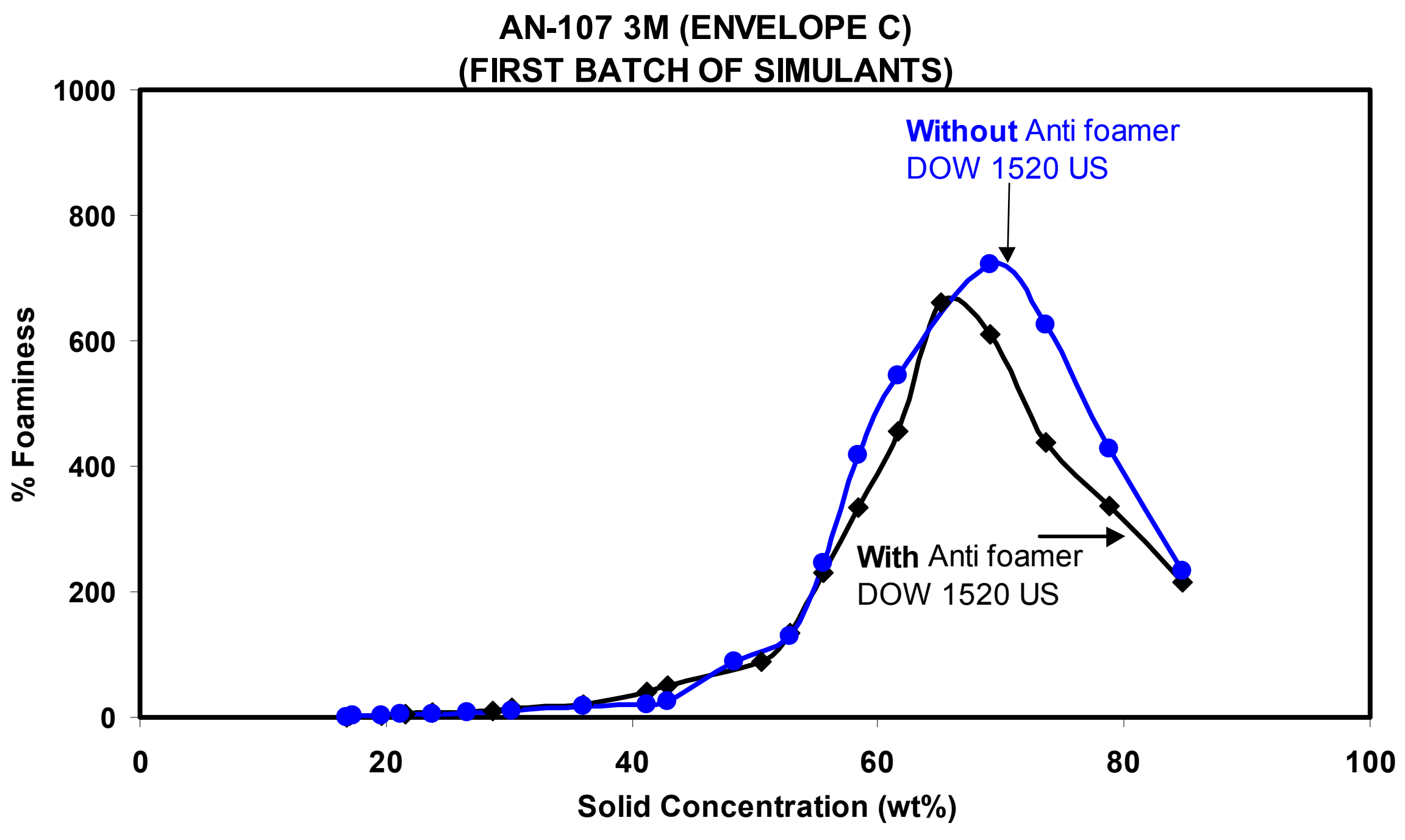

Figure 29: Effect of antifoamer (DOW 1520 US, 1400 ppm) on foaminess at atmospheric pressure $(760 \mathrm{~mm} \mathrm{Hg})$ and water evaporation flux $(0.04 \mathrm{ml} / \mathrm{minn} \mathrm{sq.cm})$ 


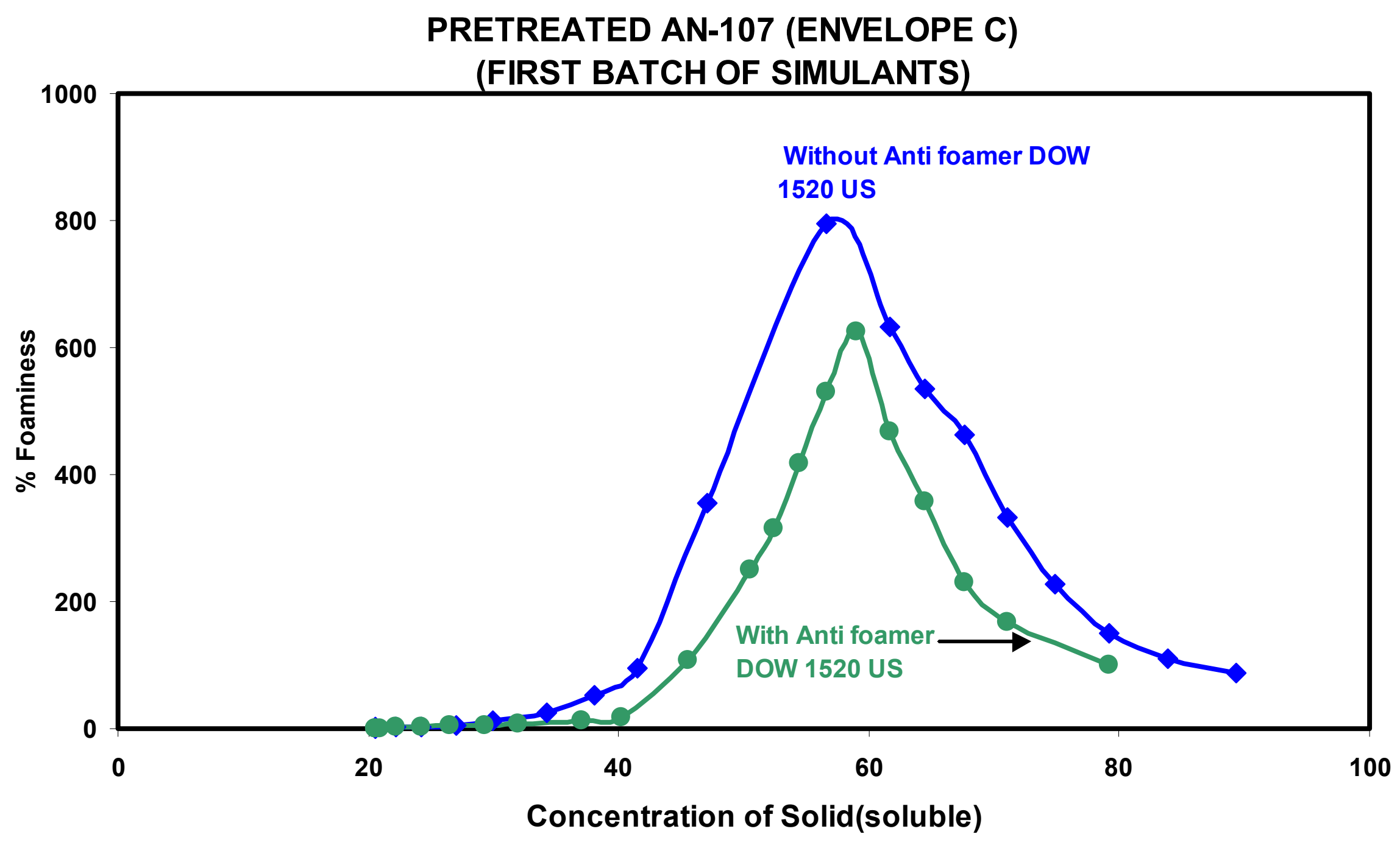

Figure 30: Effect of antifoamer (DOW 1520 US, $1400 \mathrm{ppm}$ ) on foaminess at atmospheric pressure $(760 \mathrm{~mm} \mathrm{Hg})$ and water evaporation flux $(0.04 \mathrm{ml} / \mathrm{min} \mathrm{sq.cm}$.) 
AN-107 with Entrained Solids (ENVELOPE C) (SECOND BATCH OF SIMULANTS)

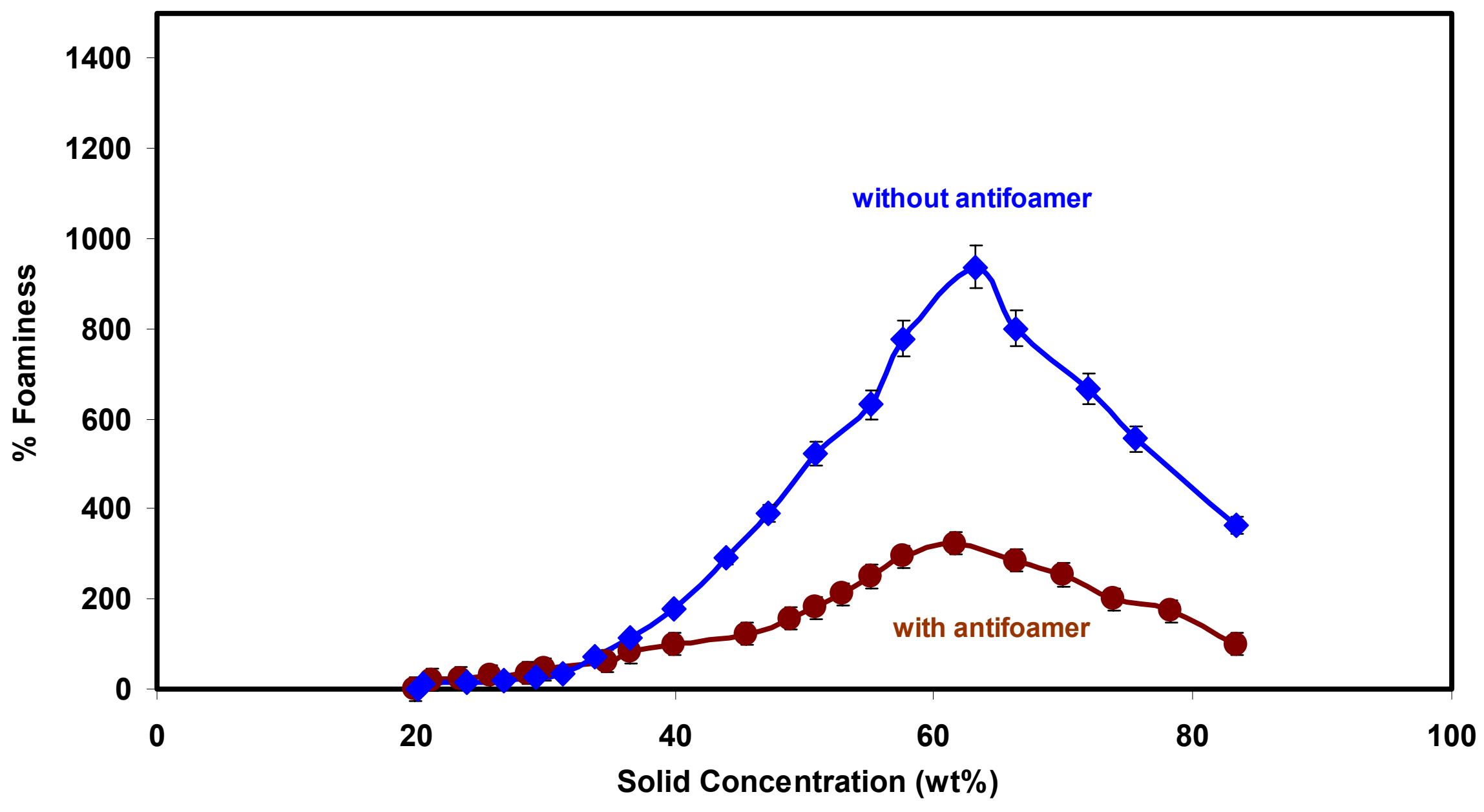

Figure 31: Effect of antifoamer (DOW PULPAID CONCENTRATE 3472, $1400 \mathrm{ppm}$ ) on foaminess at pressure $(110 \mathrm{~mm} \mathrm{Hg})$ and water evaporation flux $(0.09 \mathrm{ml} / \mathrm{min} \mathrm{sq.} \mathrm{cm})$ 
AN-107 3M (ENVELOPE C)

(SECOND BATCH OF SIMULANTS)

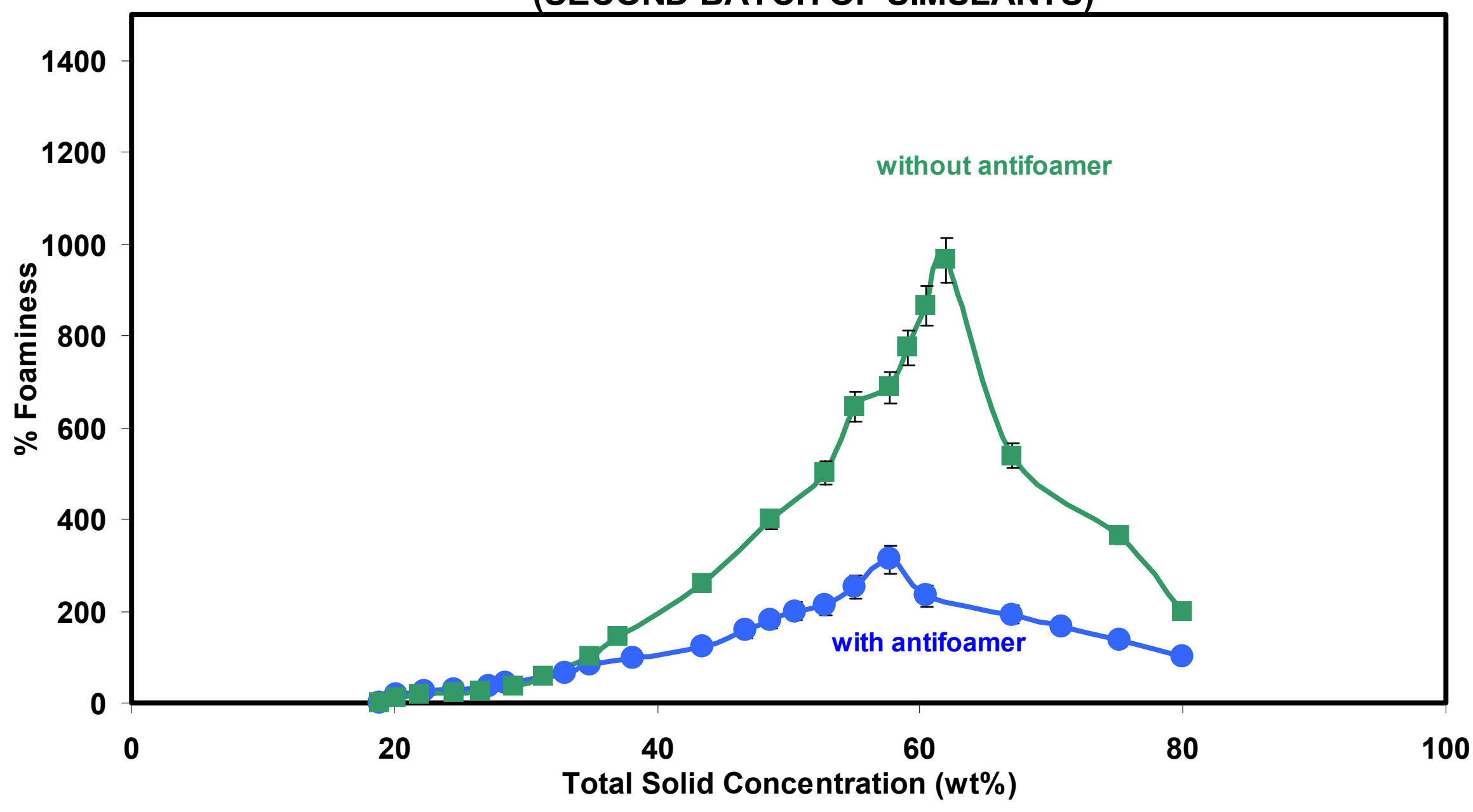

Figure 32: Effect of antifoamer (DOW PULPAID CONCENTRATE 3472, $1400 \mathrm{ppm}$ ) on foaminess at pressure $(110 \mathrm{~mm} \mathrm{Hg})$ and water evaporation flux $(0.09 \mathrm{ml} / \mathrm{min} \mathrm{sq.cm})$ 


\section{PRE TREATED AN-107 (ENVELOPE C)}

(SECOND BATCH OF SIMULANTS)

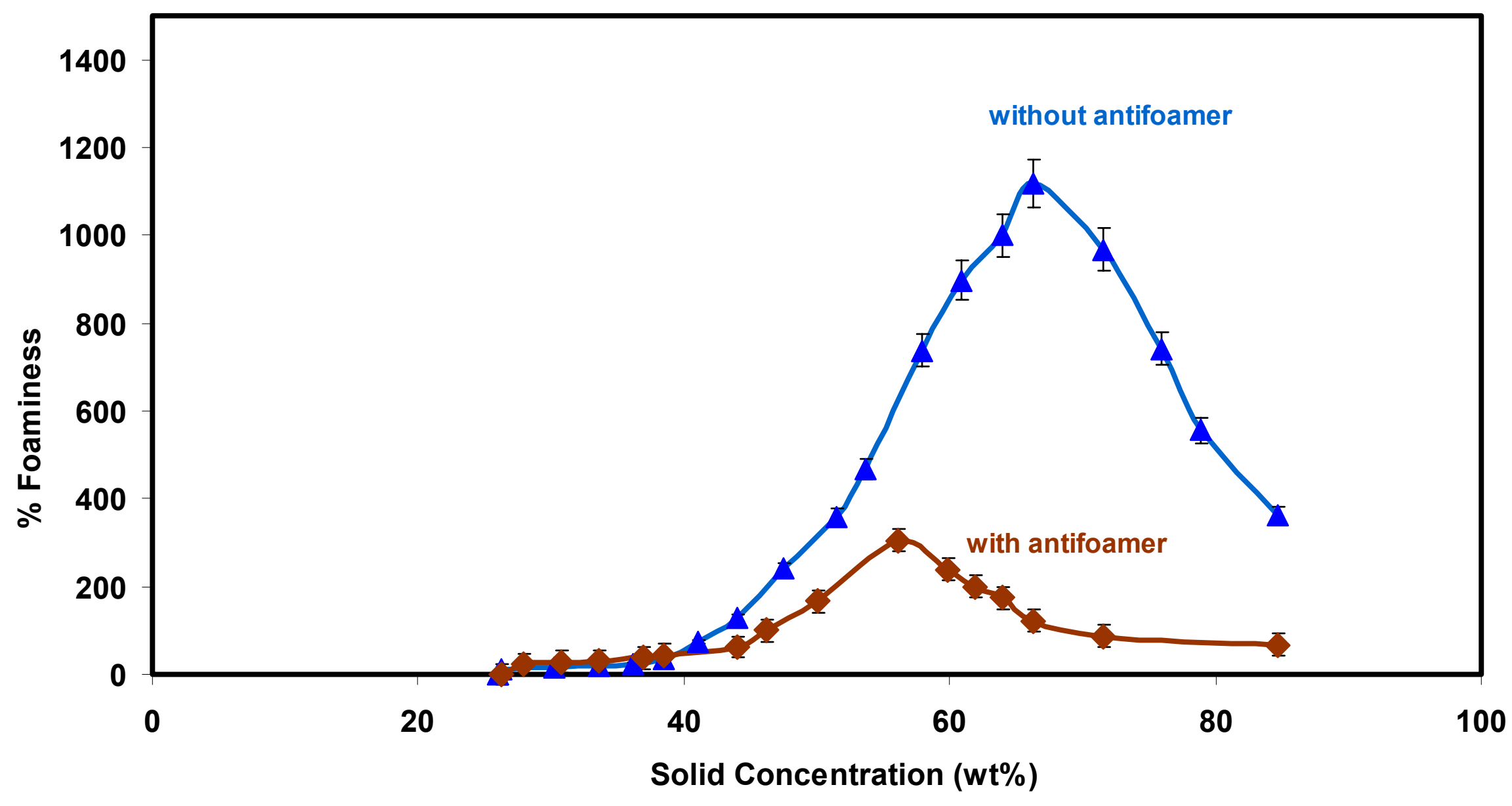

Figure 33: Effect of antifoamer (DOW PULPAID CONCENTRATE 3472, $1400 \mathrm{ppm}$ ) on foaminess at pressure $(110 \mathrm{~mm} \mathrm{Hg})$ and water evaporation flux $(0.09 \mathrm{ml} / \mathrm{min} \mathrm{sq.cm})$ 


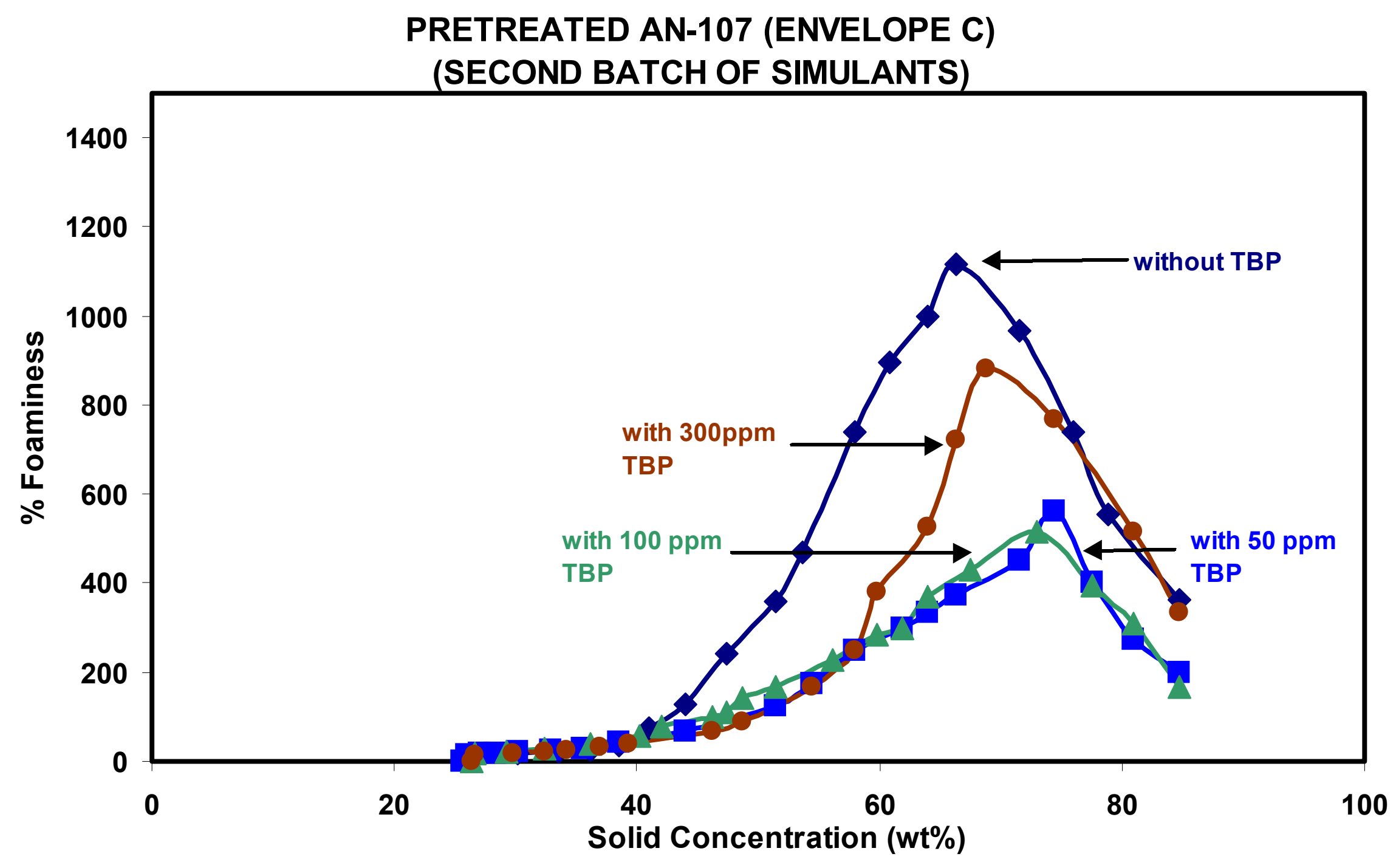

Figure 34: Effect of TBP concentration on foaminess at low pressure $(110 \mathrm{~mm} \mathrm{Hg})$ and water evaporation flux $(0.09 \mathrm{ml} / \mathrm{min}$ sq.cm) 


\section{AN-107 with Entrained Solids (ENVELOPE C)}

(FIRST BATCH OF SIMULANTS)

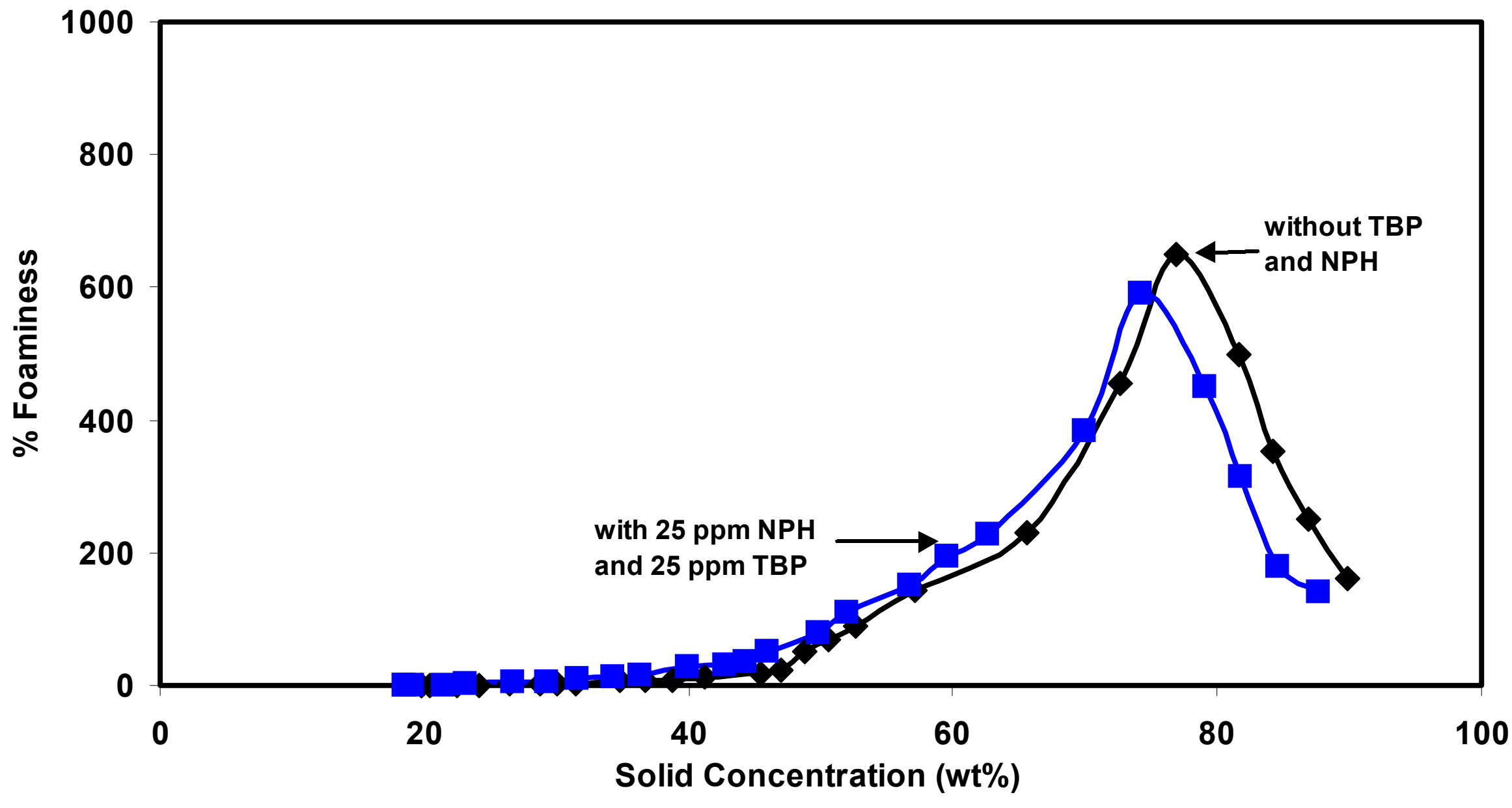

Figure 35: Effect of NPH (25 ppm) and TBP (25 ppm) on foaminess at atmospheric pressure $(760 \mathrm{~mm} \mathrm{Hg})$ and water evaporation flux $(0.04 \mathrm{ml} / \mathrm{min} \mathrm{sq} . \mathrm{cm})$ 


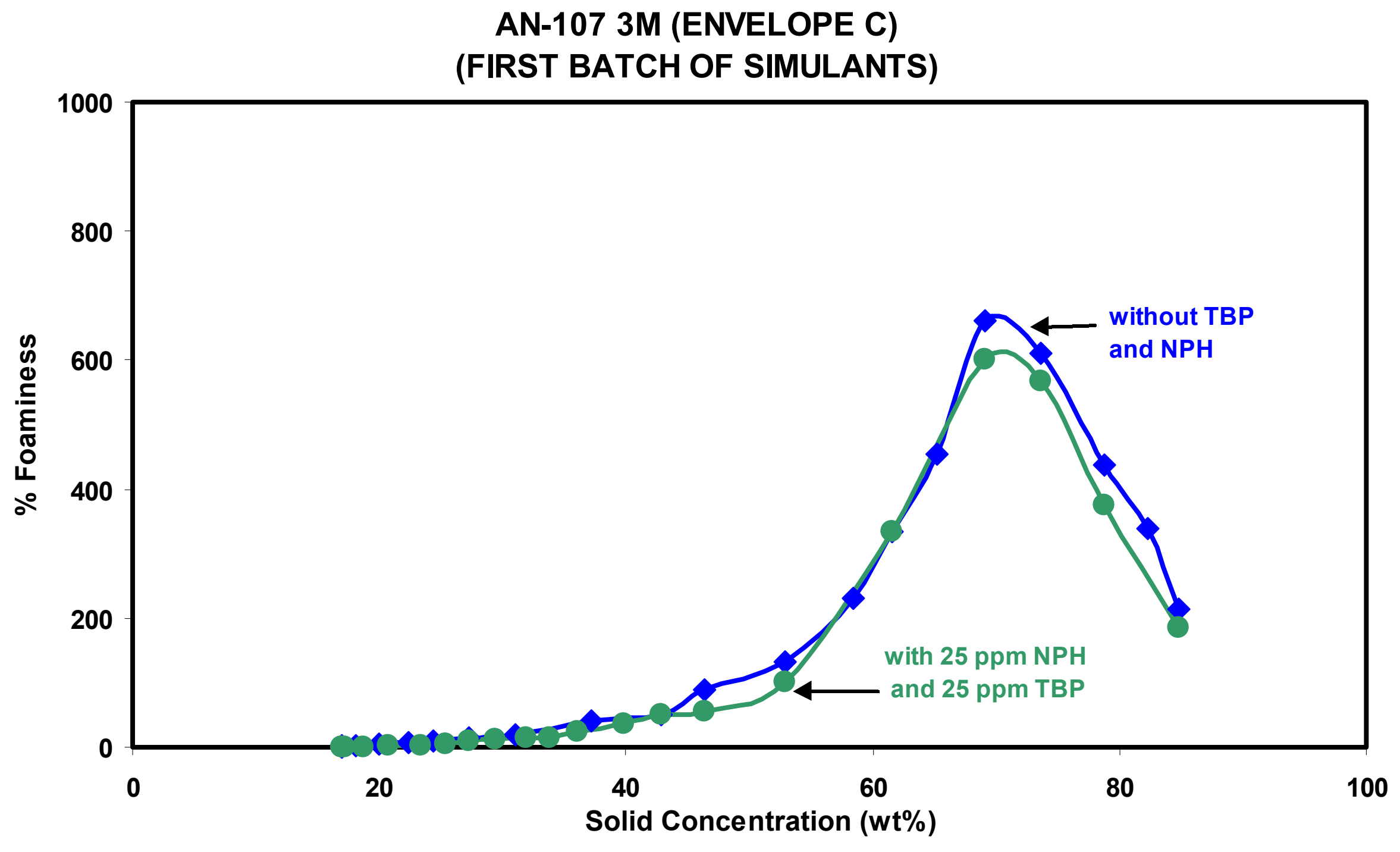

Figure 36: Effect of NPH (25 ppm) and TBP (25 ppm) on foaminess at atmospheric pressure $(760 \mathrm{~mm} \mathrm{Hg})$ and water evaporation flux $(0.04 \mathrm{ml} / \mathrm{min} \mathrm{sq.cm})$ 


\section{PRETREATED AN-107 (ENVELOPE C) \\ (FIRST BATCH OF SIMULANTS)}

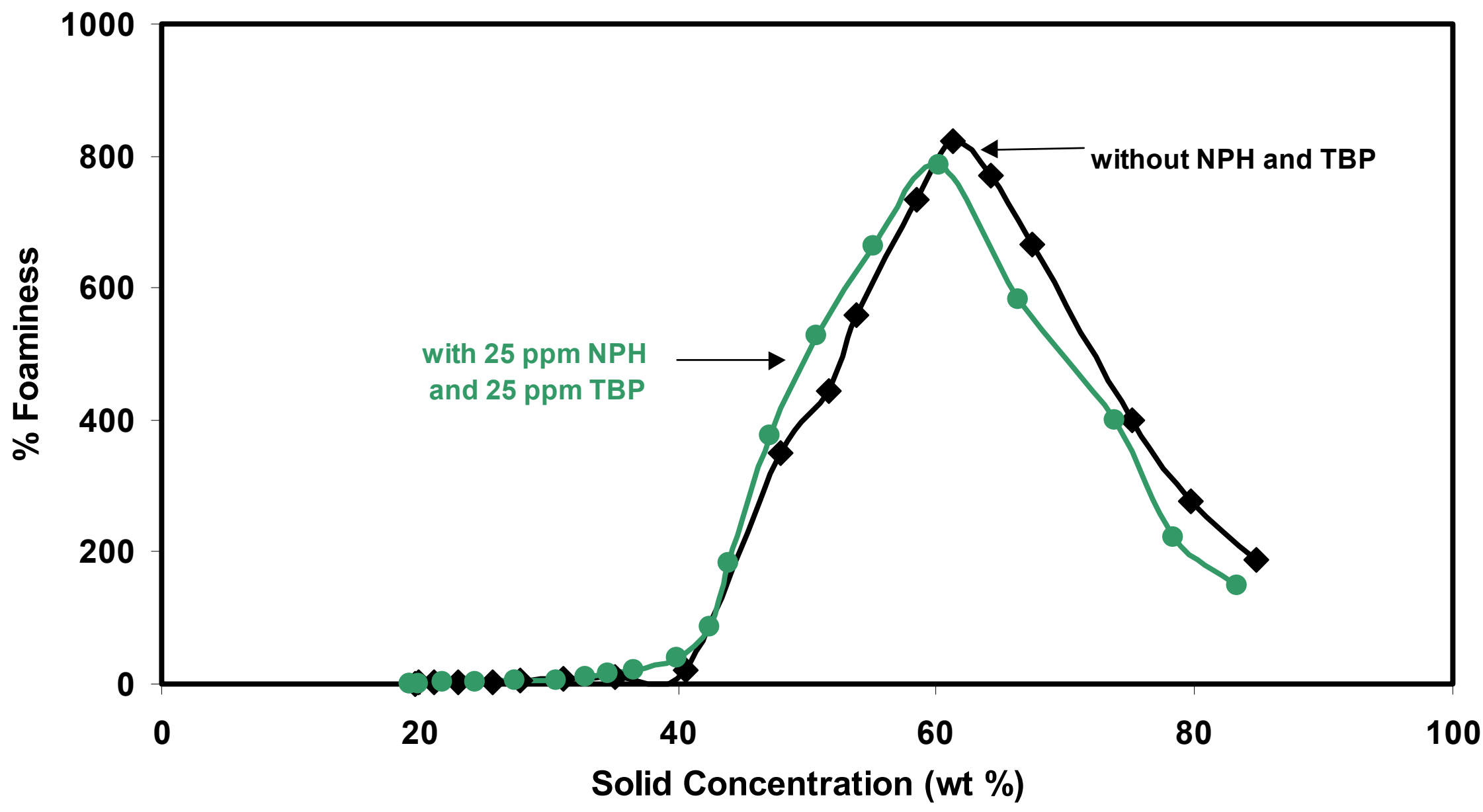

Figure 37: Effect of NPH (25 ppm) and TBP (25 ppm) on foaminess at pressure $(760 \mathrm{~mm} \mathrm{Hg})$ and water evaporation flux $(0.04 \mathrm{ml} / \mathrm{min} \mathrm{sq.cm})$ 


\begin{tabular}{|c|c|c|c|c|c|c|c|c|c|c|c|c|}
\hline \multicolumn{13}{|c|}{ Appendix B. Hanford Simulants Analytical Spreadsheet } \\
\hline \multicolumn{13}{|c|}{ Reported Data, Predicted Data, and \% Target Values } \\
\hline & & & & & & & & & & & & \\
\hline & \multicolumn{2}{|l|}{ AN105 3M Na } & & \multicolumn{3}{|c|}{ AN105 w/ entrained solids } & \multicolumn{3}{|c|}{ AN107 3M Na w/ entrained solids } & \multicolumn{2}{|l|}{ AZ101 2M Na } & \\
\hline & Reported & Predicted & $\%$ Target & Reported & Predicted & $\%$ Target & Reported & Predicted & $\%$ Target & Reported & Predicted & $\%$ Target \\
\hline \multicolumn{13}{|l|}{$(\mathrm{mg} / \mathrm{L})$} \\
\hline Al & 6740 & 8761 & 76.9 & 6920 & 8761 & 79.0 & 122 & 132 & 92.4 & 708 & 4500 & 15.7 \\
\hline $\mathrm{Ba}$ & 0.02 & & & 0.02 & & & 0.02 & & & 0.02 & & \\
\hline $\mathrm{Ca}$ & 7.75 & 0 & & 11.8 & 0 & & 105 & 202 & 52.0 & 0.06 & 0 & \\
\hline $\mathrm{Cd}$ & 0.03 & 0 & & 0.03 & 0 & & 0.03 & 0 & & 0.03 & 0 & \\
\hline Co & 0.05 & & & 0.05 & & & 0.05 & & & 0.05 & & \\
\hline $\mathrm{Cr}$ & 327 & 354 & 92.4 & 527 & 354 & 148.9 & 44.3 & 60 & 73.8 & 295 & 308 & 95.8 \\
\hline $\mathrm{Cu}$ & 0.09 & & & 0.09 & & & 7.9 & & & 0.09 & & \\
\hline \multicolumn{13}{|l|}{ Cs } \\
\hline $\mathrm{Fe}$ & 0.04 & & & 4.16 & & & 580 & & & 0.04 & & \\
\hline $\mathrm{K}$ & 3010 & 2066 & 145.7 & 2980 & 2066 & 144.2 & 983 & 617 & 159.3 & 2600 & 1951 & 133.3 \\
\hline La & 0.12 & & & 0.12 & & & 9.34 & & & 0.12 & & \\
\hline $\mathrm{Mg}$ & 0.04 & 0 & & 0.04 & 0 & & 4.94 & 8.5 & 58.1 & 0.04 & 0 & \\
\hline Mn & 0.01 & & & 0.01 & & & $\begin{array}{r}4.07 \\
129\end{array}$ & & & 0.01 & & \\
\hline Mo & 15.4 & 0 & & 15.2 & 0 & & 8.38 & 12.2 & 68.7 & 0.15 & 0 & \\
\hline $\mathrm{Na}$ & 72000 & 68971 & 104.4 & 67600 & 68971 & 98.0 & 68600 & 68786 & 99.7 & 46100 & 45981 & 100.3 \\
\hline $\mathrm{M}$ of $\mathrm{Na}$ & 3.13 & 3 & 104.3 & 2.94 & 3 & 98.0 & 2.98 & 2.99 & 99.7 & 2.01 & 2 & 100.5 \\
\hline Nd & 0.19 & & & 0.19 & & & 18.2 & & & 0.19 & & \\
\hline $\mathbf{N i}$ & 0.1 & & & 0.1 & & & 114 & & & 0.1 & & \\
\hline $\mathbf{P}$ & 194 & & & 193 & & & 199 & & & 239 & & \\
\hline $\mathrm{Pb}$ & 0.17 & 0 & & 0.17 & 0 & & 81.6 & 132 & 61.8 & 0.17 & 0 & \\
\hline $\mathrm{Si}$ & 32.8 & 42 & 78.1 & 55.3 & 42 & 131.7 & 0.709 & 0 & & 0.4 & 0 & \\
\hline $\mathrm{Ti}$ & 0.07 & & & 0.07 & & & 0.07 & & & 0.07 & & \\
\hline $\mathrm{Zn}$ & 0.201 & 0 & & 0.248 & 0 & & 14.2 & 15.4 & 92.2 & 0.01 & 0 & \\
\hline $\mathrm{Zr}$ & 0.01 & & & 0.01 & & & 11.3 & & & 0.01 & & \\
\hline $\mathrm{Cl}$ & 2230 & 2419 & 92.2 & 2340 & 2419 & 96.7 & 930 & 624 & 149.0 & 108 & 84 & 128.6 \\
\hline$F$ & 100 & 187 & 53.5 & 100 & 187 & 53.5 & $\begin{array}{l}1010 \\
\end{array}$ & 45 & 2244.4 & 730 & 765 & 95.4 \\
\hline NO3 & 50800 & 55711 & 91.2 & 53500 & 55711 & 96.0 & 70900 & 78394 & 90.4 & 30300 & 31905 & 95.0 \\
\hline NO2 & 29000 & 33058 & 87.7 & 29738 & 33058 & 90.0 & 17833 & 20802 & 85.7 & 25098 & 27450 & 91.4 \\
\hline SO4 & 1510 & 1531 & 98.6 & 1520 & 1531 & 99.3 & 2770 & 2813 & 98.5 & 7490 & 7454 & 100.5 \\
\hline PO4 & 440 & 541 & 81.3 & 1510 & 541 & 279.1 & 2940 & 378 & 777.8 & 8810 & 634 & 1389.6 \\
\hline TIC & 4849 & & & 4852 & & & 6347 & & & 3770 & & \\
\hline Wt \% Tot. Solids & 19.07 & 19.2 & 99.3 & 19.58 & 19.2 & 102.0 & 20.35 & 20.4 & 99.8 & 12.73 & 13.5 & 94.3 \\
\hline Wt \% Insol. Solids & 0.17 & & & 0.6 & & & 0.23 & & & 0.18 & & \\
\hline Wt \% Sol. Solids & 18.9 & & & 18.97 & & & 20.12 & & & 12.56 & & \\
\hline \multirow[t]{7}{*}{ Density $(\mathrm{g} / \mathrm{mL})$} & 1.1422 & 1.144 & 99.8 & 1.1452 & 1.144 & 100.1 & 1.1527 & 1.146 & 100.6 & 1.0967 & 1.099 & 99.8 \\
\hline & & & & & & & & & & & & \\
\hline & & & & & & & & & & & & \\
\hline & Reported value & s that are inacci & urate because th & ey are below the & instrument's de & etection limit. Thu & is, no \% target va & alues given for th & these. & & & \\
\hline & & & & & & & & & & & & \\
\hline & For predicted $\mathrm{v}$ & alues, this color & indicates the an & alyte was not ado & ded. & & & & & & & \\
\hline & & & & & & & & & & & & \\
\hline & Significant $(>5$ & $0 \%$ ) discrepanci & es between repo & orted analytical va & alue and predict & ted values. & & & & & & \\
\hline
\end{tabular}




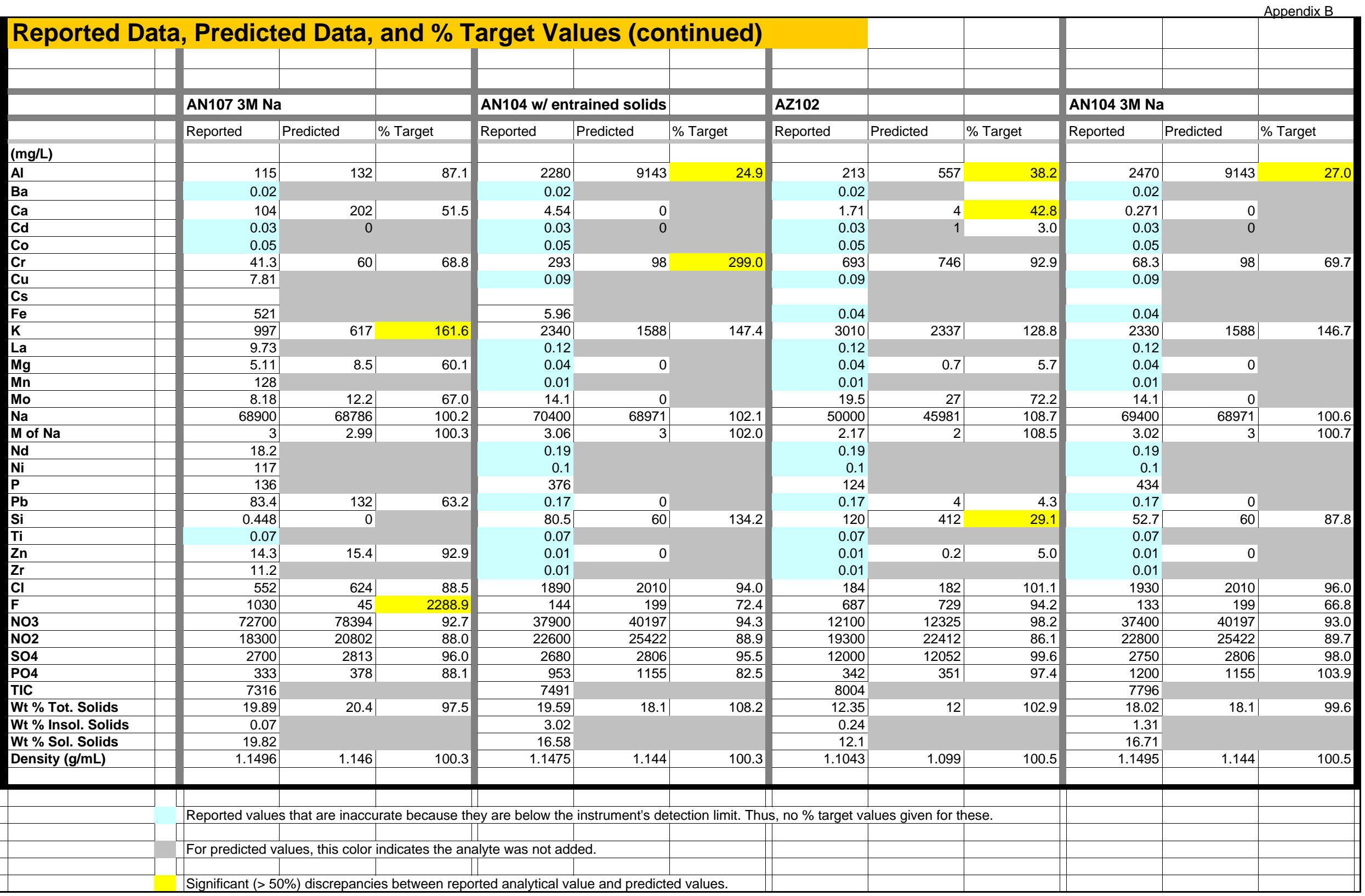

